1

2

3

Submitted for review to the International Journal of Fatigue

\title{
Parameters Influencing Thermomechanical Fatigue of a Directionally-solidified Ni-base Superalloy
}

\author{
by \\ M. M. Kirka ${ }^{1, a}$, K. A. Brindley ${ }^{1}$, R. W. Neu ${ }^{1,2 *}$, S. D. Antolovich ${ }^{1,2}$, S. R. Shinde ${ }^{3}$, P. W. \\ Gravett $^{3}$, \\ ${ }^{1}$ The George W. Woodruff School of Mechanical Engineering \\ ${ }^{2}$ School of Materials Science and Engineering \\ Georgia Institute of Technology, Atlanta, GA, USA \\ ${ }^{3}$ Siemens Energy Inc., Orlando, FL 32826, United States \\ ${ }^{a}$ Current address: Oak Ridge National Laboratory, One Bethel Valley Road, Oak Ridge, \\ TN 37831, USA. \\ *corresponding author: email: rick.neu@gatech.edu, tel: 1-404-894-3074
}

\begin{abstract}
Thermomechanical fatigue (TMF) is a low cycle fatigue process in which material life is correlated to the mechanical strain amplitude. However, it is well known that several other factors influence this life. This paper examines several of these parameters and their influence on life using experiments conducted on a second generation directionally-solidified (DS) Ni-base superalloy. The parameters considered include the influence of the temperature extremums $\left(T_{\max }\right.$ of either 750 or $950^{\circ} \mathrm{C}$ and $T_{\min }$ of either 100 or $500^{\circ} \mathrm{C}$ ), strain ratio $\left(R_{\epsilon}\right)$, the strain-temperature phasing (in-phase (IP) and out-of-phase $(\mathrm{OP})$ ), the influence of dwells at the high temperature end of the cycle resulting in a creep-fatigue $(\mathrm{CF})$ interaction, and material anisotropy associated with the grain growth direction (longitudinal versus transverse). Results suggest that the phasing has a primary role in controlling the mechanism of degradation. IP TMF is dominated by crack formation in volumes surrounding debonded carbides for both continuously cycling (CC) and $\mathrm{CF}$ at 950 and $750^{\circ} \mathrm{C}$, while $\mathrm{OP}$ TMF is dominated by surface oxidation and repetitive cracking of the oxide that reforms at the crack tip at $950^{\circ} \mathrm{C}$. Decreasing the $T_{\max }$ to $750^{\circ} \mathrm{C}$ the environmental and creep effects are reduced resulting in virtually pure fatigue exposure under OP conditions. With decreasing $T_{\text {min }}$ from $500^{\circ} \mathrm{C}$ to $100^{\circ} \mathrm{C}$ was observed an increase in inelastic strain amplitude and
\end{abstract}


corresponding decrease in life. Variations in $R_{\epsilon}$ were found to have no significant influence on life or stabilized stress behavior. TMF loading in the transverse orientation resulted in life reductions over the longitudinal orientation due to cracks propagating in a transgranular manner. Lastly, only in material exposed to $\mathrm{CF}$ with a $T_{\max }$ of $950^{\circ} \mathrm{C}$ rafting of the $\gamma^{\prime}$ precipitates was observed.

Keywords: thermomechanical fatigue, nickel-base superalloy, strain-life, directional solidification 


\section{Introduction}

Nickel-base (Ni-base) superalloys find widespread use as blade materials for airfoils used in the hot sections of gas turbine engines due to their ability to withstand extreme temperature conditions while maintaining excellent fracture toughness [1]. Much effort has been invested in understanding the creep [2-9] and fatigue [10-15] responses of Ni-base superalloys. However, understanding the effects of thermomechanical fatigue (TMF) on the life of Ni-base superalloys is paramount because the deformation and damage mechanisms observed in creep and fatigue typically do not directly transfer to the behavior of Ni-base superalloys under TMF loadings [16,17]. Additionally, the deformation mechanisms that do occur are not the same for single-crystal, directionally solidified, and polycrystalline Ni-base superalloys undergoing identical loadings due to the microstructure, orientation sensitivity, and grain size [18].

Because of the complexities associated with TMF cycles, attempts have been made to propose the use of an equivalent temperature at which to conduct isothermal LCF such that the material life values are similar to the corresponding TMF experiment. However, this has been shown only to work in practices when the deformation mechanisms are similar between the isothermal and TMF experiment [19]. At low temperatures $\left(<750^{\circ} \mathrm{C}\right)$ dislocations shear the $\gamma^{\prime}$ precipitates and at high temperatures $\left(>850^{\circ} \mathrm{C}\right)$ the $\gamma^{\prime}$ precipitates are by-passed by dislocations. This occurs as a result of the increase in hardness of the $\gamma^{\prime}$ precipitates with increasing temperature [20]. Further, previous studies on the influence of IP and OP TMF on the damage mechanisms have shown that OP TMF failure primarily occurs through environmental desegregation $[?, 21-26]$.

Overall, no single set of TMF conditions can be considered truly representative of those that impact hot section components. As a result, idealized TMF cycles are used in which meaningful damage interactions can be studied to. Two of the most common are in-phase (IP) TMF where the maximum temperature $\left(T_{\max }\right)$ and strain occur at the same time, and out-of-phase (OP) TMF where the maximum temperature occurs at the minimum strain. Further realism can be included through the introduction of stress or strain holds at peak temperature to promote creep-fatigue (CF) interactions. To summarize, there are several considerations that can influence TMF life of Ni-base superalloys:

i) Temperature-strain phasing (IP or OP TMF) [23]

ii) Maximum temperature extreme $[21,24,27,28]$

iii) Minimum temperature extreme [21, 24, 27, 28] 
iv) Mean Strain $[29,30]$

v) Creep-fatigue interactions due to long dwells coupled with periodic TMF cycles $[24,31-41]$

vi) Elastic anisotropy due to crystal orientation [12,14,21,32, 42-45]

vii) Over-aging of the microstructure during service conditions [18, 46-49].

The goal of this work is to evaluate the significance of these various considerations on TMF life behavior through an extensive experimental program. The effects of aging of the microstructure on fatigue life will be considered in a follow-on work. Within this work a second generation directionally-solidified (DS) Ni-base superalloy used in industrial gas turbine applications is the focus of this investigation.

\section{Material and Experimental Procedure}

\subsection{Material}

TMF tests were performed on a second-generation directionally solidified (DS) Ni-base superalloy of chemical composition shown in Table 1 provided in the form of cast slabs having dimensions $127 \times 228 \times 25.4 \mathrm{~mm}$ and cast by PCC Airfoils (Minerva, OH). From the as-cast condition, the material was given a proprietary two-step heat treatment. The heat treatment is meant to promote elemental homogenization and precipitation of the $\gamma^{\prime}$ precipitates. As a result of the composition and heat treatment, the alloy is comprised of $65 \% \gamma^{\prime}$ by volume fraction, with the $\gamma^{\prime}$ being cubic in shape and having an average side length of $0.7 \mu \mathrm{m}$ and the $\gamma$ channels having an average thickness of 0.17 $\mu m$ in the dendritic core (Figure 1). The average grain diameter in the material is 2 $\mathrm{mm}$, with the primary dendrites being $500 \mu \mathrm{m}$, and the secondary dendrite arm spacing being $100 \mu \mathrm{m}$. Present are intermittent script grain boundary MC type carbides and blocky type $M_{23} C_{6}$ carbides within the interdendiritc regions of the alloy. The carbides ranged in size from a few microns to $25 \mu \mathrm{m}$.

Table 1: Nominal chemical compositions of the DS Ni-base superalloy used in this work given as weight percent [50].

\begin{tabular}{cccccccccccc}
\hline Cr & Co & Mo & W & Al & Ti & Ta & Hf & C & B & Zr & Ni \\
\hline 8.1 & 9.2 & 0.5 & 9.5 & 5.6 & 0.7 & 3.2 & 1.4 & 0.07 & 0.015 & 0.01 & Bal
\end{tabular}




\subsection{TMF Test Procedure}

TMF experiments were performed on cylindrical dog-bone specimens fabricated from the cast slabs in accordance with ASTM E606-12 [51] having a gage section length of $13.2 \mathrm{~mm}(0.52 \mathrm{in})$ and diameter of $6.35 \mathrm{~mm}$ (0.25 in). The TMF experiments were performed on computer controlled closed loop servohydraulic test systems equipped with MTS FlexTest 40 controllers. Induction heating was used to heat the specimens with a 26 gage K-type thermocouple spot welded near the end of the specimen gage section for reading the temperature. The temperature gradient over the gage section was minimized by optimization of the induction coil configuration to be within the $+/-5^{\circ} \mathrm{C}$ requirements mandated by ASTM standard E2368-12 [52]. Total strain, $\epsilon_{\text {tot }}=\epsilon_{m e c h}+\epsilon_{\text {th }}$ was measured over the gage length with a $12.7 \mathrm{~mm}$ MTS high temperature axial extensometer utilizing alumina rods. All experiments were conducted in mechanical strain control, where the mechanical strain was calculated through subtraction of the thermal strain from the total strain measured by the extensometer, $\epsilon_{m e c h}=\epsilon_{t o t}-\epsilon_{t h}$. The thermal strain was determined through polynomial fit to free thermal expansion measured before the start of each test. 
TMF experiments were conducted on specimens with longitudinal (L-orientation) and transverse (T-orientation) orientations with respect to the direction of solidification. Generally, the experimental conditions were chosen such that the TMF life was on the order of a few thousand cycles, which is representative of the number of start-up and shutdown cycles of a land-based gas turbine [53]. Continuous cycling (CC) and creep-fatigue ( $\mathrm{CF}$ ) TMF experiments were conducted for the temperature ranges of $100-750^{\circ} \mathrm{C}$ and $100-950^{\circ} \mathrm{C}$ in both the L-orientation and T-orientation for both the IP, $R_{\epsilon}=0$ and $\mathrm{OP}, R_{\epsilon}=-\infty \mathrm{TMF}$ waveforms. The CC cycle time for the large temperature range of $100-950^{\circ} \mathrm{C}$ was $600 \mathrm{~s}$ and that for the temperature range of $100-750^{\circ} \mathrm{C}$ was $480 \mathrm{~s}$. The differences in cycle time were done to maintain a near constant heating and cooling rate amongst the different temperature ranges. All CF experiments were conducted with the 1200 second strain hold occurring at the peak temperature of the cycle. Additionally, CC TMF experiments were conducted with a higher minimum temperature and three different maximum temperatures $\left(500-750^{\circ} \mathrm{C}, 500-850^{\circ} \mathrm{C}\right.$, and $500-950^{\circ} \mathrm{C}$ ) in the L-orientation under both IP and OP waveforms. In these cases the cycle times were 120, 150, and 180 seconds. The criterion for crack initiation was defined as a $5 \%$ load drop from the peak of the stabilized hysteresis response. This failure criterion corresponds to a crack in the range of 0.5 and $1.0 \mathrm{~mm}$ [33].

\section{Results and Discussion}

\subsection{Influence of Temperature Extremum}

The minimum temperature $\left(T_{\min }\right)$ experienced by material within gas turbine engines relates to the length of the engine's shutdown. Short shutdowns are associated with minimum temperatures of 500 and $100^{\circ} \mathrm{C}$ with long ones. Most often it is desirable to conduct TMF experiments in laboratories with a minimum cycle temperature as low as possible to replicate long-term shutdowns conditions; however, to accelerate testing by increasing the frequency of the cycle, a higher minimum temperature is often used. This has typically been justified by assuming that TMF life is controlled by degradation processes occurring during the high temperature excursions in the cycle, while the yield strength for most Ni-base superalloys remains nearly constant below $500^{\circ} \mathrm{C}$. The reductions in the $T_{\min }$ of the cycle have two possible impacts on the material. First there can be a reduction in the fatigue resistance, due to an increase in the inelastic strain range arising from increases in the elastic modulus with the decreasing temperature [27]. Second, the aging of the $\gamma^{\prime}$ microstructure has been 
reported to be observed at elevated temperatures [27]. However, in light of these observations, extension of these trends to $T_{\max }$ below $950^{\circ} \mathrm{C}$ when aging is insignificant is unclear.

TMF experiments were conducted under both IP, $R_{\epsilon}=0$ and OP, $R_{\epsilon}=-\infty$ phasing conditions with a $T_{\min }$ of 100 or $500^{\circ} \mathrm{C}$ on specimens with an L-orientation. The $T_{\max }$ investigated for each phasing condition were 750,850 , and $950^{\circ} \mathrm{C}$, with the corresponding mechanical strain amplitudes of 1.2, 1.1, and $1.0 \%$ respectively. Through reducing not only the $T_{\min }$, but also the $T_{\max }$, the various damage mechanisms thought to be associated with this reduced $T_{\min }$ effect can be isolated. For $T_{\max }$ of $750^{\circ} \mathrm{C}$, one can expect the failure mechanisms to be dominated by pure fatigue, when $T_{\max }$ is $850^{\circ} \mathrm{C}$ a mixture of creep-fatigue, and when $T_{\max }$ is $950^{\circ} \mathrm{C}$, a combination of microstructure evolution, creep, and fatigue damage is occurring.

Through the introduction of a reduced $T_{m i n}$, the number of cycles required for crack initiation was observed to successively decrease with increasing temperature differential for both IP and OP TMF. Using the isothermal life results at the $T_{\max }$ of interest as a reference, a $T_{\min }$ of $500^{\circ} \mathrm{C}$ resulted in a $4 \mathrm{x}$ reduction in the cycle to crack initiation on average, with a $T_{\min }$ of $100^{\circ} \mathrm{C}$ further decreasing the life by $20 \mathrm{x}$ on average for IP TMF. This is depicted in Figure 2. OP TMF exhibited similar trends with reductions in the number of cycles being 2.5 and $8 \mathrm{x}$ on average for $T_{\min }$ of 500 and $100^{\circ} \mathrm{C}$ respectively as shown in Figure 3. 


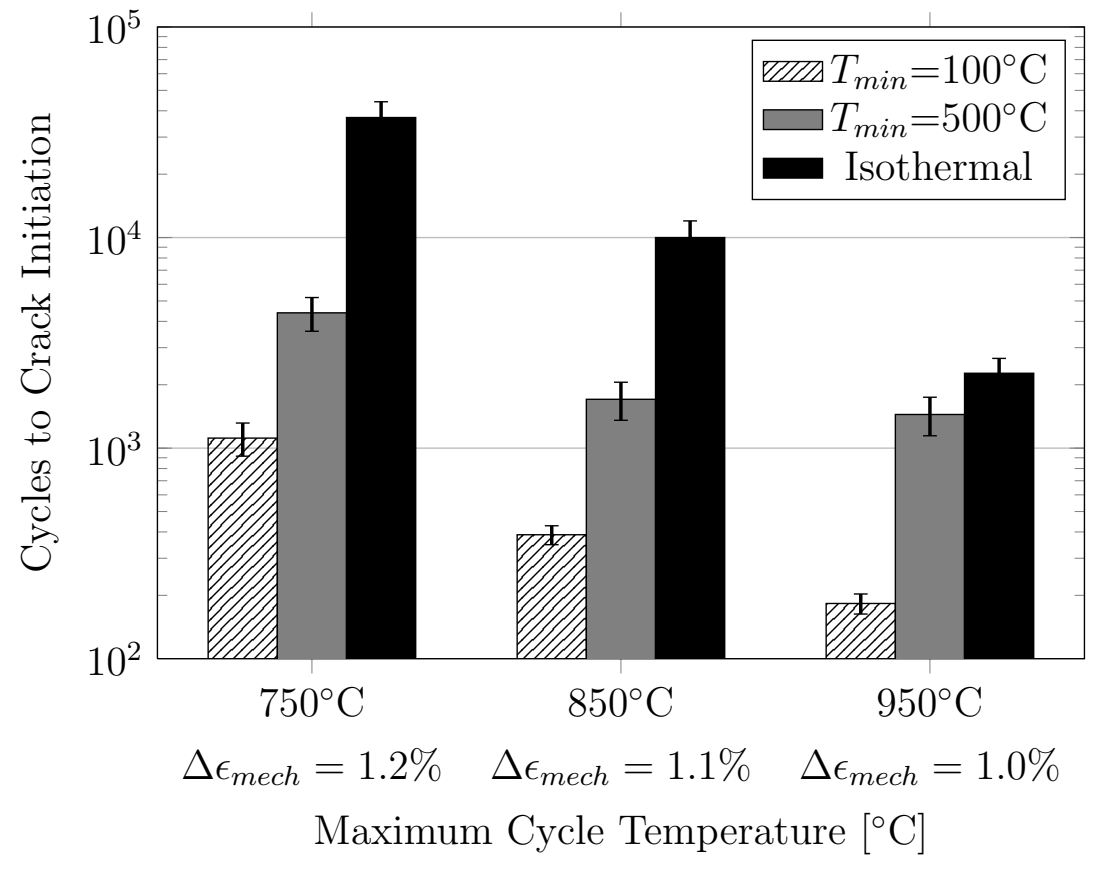

Figure 2: Influence of $T_{\min }$ on IP $R_{\epsilon}=0 \mathrm{TMF}$ life in the L-orientation. Isothermal results are for $R_{\epsilon}=-1$ [33]. 


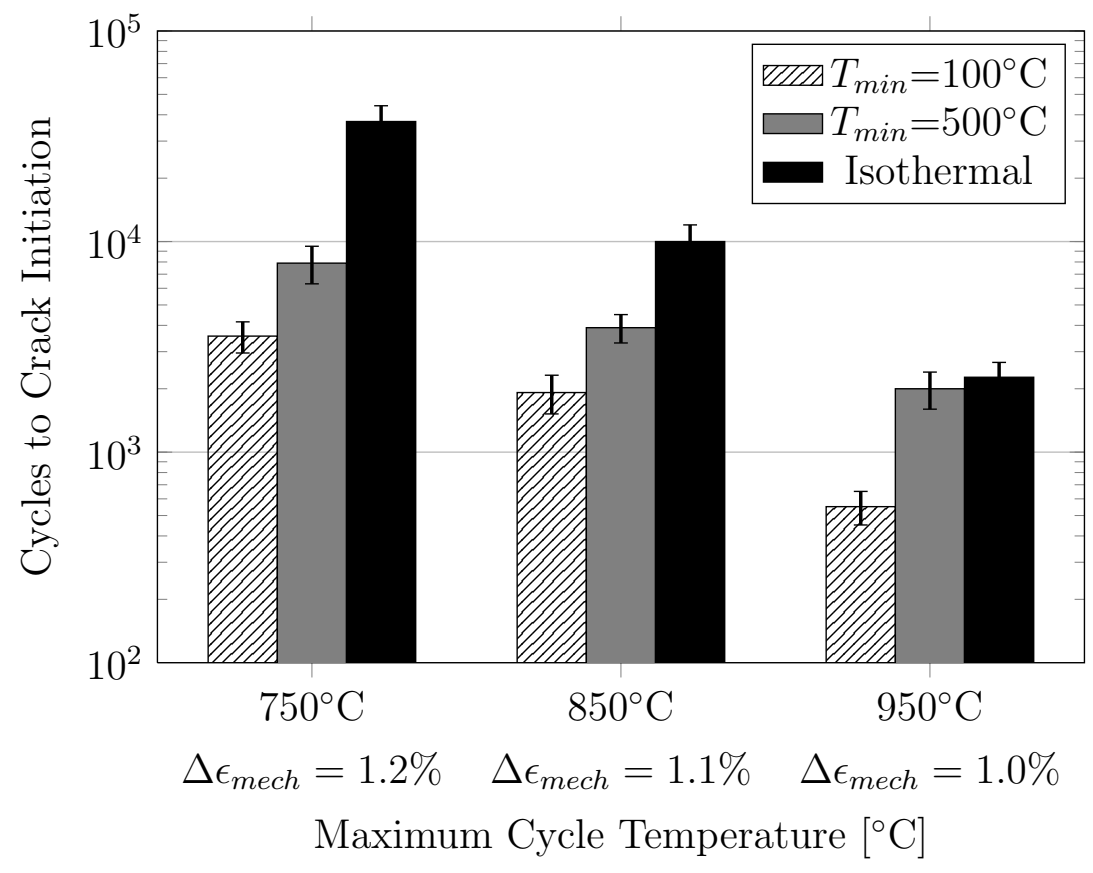

Figure 3: Influence of $T_{\text {min }}$ on OP $R_{\epsilon}=-\infty$ TMF life in the L-orientation. Isothermal results are for $R_{\epsilon}=-1$ [33].

The respective hysteresis responses at half-life were compared. All reduced $T_{\min }$ experiments exhibited increases in the inelastic strain range compared to the higher $T_{\text {min }}$ responses under both IP and OP TMF loadings as shown by the representative results in Figure 4 at half-life. In addition, the stress amplitude of the reduced $T_{\min }$ is greater. While the yield strength remains nearly constant in the $100-650^{\circ} \mathrm{C}$ temperature range, the elastic modulus increases nearly $20 \%$ when temperature decreases from 500 to $100^{\circ} \mathrm{C}$ [54]. For a given mechanical strain range, when the temperature is lower, the elastic strain range is reduced resulting in a greater inelastic strain range. 


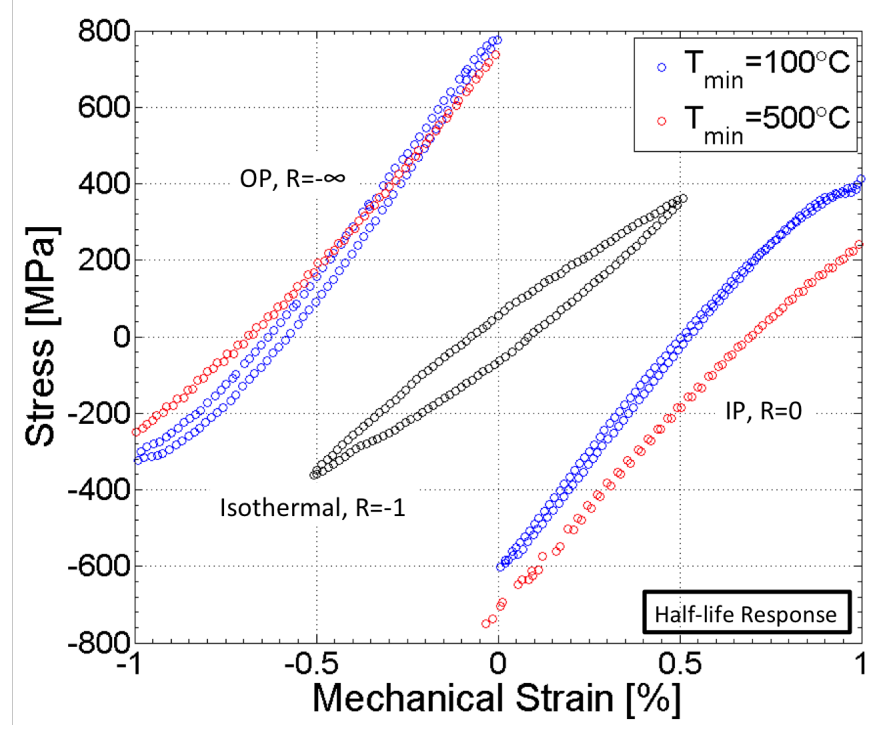

Figure 4: Half-life hysteresis curves for material undergoing IP, $R_{\epsilon}=0$ and $\mathrm{OP}, R_{\epsilon}=$ $-\infty$ showing the effect of $T_{\min }$ upon the stress-strain response in relation to the material's isothermal behavior at $950^{\circ} \mathrm{C}$.

The reduced $T_{\min }$ experiments exhibit a 10-20\% higher stress amplitude than $T_{\min }=500^{\circ} \mathrm{C}$ as shown in Figure 5 from the onset of cycling. In most cases, the specimens were observed to have achieved stabilized hysteresis within the first $10 \mathrm{cy}-$ cles; however, the IP TMF $100-850^{\circ} \mathrm{C}$ experiment and the IP TMF experiments with a $T_{\max }$ of $950^{\circ} \mathrm{C}$ exhibited cyclic softening with the peak tensile stress occurring on the first cycle.
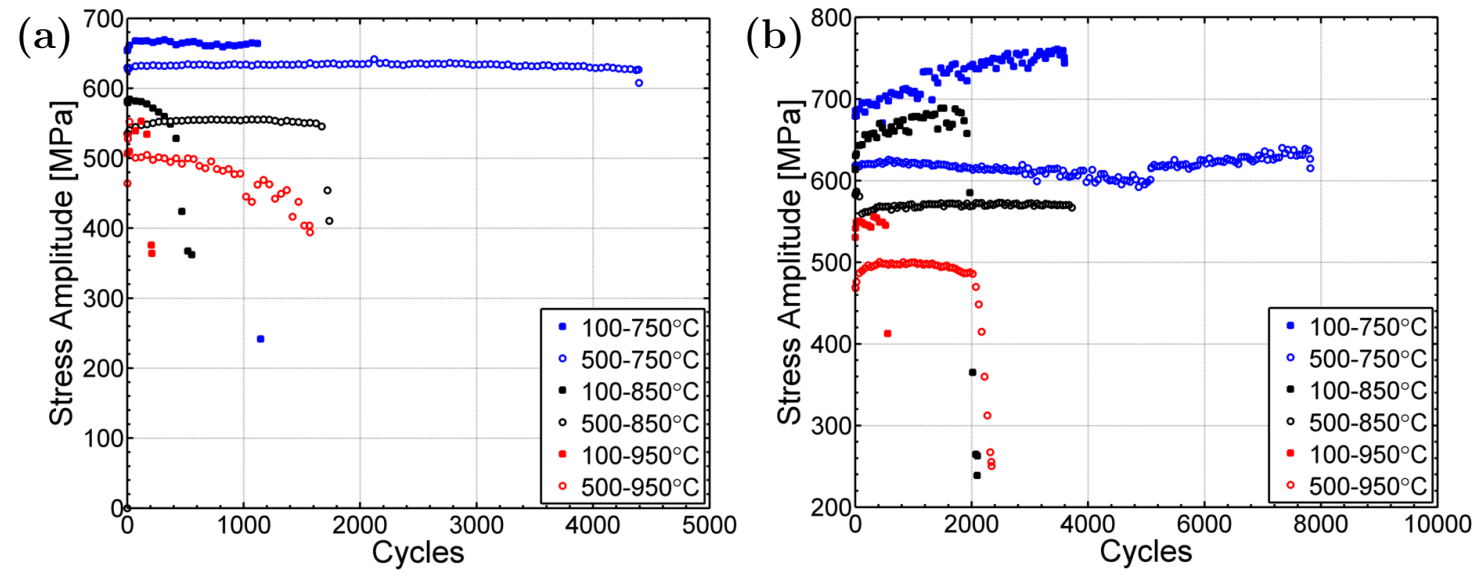

Figure 5: Stress amplitude curves for (a) IP TMF experiments with $R_{\epsilon}=0$ (b) OP TMF experiments with $R_{\epsilon}=-\infty$. 
In the case of IP TMF experiments with $T_{\max }=950^{\circ} \mathrm{C}$, the cyclic softening can be attributed to extensive inelastic strains occurring in the $\gamma$ channels perpendicular to the loading axis at peak temperatures as a result of the alignment of the peak temperature with the peak tensile strain that occurs in IP TMF [55]. In the case of OP TMF, the greatest inelastic deformation occurs in the $\gamma$ channels parallel to the applied axial load [55]. In comparison, the cyclic softening observed in the 100$850^{\circ} \mathrm{C}$ IP experiments, is a combination of accumulation of plastic deformation in the $\gamma$ channels perpendicular to the load and shearing of the $\gamma^{\prime}$ that occurs at temperatures below $750^{\circ} \mathrm{C}$ during the TMF cycle $[1,55]$.

OP TMF failure was dominated by preferential cracking along the oxidation spikes (Figure 6) when $T_{\max }=850^{\circ} \mathrm{C}$ and $950^{\circ} \mathrm{C}$, but when $T_{\max }=750^{\circ} \mathrm{C}$ the mechanism of failure was pure fatigue, with the crack exhibiting macroscopic cube shear behavior. In dropping the temperature from $950^{\circ} \mathrm{C}$ to $750^{\circ} \mathrm{C}$, a $80 \%$ reduction in the rate of oxidation occurs [56]. As a result, the $750^{\circ} \mathrm{C}$ behavior was attributed to stress concentrations on fewer slip planes and $\gamma^{\prime}$ shearing, whereas above $800^{\circ} \mathrm{C}$ the deformation becomes more homogeneous with damage being localized to the $\gamma$ channels [57]. On the fracture surface (Figure 8a) of material exposed to OP conditions are observed numerous crack initiation sites near the surface as evidence of increased environmental influence in the interdendritic regions. In contrast, fatigue cracks were observed to be emanating from carbide interfaces and the surrounding material in all IP TMF specimens as shown in Figure 7. Under IP conditions, typically a single primary crack is observed on the fracture surface (Figure 8b) emanating from the surface and linking with interior cracks from debonded carbides that allow for rapid propagation of the crack through the material. In the coming sections, this IP fatigue failure mechanism will be discussed in greater detail. Ultimately, no discernible influence of minimum cycle temperature was observed on the failure mechanisms, with the temperature-strain phasing controlling which degradation mechanism operates. 


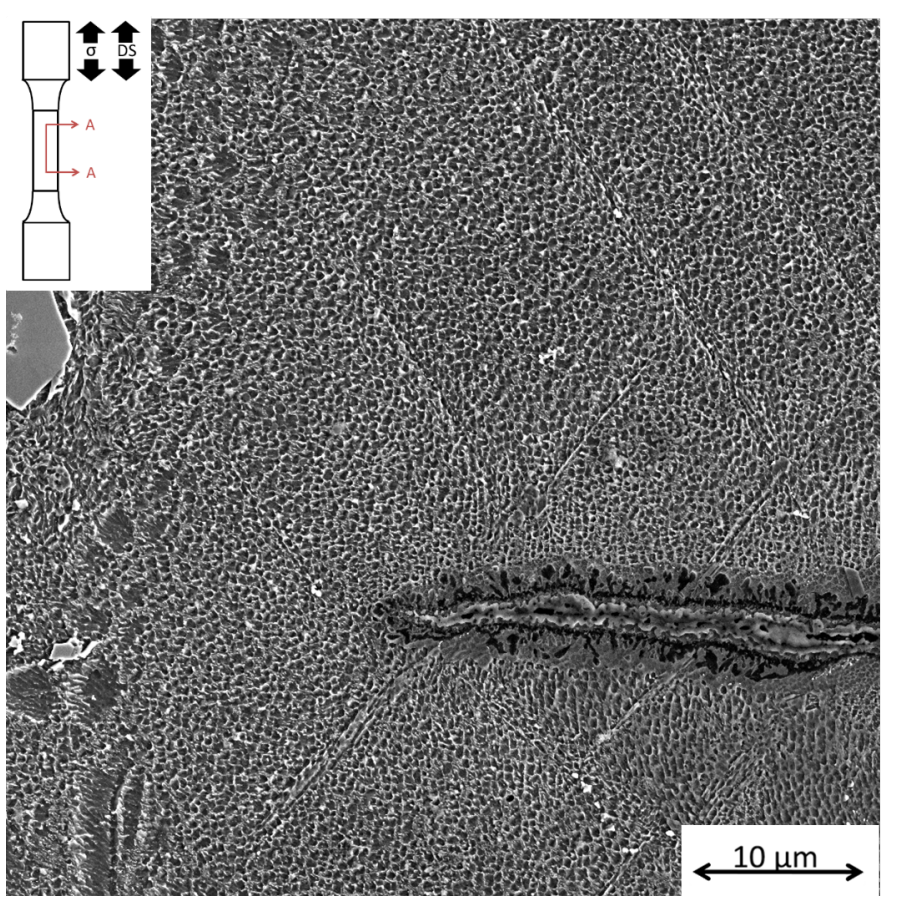

Figure 6: Fatigue crack propagating from an oxidation spike in material exposed to OP TMF $R_{\epsilon}=-\infty \operatorname{TMF}\left(T=100-950^{\circ} \mathrm{C}\right.$ and $\left.\Delta \epsilon_{m e c h}=1.0 \%\right)$. 


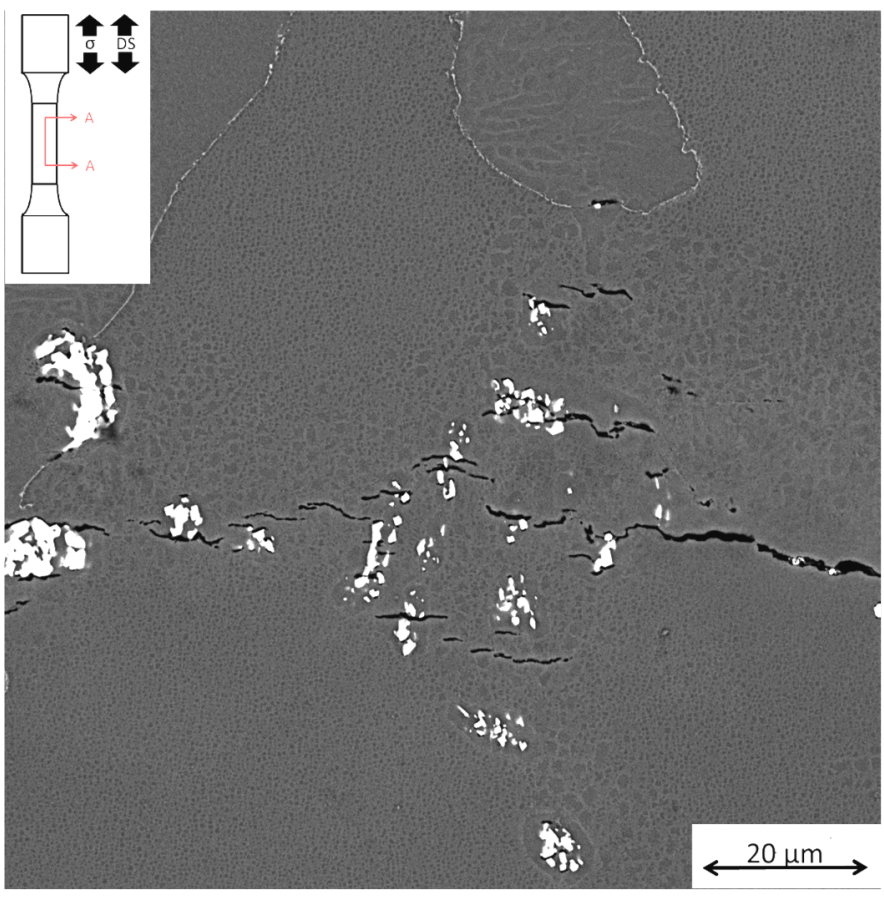

Figure 7: Fatigue cracks linking between debonded and cracked carbides in material exposed to IP $R_{\epsilon}=0 \mathrm{TMF}\left(\Delta T=100-750^{\circ} \mathrm{C}\right.$ and $\left.\Delta \epsilon_{m e c h}=1.2 \%\right)$.

(a)

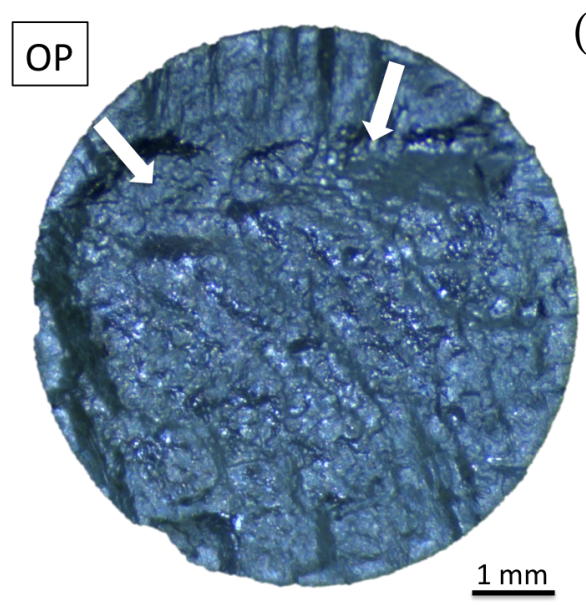

(b)

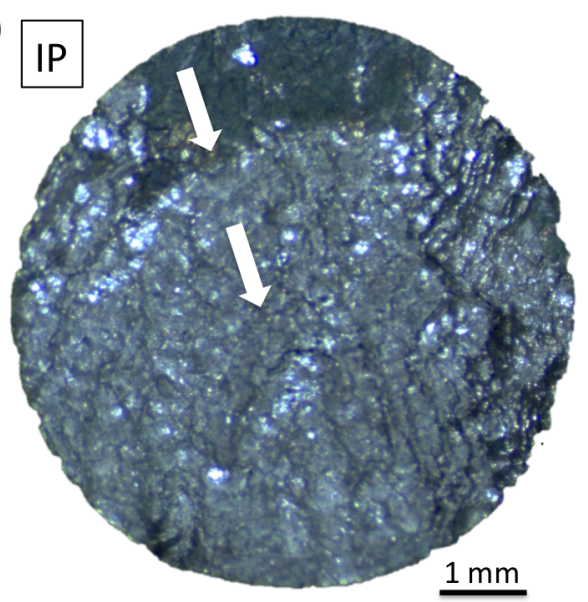

Figure 8: Optical images showing the fracture surfaces of material in the L-orientation exposed to TMF conditions. Crack initiation sites are indicated by the white arrows: (a) $\mathrm{OP}, R_{\epsilon}=-\infty, \mathrm{T}=100-950^{\circ} \mathrm{C}$, and $\Delta \epsilon_{m e c h}=1.0 \%$ (b) IP, $R_{\epsilon}=0, \mathrm{~T}=100-950^{\circ} \mathrm{C}$, and $\Delta \epsilon_{\text {mech }}=1.0 \%$

At failure of the material, the $\gamma^{\prime}$ precipitates were found to not yet exhibit directional coarsening for specimens tested with a $T_{\max }$ of $950^{\circ} \mathrm{C}$ as shown by the primarily 
cuboidal primary $\gamma^{\prime}$ precipitates (Figure 9). No detectable microstructure evolution was observed in the experiments conducted at maximum temperatures of either $750^{\circ} \mathrm{C}$ or $850^{\circ} \mathrm{C}$. These findings are consistent with analytical model predictions for aging of the alloy where directional coarsening was only observed at temperatures above $900^{\circ} \mathrm{C}$ [54]. Further, the cumulative exposure time for the $T_{\max }=950^{\circ} \mathrm{C}$ specimens during the TMF experiment is too short to bring about a fully rafted structure, even though the thermodynamic driving force for directional coarsening is sufficient.

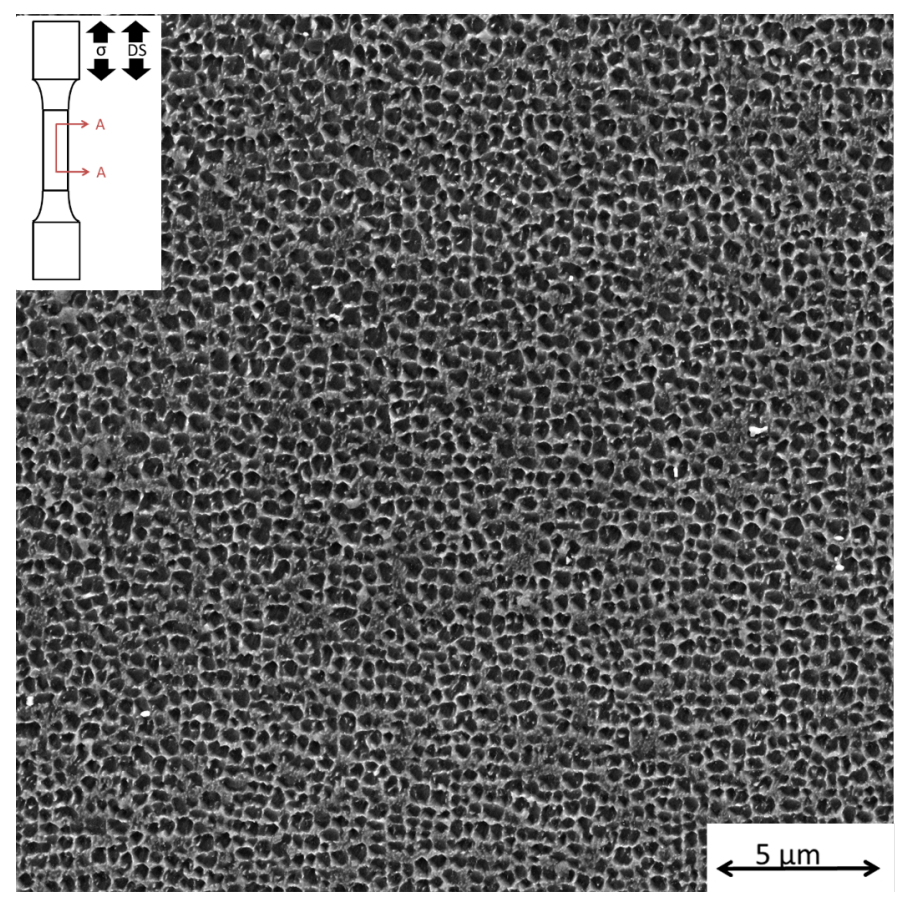

Figure 9: Resultant cubodial primary $\gamma^{\prime}$ precipitates in failed material exposed to OP $R_{\epsilon}=$ $-\infty \mathrm{TMF}\left(T=100-950^{\circ} \mathrm{C}\right.$ and $\left.\Delta \epsilon_{m e c h}=1.0 \%\right)$ indicating negligible changes in precipitate size and morphology.

As a result of the experiential findings, the following can be stated about the potential life limiting mechanisms:

1) Microstructural analysis determined coarsening to be a non-factor in the TMF experiments conducted at all $T_{\max }$ considered [58].

2) Continuous cracking and re-oxidizing of the specimen surfaces and subsurface $\gamma^{\prime}$ depletion at $T_{\max }$ of $850^{\circ} \mathrm{C}$ and $950^{\circ} \mathrm{C}$ can be considered primary contributing factors for $\mathrm{OP} \mathrm{TMF}$ life. At $T_{\max }$ of $750^{\circ} \mathrm{C}$ the rate of oxidation is reduced $80 \%$ due to limiting the oxidation kinetics having an exponential dependence on temperature [56]. 
3) Accumulated creep damage can be considered the contributing factor for TMF with a $T_{\max }$ of $850^{\circ} \mathrm{C}$ and $950^{\circ} \mathrm{C}$ as evidenced by the cyclic softening in the stress amplitude curves.

4) With a $T_{\max }$ of $750^{\circ} \mathrm{C}$ and under both IP and OP conditions, the observed reduction in life when the minimum cycle temperature is reduced can be attributed to the greater inelastic strain that occurs from an increase in the elastic modulus in the sub- $500^{\circ} \mathrm{C}$ temperature regime. The peak stresses do not allow for creep damage, and environmental and aging effects are mitigated [59].

\subsection{Effect of Mean Strain}

While the loading conditions in service components are typically associated with OP $R_{\epsilon}=-\infty$ TMF and IP $R_{\epsilon}=0$ TMF loadings, variations in mean strains do occur within service components. To examine the influence of mean strain on strain-life behavior in the L-orientation, OP $R_{\epsilon}=-\infty$ and $R_{\epsilon}=-1$ TMF experiments in the 500$950^{\circ} \mathrm{C}$ temperature range were conducted. Similarly, IP experiments were conducted for both $R_{\epsilon}=0$ and $R_{\epsilon}=-1$ in the $500-950^{\circ} \mathrm{C}$ range. The strain-life curves for each set of mean strain conditions is shown in Figure 10 with the isothermal LCF behavior at $950^{\circ} \mathrm{C}$ under fully-reversed conditions as a reference to the upper strain-life limit. 
Figure 10: Life curves for TMF experiments for material in the L-orientation conducted in the $500-950^{\circ} \mathrm{C}$ temperature range under IP $R_{\epsilon}=-1$ and $R_{\epsilon}=0$ loading conditions and OP $R_{\epsilon}=-1$ and $R_{\epsilon}=-\infty$ conditions in comparison to the strain-life at $950^{\circ} \mathrm{C}$ under fully-reversed loading conditions.

Specimens tested under both IP and OP $R_{\epsilon}=-1 \mathrm{TMF}$ generally exhibited shorter fatigue lives than the TMF experiments with a mean strain. However, the results are well within the experimental scatter of the material and the allowable variations for grain misorientation. Through repetition of the TMF experiments, a $+\backslash-20 \%$ range in the life from the mean value was found.

Comparative sets of initial cycle and half-life stress-train curves with the corresponding mean stress evolution curves for both IP and OP TMF are shown in Figures 11 and 12. Aside from the shift in strain associated with the difference in strain ratios, the half-life hysteresis behavior under both IP and OP conditions with a mean strain result in statistically identical peak stresses as the corresponding fully-reversed experiments at half-life. In addition the accumulated inelastic strains were also equivalent between the cycles. From the evolution of the non-zero mean stress it is observed that IP and OP experiments conducted with a mean strain exhibited nearly symmetric loading on the initial cycle, with the material ultimately reaching stabilized hysteresis at approximately $15 \%$ life, whereas the fully-reversed experiments stabilized within $10 \%$ of the life value. Further, both IP and OP experiments with $R_{\epsilon}=-1$ experienced higher stresses in the cold portion of their respective TMF cycles early in life controlling the rate of stress stabilization. 

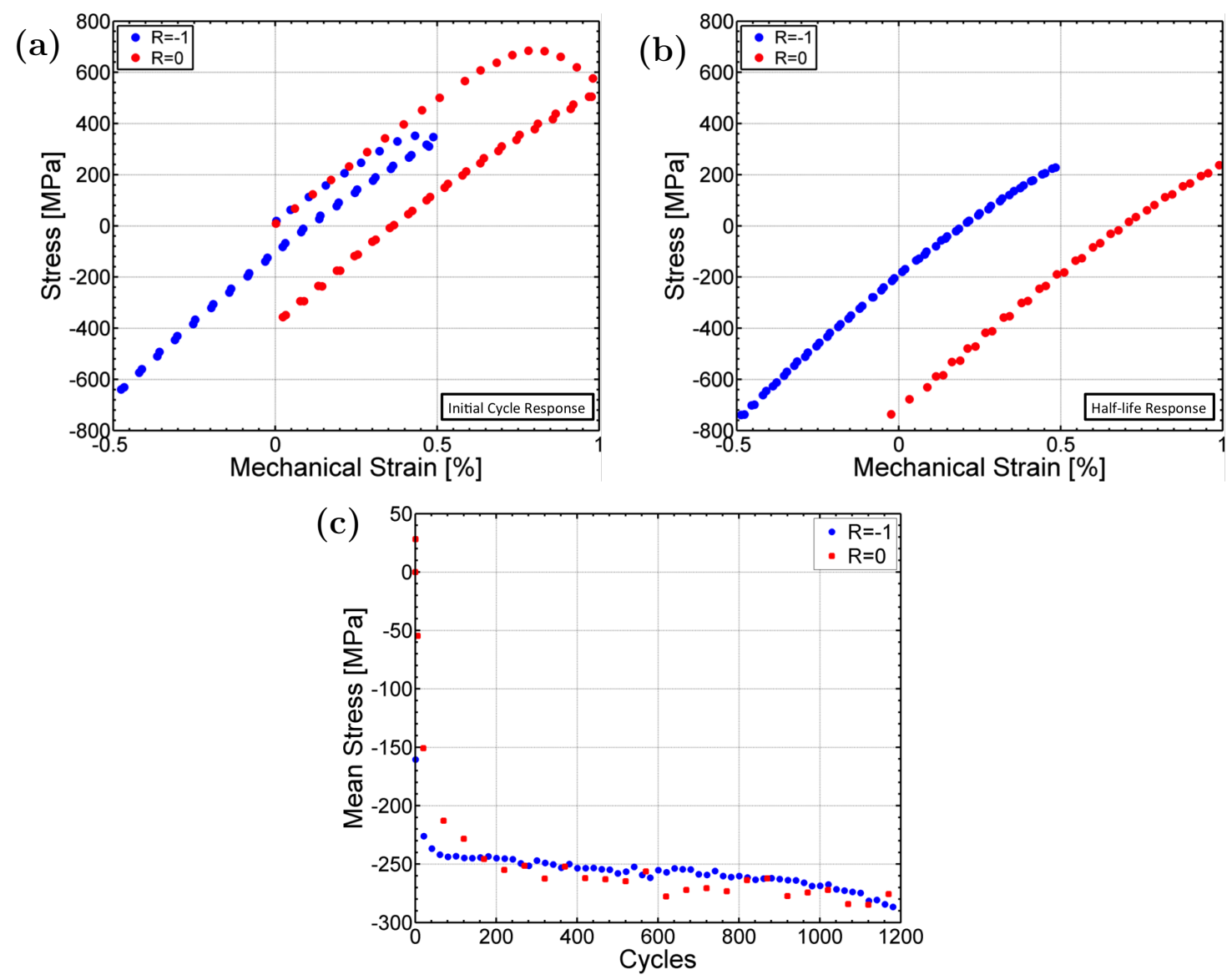

Figure 11: IP TMF results with $T=500-950^{\circ} \mathrm{C}$ comparing the effect of mean strain on (a) First cycle response (b) Half-life hysteresis response (c) Mean stress evolution. 

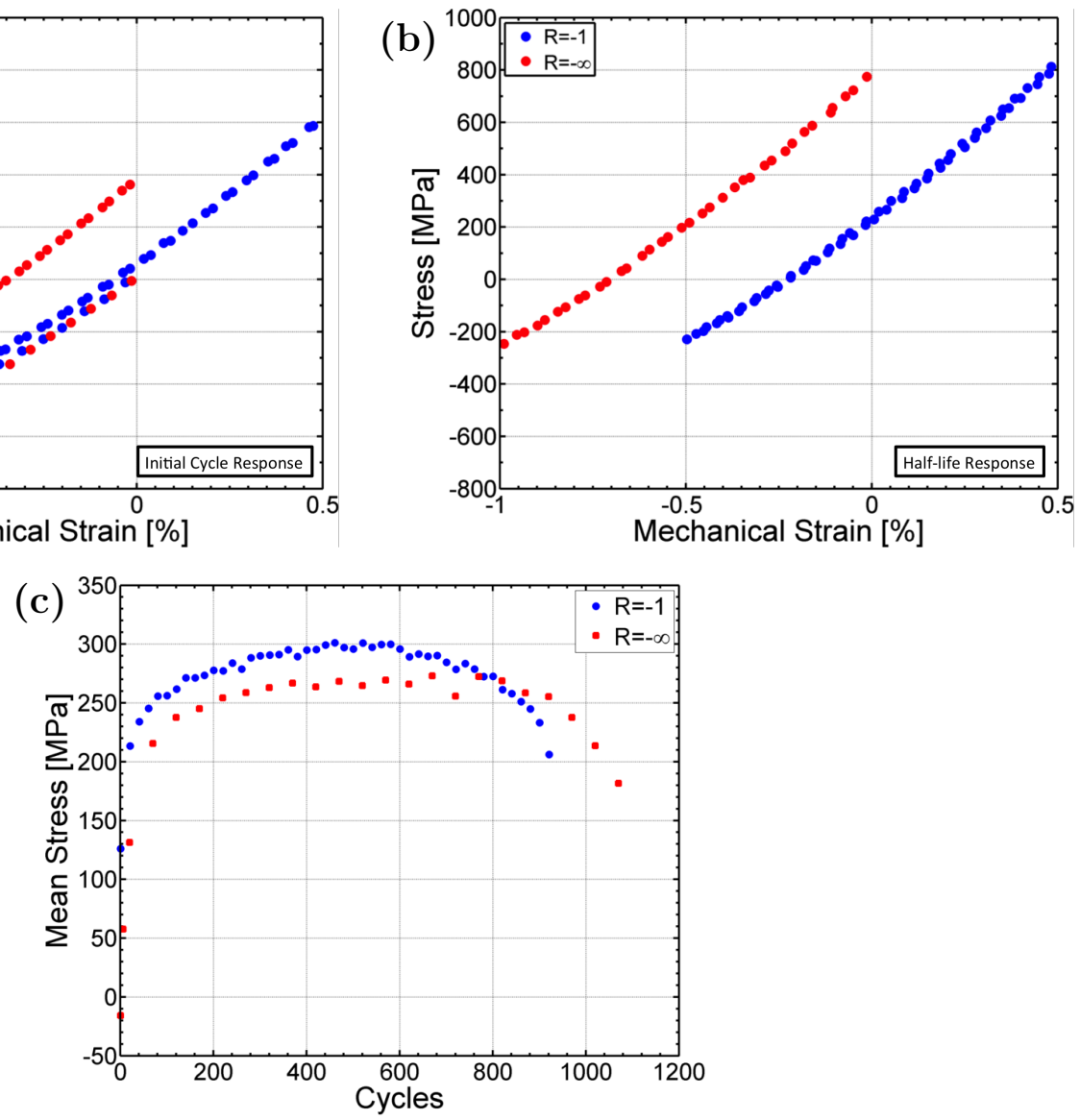

Figure 12: $\mathrm{OP}$ TMF results with $T=500-950^{\circ} \mathrm{C}$ comparing the effect of mean strain on (a) First cycle response (b) Half-life hysteresis response (c) Mean stress evolution.

While differences exist in the stress evolution, consideration of the known variation in the strain-life results and the similarities of the resultant strain-life and stress response, the TMF response independent of mean strain. As a result, the mechanical strain amplitude can be considered to control the strain-life under TMF conditions where different mean strains are of concern. These findings are consistent with the behavior of other Ni-base superalloys under various mean strain conditions [30].

\subsection{Temperature-Force Interactions}

Amongst TMF loadings, OP TMF loadings generally become the life limiting cycle type $[48,57,60]$. This is attributed to the material degradation that occurs from the the continuous cracking of oxide layers and re-oxidation in the areas surrounding a growing fatigue crack $[21,61]$. For the cases where a maximum cycle temperature of 
$1223 \mathrm{~K}\left(950^{\circ} \mathrm{C}\right)$ was used;

1. An IP-OP TMF crossover was observed

2. IP behavior is life limiting at high $\Delta \epsilon_{m e c h}$ and OP TMF at low mechanical strain amplitudes

3. A shift in the $T_{\min }$ is observed a shift in the IP-OP mechanical strain from a $\Delta \epsilon_{\text {mech }} \approx 0.9 \%$ for $500-950^{\circ} \mathrm{C}$ to a $\Delta \epsilon_{\text {mech }} \approx 0.7 \%$ for $\Delta \mathrm{T}=100-950^{\circ} \mathrm{C}$.

4. In the case of the IP-OP curves in the $100-750^{\circ} \mathrm{C}$ temperature range, an IP-OP crossover is not observed and the OP TMF behavior always exhibits a greater life than that of the IP cycle

Similar IP-OP crossovers have also been reported for the Ni-base superalloys MarM247LC-DS and GTD-111 undergoing TMF with a $T_{\max }$ in the $871-971^{\circ} \mathrm{C}$ range $[17$, $22,48]$.

Examination of specimens exposed to IP TMF conditions above the cross-over point revealed that a large majority of the $M_{23} C_{6}$ carbides within the microstructure had fatigue cracks either emanating from their interfaces with the $\gamma-\gamma^{\prime}$ matrix or in the matrix material directly surrounding them as shown in Figure 7. Due to the three-dimensional sub-surface nature of the carbides, the cracks in the matrix are most likely the result of below carbide debonding [62]. In addition, the minority of carbides with chord lengths greater than $20 \mu \mathrm{m}$ were themselves observed to have cracked; most likely on the initial cycle $[10,63]$. Similar microstructural observations have been reported for IP TMF of other Ni-base superalloys where the $T_{\max }$ values used were in the $870-970^{\circ} \mathrm{C}$ range; however, these occurrences were primarily attributed creep and casting porosity $[17,22,48]$. For IP $500-950^{\circ} \mathrm{C}$ experiments conducted below the mechanical strain crossover point, fatigue cracks were still observed to be emanating from debonded carbides and the surrounding regions.

The preferred fatigue crack growth and propagation mechanisms were observed to be the linking-up of cracks with neighboring carbides as shown in Figure 7. While creep interactions between the carbides and surrounding matrix can be assumed to most certainly occur for TMF tests conducted with high mechanical strain amplitudes and $T_{\text {max }} s$ of either $750^{\circ} \mathrm{C}$ and $850^{\circ} \mathrm{C}$, the presence of debonded carbides in specimens tested under IP TMF conditions with a $T_{\max }=750^{\circ} \mathrm{C}$ and low mechanical strain amplitude (relatively speaking) is indicative that this is a creep moderated mechanism for TMF cycles with a $T_{\max }$ above $850^{\circ} \mathrm{C}$. Under OP TMF conditions carbide decohesion is not observed. However, the carbides can still be seen to be stress concentrators as indicated by slip bands eminating from the carbides as shown in Figure 13. 


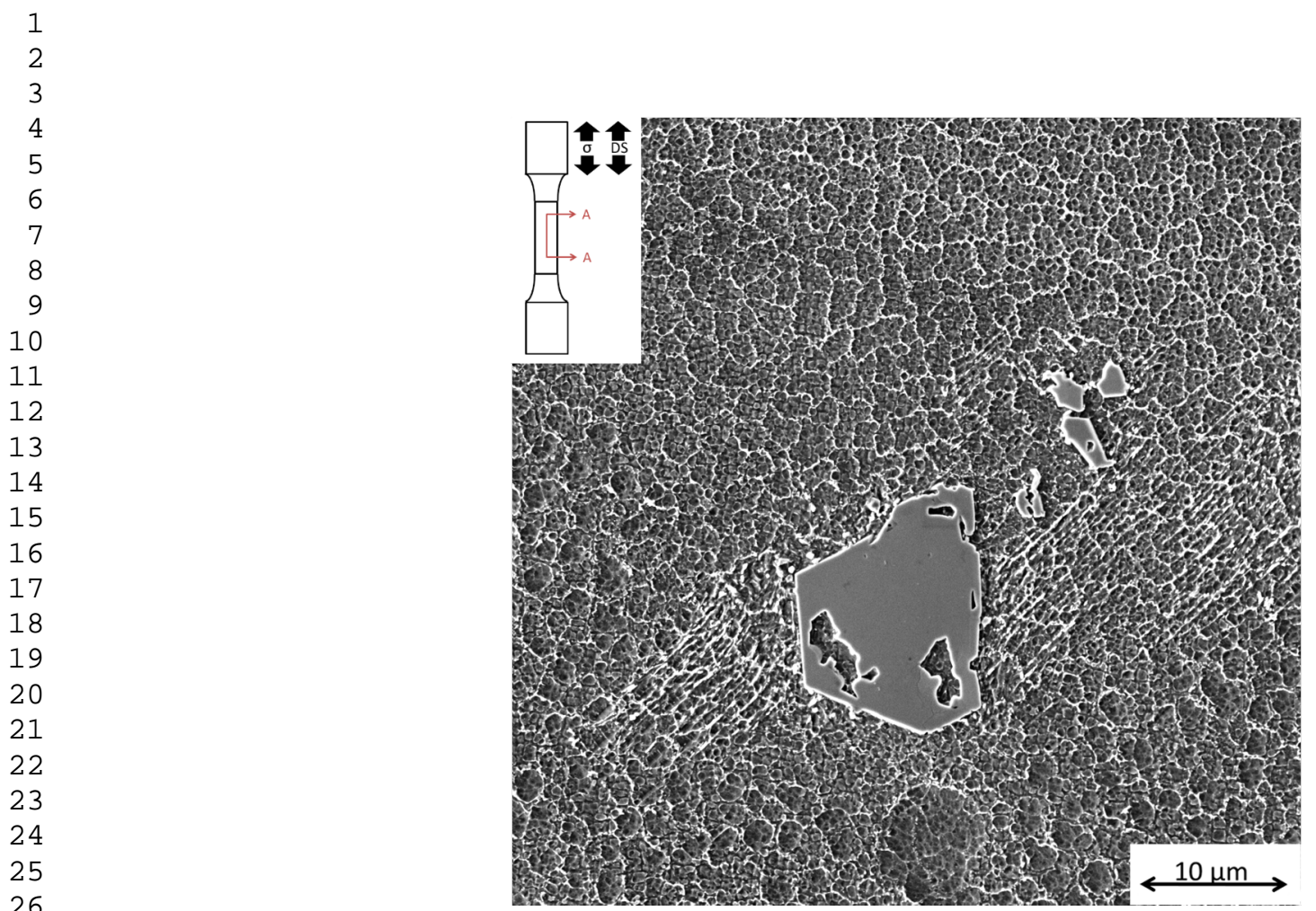

Figure 13: Slip band emination on a $M_{23} C_{6}$ carbide occurring as a result of OP $R_{\epsilon}=-\infty$ $\mathrm{TMF}$ exposure within a interdendritic region $\left(T=100-950^{\circ} \mathrm{C} \Delta \epsilon_{\text {mech }}=0.8 \%\right)$.

For Mar-M200 undergoing isothermal LCF in the $20-800^{\circ} \mathrm{C}$ temperature range, the primary fatigue crack propagation mechanism was determined to be the linking of cracks emanating from debonded carbides [10,64]. Above, $850^{\circ} \mathrm{C}$ it was reported that the fatigue crack propagation mechanism changed to that of cracks initiating at casting porosity in Mar-M200 [10,64]. However, in the case of of the presently tested CM247LC-DS there is no significant casting porosity. Additionally, quantitative fractography measurements of failed tensile surfaces tested in the $20-880^{\circ} \mathrm{C}$ range revealed the carbide area fraction was found to average $10 \%$, while the average volume fraction of carbides within the bulk was determined to be less than $2 \%$ [65]. Further, the expected thermal strain mismatch between the bulk superalloy and the $\mathrm{MC} / M_{23} C_{6}$ carbides is $\approx 1.0 \%$ resulting in compressive strains developing in the material surrounding the carbides at room temperature [66-68].

Overall, the IP-OP mechanical strain-life crossover point and the associated temperature dependence can be linked with the microscopic TMF conditions in the material surrounding the carbides and the associated interfaces. When accounting for the strains induced by the thermal strain mismatch, the matrix material in regions in the immediate vicinity of the carbides experiences a local mechanical strain amplitude that is a combination of the thermal misfit and the applied mechanical strain amplitude for 

these localized regions. Ultimately, below the IP-OP crossover point, fatigue damage accumulation in regions near the debonded carbides under IP TMF continues to occur, however the damage accumulation is at a reduced rate compared to the OP TMF experiments which is the reason for the OP TMF being the life limiting cycle [22]. Further, rafting was not observed for CC conditions with a $T_{\max }$ of $950^{\circ} \mathrm{C}$.

\subsection{Creep-Fatigue Interactions}

The life comparisons between CC TMF and CF TMF experiments in the L-orientation were shown previously in Figure 14. On average, the inclusion of a dwell period resulted in a $2 \mathrm{x}$ or greater reduction in TMF life, with the greatest life reductions occurring for IP TMF conditions. On average, the inclusion of a strain hold resulted in a $5 \mathrm{x}$ reduction in life for both IP and OP TMF with a $T_{\max }$ of $950^{\circ} \mathrm{C}$. For $\mathrm{CF}$ with a $T_{\max }$ of $750^{\circ} \mathrm{C}$, the life reduction associated with the dwell conditions resulted in a temperature-strain phasing dependent effect, with OP CF exhibiting an increasing life knockdown factor with decreasing strain amplitude, while IP CF exhibited a decreasing knockdown when compared to CC conditions. This IP life reduction can be attributed to the rapid debonding of the carbides and fatigue crack nucleation in the surrounding matrix material through the accumulation of voids. In the case of OP TMF, the increase in cyclic inelastic strain coupled with the accelerated environmental damage is the primary reason for the life reduction.
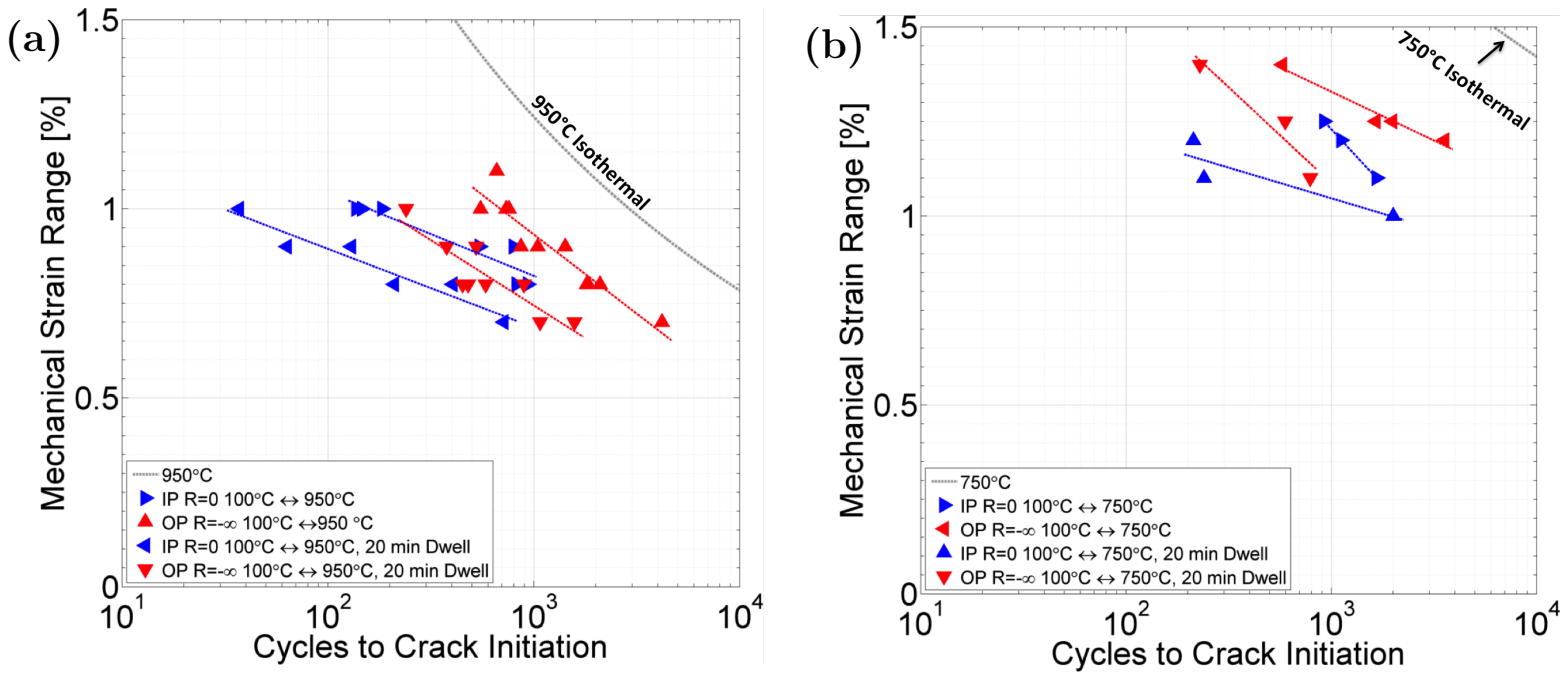

Figure 14: IP-OP TMF strain-life curves for material in the L-orientation for $\mathrm{CC}$ and $\mathrm{CF}$ $\mathrm{TMF}$ cycling a) $\mathrm{T}=500-950^{\circ} \mathrm{C}$ and b) $T=100-750^{\circ} \mathrm{C}$. 
The half-life hysteresis and mean stress evolution curves are shown in Figures 15-18 comparing the $\mathrm{CC}$ and $\mathrm{CF}$ responses for the life results in Figure 14. The dwell periods were generally found to result in an increase in the amount of accumulated inelastic strain, with nearly complete stress relaxation occurring for CF TMF cycles with $T_{\max }$ of 850 and $950^{\circ} \mathrm{C}$. At a $T_{\max }$ of $750^{\circ} \mathrm{C}$, minimal stress relaxation is observed to occur as a result of the limited ductility at intermediate temperatures. This is consistent with trends observed for DS Ni-base superalloys under isothermal CF conditions [30].
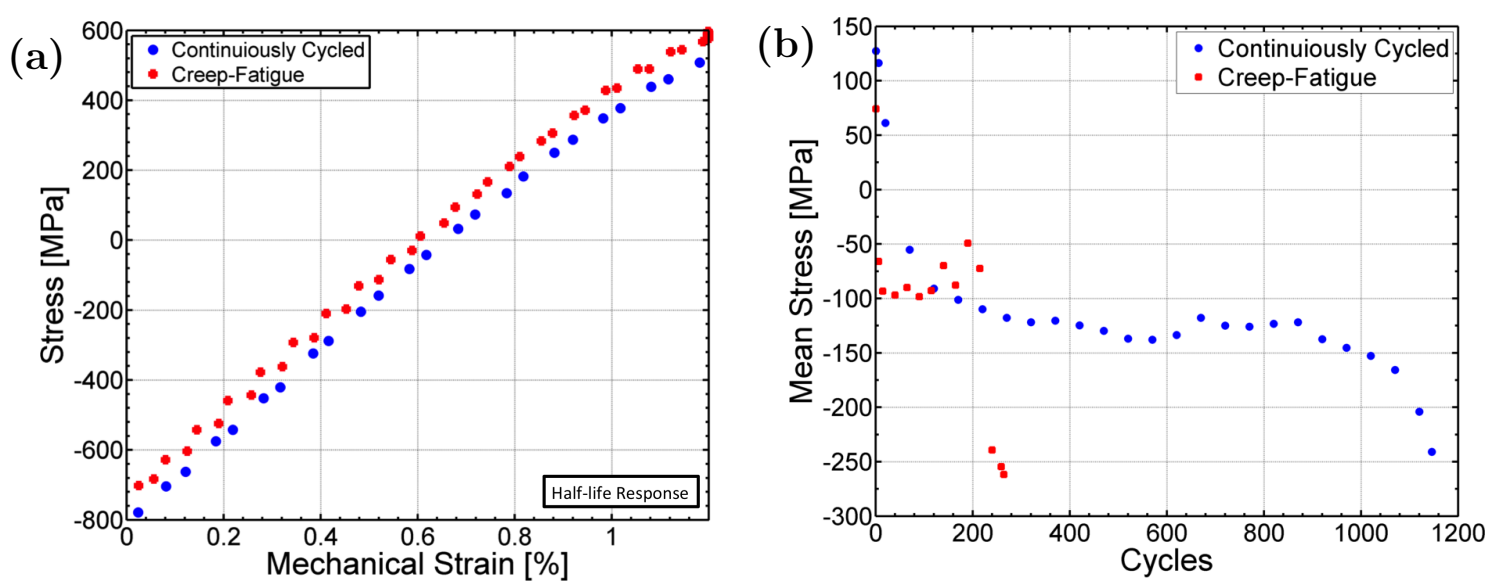

Figure 15: IP $R_{\epsilon}=0$ TMF results for $T=100-750^{\circ} \mathrm{C}$ comparing CC to $\mathrm{CF}$ in the L-orientation on the (a) Half-life hysteresis response (b) Mean stress evolution.

(a)

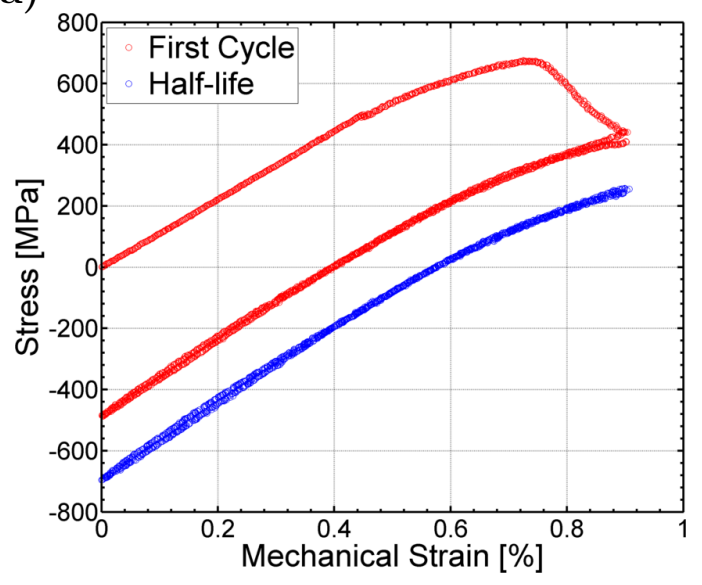

(b)

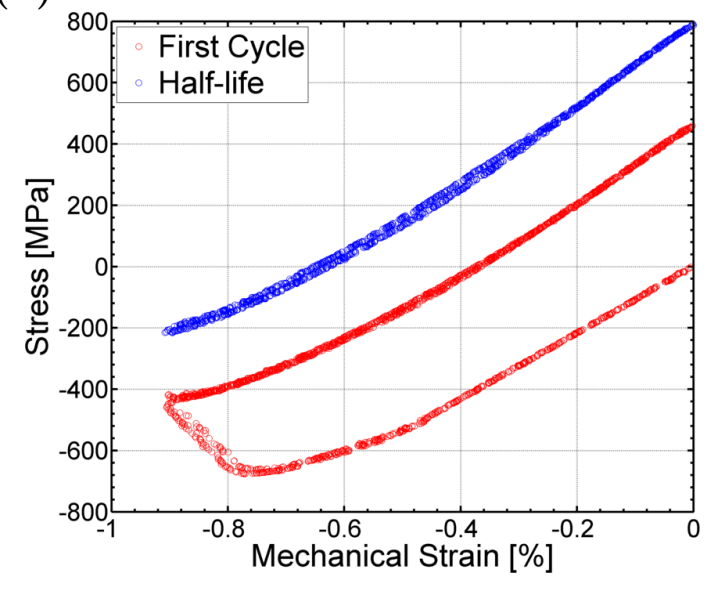

Figure 16: Representative initial and half-life hysteresis responses for material subjected to $T=100-950^{\circ} \mathrm{C} \mathrm{CC} \mathrm{TMF} \mathrm{(a)} \mathrm{IP} R_{\epsilon}=0$ and (b) OP $R_{\epsilon}=-\infty$ 


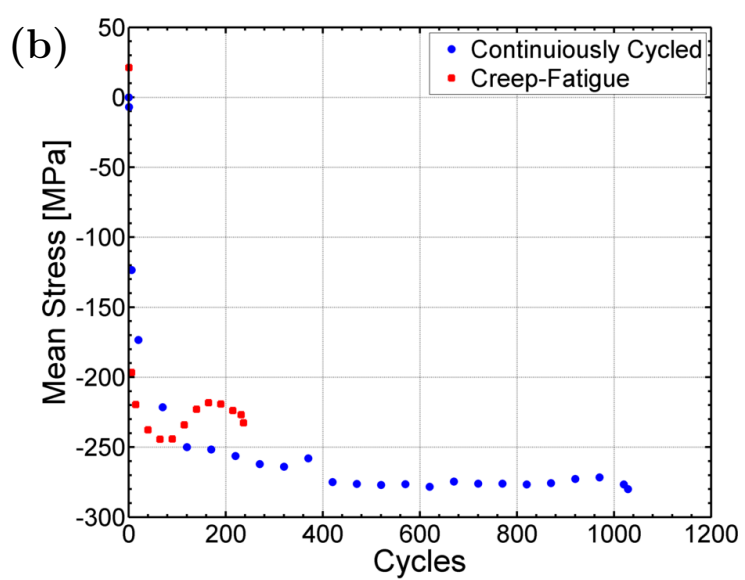

Figure 17: IP $R_{\epsilon}=0$ TMF results for $T=100-950^{\circ} \mathrm{C}$ comparing $\mathrm{CC}$ to $\mathrm{CF}$ in the L-orientation on the (a) Half-life hysteresis response (b) Mean stress evolution.
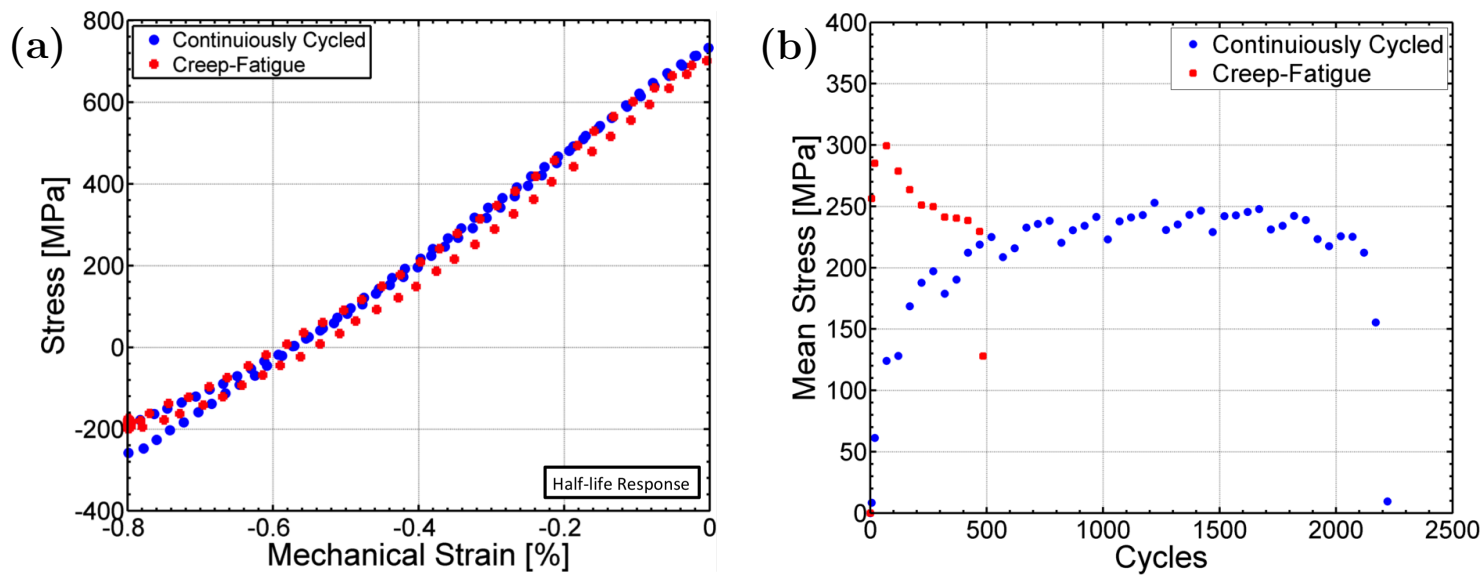

Figure 18: OP $R_{\epsilon}=-\infty$ TMF results for $T=100-950^{\circ} \mathrm{C}$ comparing $\mathrm{CC}$ to $\mathrm{CF}$ in the Lorientation on the (a) Half-life hysteresis response (b) Mean stress evolution.

Shown in Figures 15-18 are representative half-life hysteresis and mean stress evolution curves comparing the $\mathrm{CC}$ and $\mathrm{CF}$ responses for the life results in Figure 14. For cycle with a $T_{\max }$ of $950^{\circ} \mathrm{C}$ and large strain amplitudes, the addition of a strain hold resulted in an increase in the accumulated inelastic strain, however, at lower applied strains and for $\mathrm{CF}$ with a $T_{\max }$ of $750^{\circ} \mathrm{C}$ no measurable differences in accumulated inelastic strain were observed when compared to corresponding CC cycles.

Under IP CF with a $T_{\max }$ of $950^{\circ} \mathrm{C}$, the mean stress was observed to initially decrease before stabilizing at a value $20 \%$ above the peak mean stress. Whereas, in the OP CF case, the mean stress initially decreased about $20 \%$ before increasing again, 
(a)

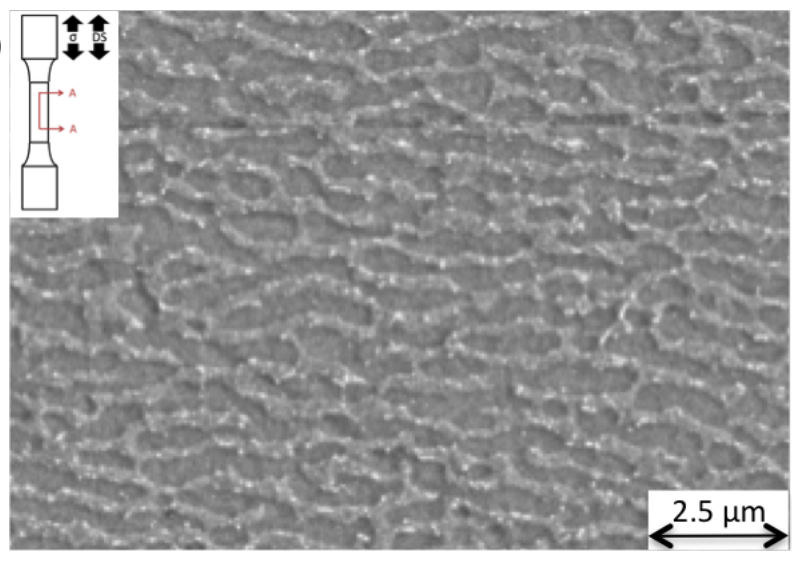

(b)

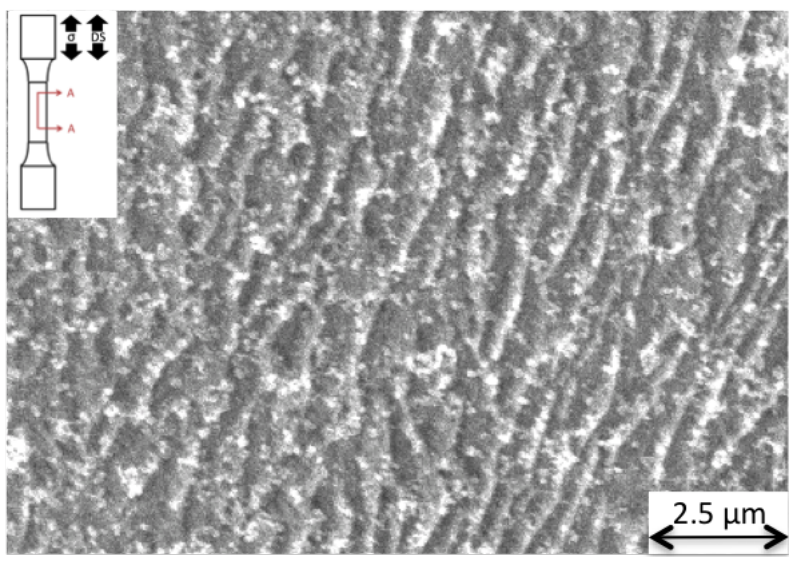

Figure 19: Rafted microstructures at material failure after exposure to CF conditions a) IP $\mathrm{TMF}, R_{\epsilon}=0 \mathrm{~T}=100-950^{\circ} \mathrm{C}, \Delta \epsilon_{m e c h}=0.7 \%$ b) OP TMF, $R_{\epsilon}=-\infty \mathrm{T}=100-950^{\circ} \mathrm{C}$, $\Delta \epsilon_{\text {mech }}=0.8 \%$.

While other studies concerning the high temperature LCF behavior of Ni-base superalloys have reported rafting to occur under CC TMF conditions, in those particular cases the TMF cycles involved $T_{\max }>950^{\circ} \mathrm{C}$ or stress concentrators $[21,23,27]$. Additionally, other studies have noted rafting results in a softening effect which ultimately leads to premature failure [27]. In the present work, cyclic softening and hardening were observed, however, these occurrences did not directly relate to the presence of a rafted microstructure. Rather, fluctuations in the mean stress were observed to relate to the occurrence of a rafted microstructure. 


\subsection{Material Anisotropy}

Many of the life trends observed for TMF loadings in the L-orientation, were observed in the transverse orientation, however the transverse life was generally reduced from that of the L-orientation as a result of increases in the elastic moduli. For the $500-950^{\circ} \mathrm{C}$ temperature range, the material life was found to be insensitive to temperature-force phasing when $T_{\min }=500^{\circ} \mathrm{C}$ as shown in Figure 20a. With a decrease in $T_{\min } 500{ }^{\circ} \mathrm{C}$ to $100^{\circ} \mathrm{C}$, a $10 \mathrm{x}$ decrease in the IP TMF life was observed, whereas the OP TMF life was insensitive to the decreased $T_{\min }$. The IP life sensitivity to $T_{\min }$ can be attributed to temperature-carbide interactions. It is unclear whether or not the T-orientation exhibits a IP-OP crossover similar to the L-orientation. If a crossover does occur, the crossover would likely occur below $\Delta \epsilon_{\text {mech }} \approx 0.3 \%$ based on the material life trends.
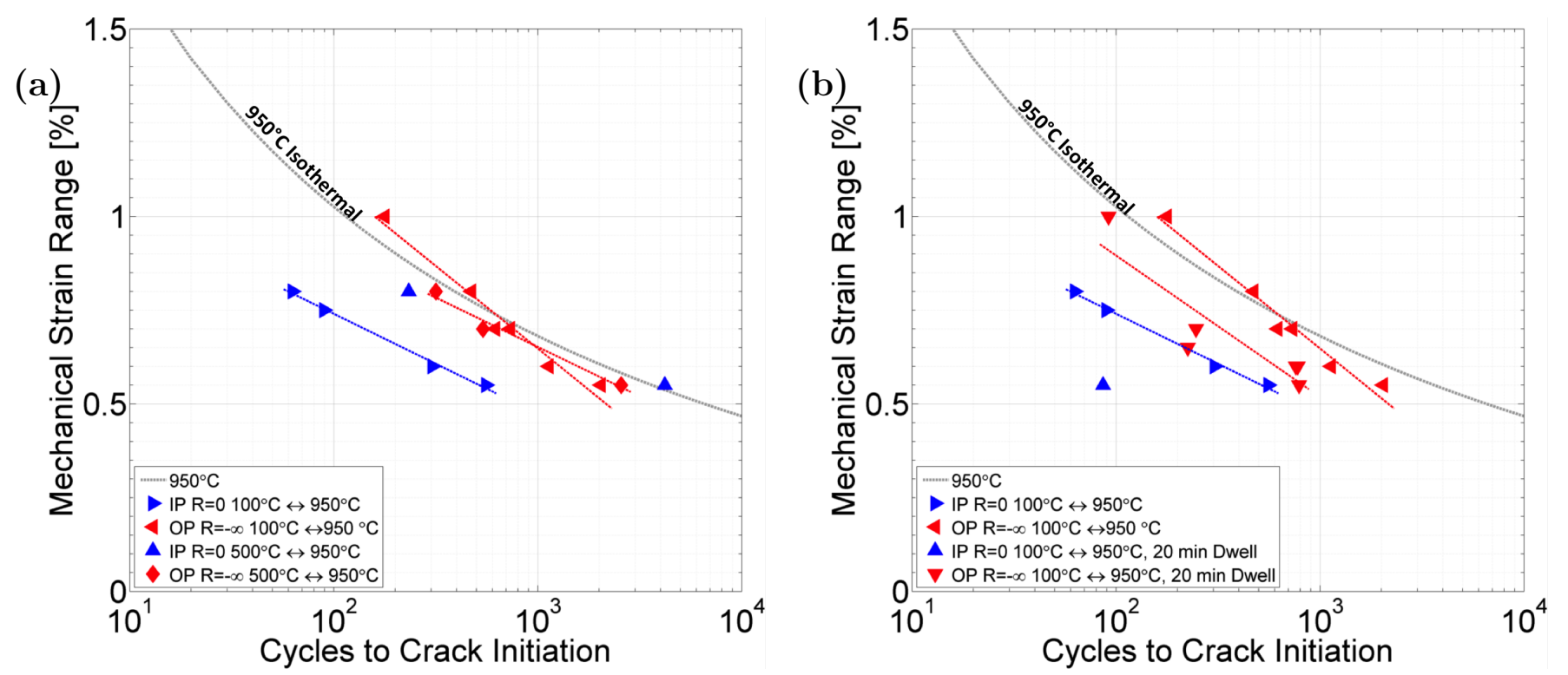

Figure 20: IP-OP TMF strain-life curves for material in the T-orientation a) Depicting the effect of $T_{\min }$ and $\mathrm{b}$ ) the effect of $\mathrm{CF}$ in the $100-950^{\circ} \mathrm{C}$ temperature range.

Similar to the L-orientation, CF fatigue conditions in the T-orientation result in a nearly $2 \mathrm{x}$ reduction in the fatigue life for OP TMF conditions and 10x for IP TMF as shown in Figure 20. Comparisons of the half-life behaviors between $\mathrm{CC}$ and $\mathrm{CF}$ reveal little difference in the mechanical response as shown in Figure 21. In the case of the failed gage sections exposed to OP TMF, there were significant differences between the material exposed to $\mathrm{CC}$ and $\mathrm{CF}$ conditions as shown in Figure 22 where grain realignment can be observed in the $\mathrm{CF}$ exposed material. 


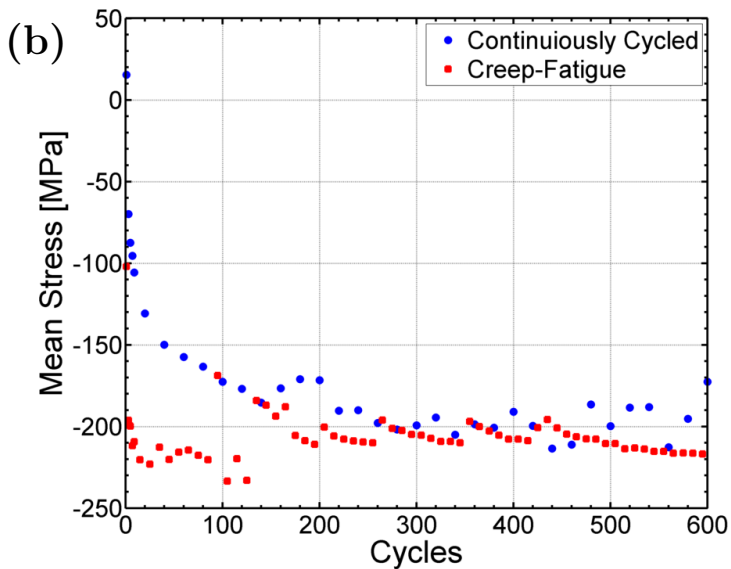

Figure 21: IP TMF results for $T=100-950^{\circ} \mathrm{C}$ comparing $\mathrm{CC}$ to $\mathrm{CF}$ in the T-orientation on the (a) Half-life hysteresis response (b) Mean stress evolution.
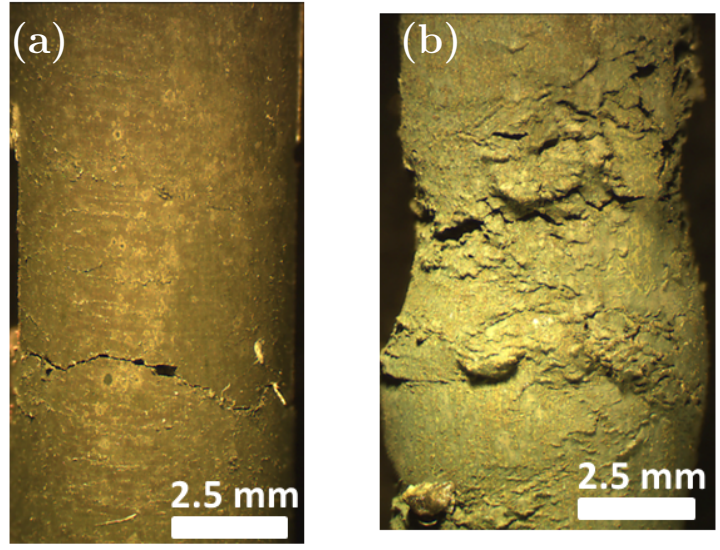

Figure 22: Comparison of the failed gage surfaces exposed to OP TMF, $T=100-950^{\circ} \mathrm{C}$ and $\Delta \epsilon_{\text {mech }}=0.55 \%$ in the T-orientation (a) under CC conditions (b) under CF conditions.

Microscopy of the failed specimens indicates that under IP TMF conditions, fatigue crack propagation is dominated by intergranular cracking and cracks emanating from grain boundary carbides. This can be seen in the macroscopic micrograph in Figure 23 and the microscopic micrograph in Figure 24. The implications of the grain boundaries become significant in deciding the mode of fatigue crack growth and the materials susceptibility to environmental damage under TMF conditions. This behavior is similar to that reported for the DS Ni-base superalloy Mar-M247 [17, 22]. Further, aging of the $\gamma-\gamma^{\prime}$ microstructure in the T-oriented specimens was not observed as a result of exposure to $\mathrm{CF}$ conditions as in the L-oriented. This can be attributed to the sensitivity of the evolution kinetics to crystallographic orientation [69]. 
Figure 23: Transgranular cracking occurring under IP $R_{\epsilon}=0$ TMF conditions ( $T=100$ $950^{\circ} \mathrm{C}$ and $\Delta \epsilon_{\text {mech }}=0.55 \%$ ).

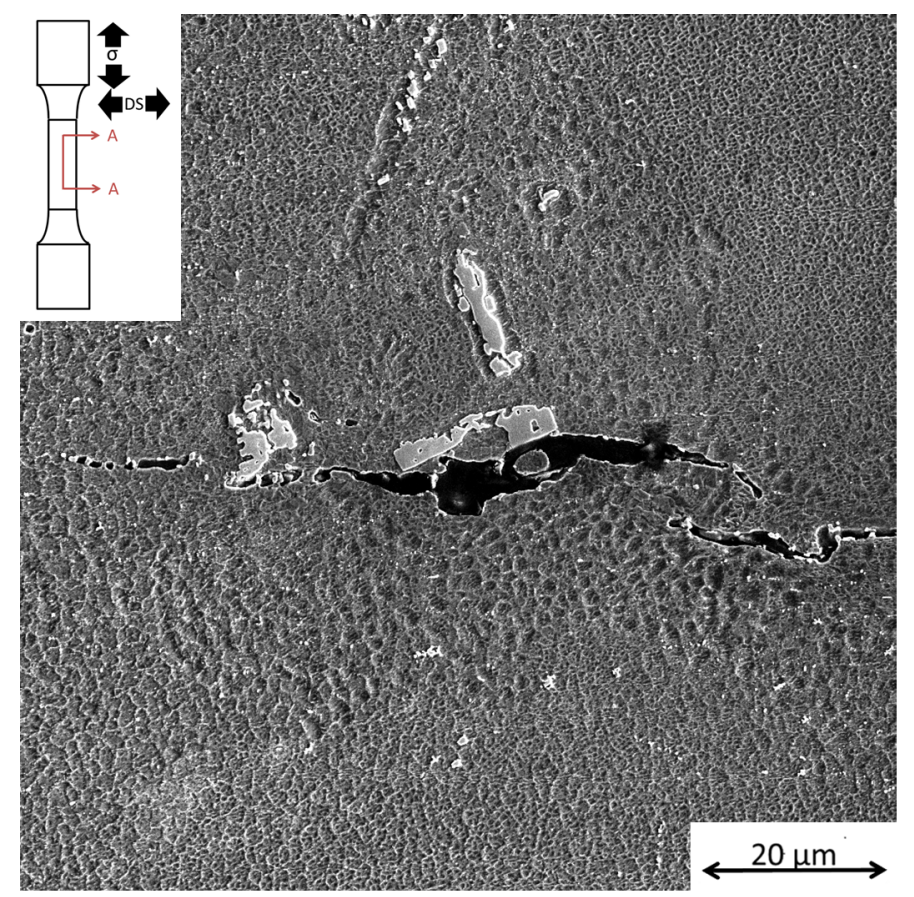

Figure 24: Fatigue crack emanating from a carbide along a grain boundary in material tested under IP $R_{\epsilon}=0$, CC TMF conditions $\left(T=100-950^{\circ} \mathrm{C}\right.$ and $\left.\Delta \epsilon_{\text {mech }}=0.55 \%\right)$.

\subsection{Review}

Based on the experimental findings of this work, the effects of TMF variables can be summarized as follows: 
Table 2: Summary of TMF Findings.

\begin{tabular}{|c|c|c|}
\hline TMF Cycle Variable & Material Effect & Life Effect \\
\hline$\downarrow T_{\min }$ & Increases inelastic strain & $\downarrow$ \\
\hline$\uparrow T_{\max }$ & Accelerated environment and creep interactions \\
\hline$R_{\epsilon}$ & Stabilization at identical stress states & No effect \\
\hline IP/OP & Shifts dominant damage mechanism from carbide interactions for IP to environment interactions for OP TMF & Variable dependent \\
\hline Dwell & Enhanced inelastic strain accumulation and $\gamma^{\prime}$ rafting & \\
\hline Anisotropy & Transgranular crack propagation & $\downarrow$ \\
\hline
\end{tabular}

*Note: The summary table does not reflect effects of aged microsructure on strainlife. For microstructure influence refer to [70].

\section{Conclusions}

1) Experiments were conducted under both IP and OP TMF conditions with $T_{\min }$ of $100^{\circ} \mathrm{C}$ and $500^{\circ} \mathrm{C}$, while the $T_{\max }$ was varied between $750^{\circ} \mathrm{C}$ and $950^{\circ} \mathrm{C}$. Overall, experiments with the $T_{\min }=100^{\circ} \mathrm{C}$ were observed to have a $50-80 \%$ reduced TMF life over the TMF life of material exposed to identical mechanical strain amplitudes at the $T_{\min }=500^{\circ} \mathrm{C}$. Ultimately, due to the lack of observed microstructure evolution and creep interactions, especially with $T_{\max }=750^{\circ} \mathrm{C}$, the reduction in TMF life was related to the increase in the elastic properties with decreasing temperature from $500^{\circ} \mathrm{C}$ to $100^{\circ} \mathrm{C}$ resulting in an increase in the plastic strain amplitude.

2) TMF life was found to be independent of mean strain. This was determined through conducting TMF experiments under IP $R_{\epsilon}=-1$ and $R_{\epsilon}=0$ as well as OP $R_{\epsilon}=-1$ and $R_{\epsilon}=-\infty$. While the starting stresses and strain were different, the half-life, cyclic deformation response, and cycles to crack initiation were found to be within typical variations for TMF experiments conducted with the same temperature-load phasing and mean strains.

3) Above a threshold mechanical strain amplitude, IP TMF loading was life limiting, while below OP TMF loading was. Ultimately this occurrence was found to be associated with fatigue crack propagation from debonded carbides under IP TMF conditions within the interdendritic regions and along the grain boundaries in the L-orientation. Additionally, the transition between IP and OP TMF dominance was determined to be sensitive to the TMF cycle temperature range and material orientation.

4) CF interactions were found to result in a drastic life reduction over material exposed to identical conditions under $\mathrm{CC}$ conditions for both $\mathrm{T}=100-750^{\circ} \mathrm{C}$ and 
$\mathrm{T}=100-950^{\circ} \mathrm{C}$. Under low mechanical strain amplitude $(>0.7 \%)$ conditions, material exposed to both IP and OP CF TMF conditions with a $T_{\max }$ of $950^{\circ} \mathrm{C}$ was observed to have undergone directional coarsening. Material exposed to large mechanical strain amplitudes did not directionally coarsen as a result of insufficient time for rafting to occur.

5) Experiments conducted in the T-orientation were found to exhibit the same TMF life traits as the longitudinal orientation, except that primary fatigue crack propagation mechanism was observed to be transgranular cracking and the life was reduced in comparison to the L-orientation.

\section{Acknowledgment}

The authors would like to thank Siemens Energy Inc., Orlando, FL for supporting this work through subcontract to DOE Award DE-FC26-05NT42644 on Advanced Hydrogen Turbine Development. 


\section{References}

[1] Reed, R. C., 2006. The Superalloys Fundamentals and Applications. Cambridge University Press.

[2] Caron, P., and Khan, T., 1983. "Improvement of Creep strength in a nickel-base single-crystal superalloy by heat treatment". Materials Science and Engineering, 61(2), pp. $173-184$.

[3] Caron, P., Henderson, P., Khan, T., and McLean, M., 1986. "On the Effects of Heat Treatments on the Creep Behaviour of a Single Crystal Superalloy". Scripta Metallurgica, 20, pp. 875-880.

[4] Nathal, M., 1987. "Effect of initial gamma prime size on the elevated temperature creep properties of single crystal nickel base superalloys". Metallurgical and Materials Transactions A, 18, pp. 1961-1970.

[5] Caron, P., Ohta, Y., Nakagawa, Y., and Khan, T., 1988. "Creep Deformation Anisotropy in Single Crystal Superalloys". In Superalloys 1988, S. Reichman, D. Duhl, G. Maurer, S. Antolovich, and C. Lund, eds., pp. 215-224.

[6] Nathal, M., MacKay, R., and Miner, R., 1989. "Influence of precipitate morphology on intermediate temperature creep properties of a nickel-base superalloy single crystal'. Metallurgical and Materials Transactions A, 20, pp. 133-141.

[7] Pollock, T., and Argon, A., 1992. "Creep Resistance of CMSX-3 Nickel base Superalloy Single Crystals". Acta Metallurgica et Materialia, 40(1), pp. 1-30.

[8] Mughrabi, H., Biermann, H., and Ungar, T., 1993. "Creep-induced local lattice parameter changes in a monocrystalline nickel-base superalloy". Journal of Materials Engineering and Performance, 2, pp. 557-564.

[9] Rowe, A., Wells, J., West, G., and Thomson, R., 2012. "Microstructural Evolution of Single Crystal and Directionally Solidified Rejuvinated Nickel Superalloys". In Superalloys 2012, E. Huron, R. Reed, M. Hardy, M. Mills, R. Montero, P. Portella, and J. Telesman, eds., pp. 245-254.

[10] Gell, M., and Leverant, G. R., 1968. "The Fatigue of the Nickel-Base Superalloy, Mar-M200, in Single-Crystal and Columnar-Grained Forms at Room Temperature". Transactions of the Metallurgical Society of AIME, 242(367-369).

[11] Antolovich, S., Domas, P., and Strudel, J., 1979. "Low cycle fatigue of René 80 as affected by prior exposure". Metallurgical and Materials Transactions A, 10, pp. 1859-1868. 
[12] Wright, P., and Anderson, A., 1980. "The Influence of Orientation on the Fatigue of Directionally Solidified Superalloys". In Superalloys 1980, J. Tien, ed., pp. 689 698.

[13] Antolovich, S. D., Rosa, E., and Pineau, A., 1981. "Low cycle fatigue of René 77 at elevated temperatures". Materials Science and Engineering, 47(1), pp. $47-57$.

[14] Gabb, T., Gayda, J., and Miner, R., 1986. "Orientation and temperature dependence of some mechanical properties of the single-crystal nickel-base superalloy René N4: Part II. Low cycle fatigue behavior". Metallurgical Transactions A, 17(3), pp. 497-505.

[15] Malpertu, J., and Rémy, L., 1990. "Influence of test parameters on the thermalmechanical fatigue behavior of a superalloy". Metallurgical Transactions A, 21(1), pp. 389-399.

[16] Sehitoglu, H., and Karasek, M., 1986. "Observations of Material Behavior Under Isothermal and Thermo-Mechanical Loading". Journal of Engineering Materials and Technology, 108(2), pp. 192-198.

[17] Boismier, D. A., and Sehitoglu, H., 1990. "Thermo-Mechanical Fatigue of MarM247: Part 1-Experiments". Journal of Engineering Materials and Technology, 112(1), pp. 68-79.

[18] Moverare, J. J., Johansson, S., and Reed, R. C., 2009. "Deformation and damage mechanisms during thermal-mechanical fatigue of a single-crystal superalloy". Acta Materialia, 57(7), pp. 2266 - 2276.

[19] Fleury, E., and Rémy, L., 1994. "Behavior of Nickel-base Superalloy Single Crystals Under Thermal-mechanical Fatigue". Metallurgical and Materials Transactions A, 25(1), pp. 99-109.

[20] Lall, C., Chin, S., and Pope, D., 1979. "The Orientation and Temperature Dependence of the Yield Stress of Ni3 (Al, Nb) Single Crystals". Metallurgical Transactions A, 10(9), pp. 1323-1332.

[21] Amaro, R. L., Antolovich, S. D., and Neu, R. W., 2012. "Mechanism-based Life Model for Out-of-phase Thermomechanical Fatigue in Single Crystal Ni-base Superalloys". Fatigue \& Fracture of Engineering Materials \& Structures, 35(7), pp. $658-671$.

[22] Sehitoglu, H., and Boismier, D. A., 1990. "Thermo-Mechanical Fatigue of MarM247: Part 2-Life Prediction". Journal of Engineering Materials and Technology, 112(1), pp. 80-89. 
[23] Kupkovits, R. A., and Neu, R. W., 2010. "Thermomechanical fatigue of a directionally-solidified Ni-base superalloy: Smooth and cylindrically-notched specimens". International Journal of Fatigue, 32(8), pp. 1330 - 1342.

[24] de la Yedra, A. G., Pedrejón, J. L., and Martín-Meizoso, A., 2013. "Thermomechanical Fatigue Tests on MarM-247 Nickel-based Superalloy Using the Direct Resistance Method". Materials at High Temperatures, 30(1), pp. 19 - 26.

[25] Huang, Z., Wang, Z., Zhu, S., Yuan, F., and Wang, F., 2006. "Thermomechanical fatigue behavior and life prediction of a cast nickel-based superalloy". Materials Science and Engineering: A, 432(1-2), pp. $308-316$.

[26] Okazaki, M., and Sakaguchi, M., 2008. "Thermo-mechanical fatigue failure of a single crystal Ni-based superalloy". International Journal of Fatigue, 30(2), pp. $318-323$.

[27] Arrell, D., Hasselqvist, M., Sommer, C., and Moverare, J., 2004. "On TMF Damage, Degradation Effects, and the Associated $T_{\text {min }}$ Influence on TMF Test Results in $\gamma / \gamma^{\prime}$ prime Alloys". In Superalloys 2004, K. Green, T. Pollock, H. Harada, T. Howson, R. Reed, J. Schirra, and S. Walston, eds., pp. 291-294.

[28] Kanesund, J., Moverare, J. J., and Johansson, S., 2011. "Deformation and damage mechanisms in IN792 during thermomechanical fatigue". Materials Science and Engineering: A, 528(13-14), pp. $4658-4668$.

[29] Fang, D., and Berkovits, A., 1994. "Mean stress models for low-cycle fatigue of a nickel-base superalloy". International Journal of Fatigue, 16(6), pp. 429 - 437.

[30] Gordon, A., 2006. "Crack Initiation Modeling of a Directionally-Solidified NickelBase Superalloy". PhD thesis, Georgia Institute of Technology.

[31] Zhou, H., Ro, Y., Koizumi, Y., Kobayashi, T., Harada, H., and Okada, I., 2004. "Thermomechanical Fatigue Behavior of the Third-generation, Single-crystal Superalloy TMS-75: Deformation Structure". Metallurgical and Materials Transactions A, 35(6), pp. 1779-1787.

[32] Okada, M., Tsutsumi, M., Kitamura, T., and Ohtani, R., 1998. "Initiation and Growth of Small Cracks in Directionally Solidified Mar-M247 Under Creep-Fatigue Part II: Effects of Angle Between Stress Axis and Solidification Direction". Fatigue \& Fracture of Engineering Materials \& Structures, 21(6), pp. 751-760.

[33] Moore, Z. J., and Neu, R. W., 2011. "Creep Fatigue of a Directionally Solidified Ni-base Superalloy - Smooth and Cylindrically Notched Specimens". Fatigue and Fracture of Engineering Materials and Structures, 34(1), pp. 17-31. 
[34] Filippini, M., 2011. "Creep-Fatigue at High Temperature of Notched Single Crystal Superalloys". Jounral of ASTM International, 8(6), pp. 1-19.

[35] le Graverend, J.-B., Cormier, J., Jouiad, M., Gallerneau, F., Paulmier, P., and Hamon, F., 2010. "Effect of fine precipitation on non-isothermal creep and creepfatigue behaviour of nickel base superalloy $\{M C 2\}$ ". Materials Science and Engineering: $A, \mathbf{5 2 7}(20)$, pp. $5295-5302$.

[36] Shi, D., Liu, J., Yang, X., Qi, H., and Wang, J., 2010. "Experimental investigation on low cycle fatigue and creep-fatigue interaction of DZ125 in different dwell time at elevated temperatures". Materials Science and Engineering: A, 528(1), pp. 233 $-238$.

[37] Beck, T., Lang, K.-H., Pitz, G., and Löhe, D., 2002. "The Influence of Superimposed Creep Loadings on the Thermal-Mechanical Fatigue Behaviour of the Ni-Base Superalloy IN 792 CC'. Mechanics of Time-Dependent Materials, 6(3), pp. $271-282$.

[38] Tong, J., Dalby, S., Byrne, J., Henderson, M., and Hardy, M., 2001. "Creep, fatigue and oxidation in crack growth in advanced nickel base superalloys". International Journal of Fatigue, 23(10), pp. 897 - 902.

[39] Okada, M., Tsutsumi, M., Kitamura, T., and Ohtani, R., 1998. "Initiation and Growth of Small Cracks in Directionally Solidified Mar-M247 Under Creep-Fatigue Part I: Effect of Microstructure". Fatige and Fracture of Engineering Materials and Structures, 21, pp. 741-750.

[40] Engler-Pinto, C., Noseda, C., Nazmy, M., and Rezai-Aria, F., 1996. "Interaction Between Creep and Thermo-mechanical Fatigue of CM24 ' ${ }^{2} C-D S^{\prime \prime}$. In Superalloys 1996, R. Kissingerand, D. Deye, D. Anton, and A. Cetel, eds., TMS, pp. 319-325.

[41] Zhang, J., Harada, H., Ro, Y., Koizumi, Y., and Kobayashi, T., 2008. "Thermomechanical fatigue mechanism in a modern single crystal nickel base superalloy TMS-82". Acta Materialia, 56(13), pp. 2975 - 2987.

[42] Chieragatti, R., and Remy, L., 1991. "Influence of Orientation on the Low Cycle Fatigue of MAR-M 200 Single Crystals at $650^{\circ}$ C I: Fatigue Life Behaviour". Materials Science and Engineering: A, 141(1), pp. 1-9.

[43] Chieragatti, R., and Remy, L., 1991. "Influence of Orientation on the Low Cycle Fatigue of MAR-M 200 Single Crystals at $650^{\circ} \mathrm{C}$ II: Cyclic Stress-strain Behaviour". Materials Science and Engineering: A, 141(1), pp. 11-22. 
[44] Hasebe, T., Sakane, M., and Ohnami, M., 1992. "High Temperature Low Cycle Fatigue and Cyclic Constitutive Relation of MAR-M247 Directionally Solidified Superalloy". International Journal of Engineering Materials Transactions, 114, pp. $162-167$.

[45] Segersall, M., Moverare, J. J., Simonsson, K., and Johansson, S., 2012. "Deformation and Damage MechanismsDuring Thermomechanical Fatigue of a Single Crystal Superalloy in the $\langle 001\rangle$ and $\langle 011\rangle$ Directions". In Superalloys 2012, E. Huron, R. Reed, M. Hardy, M. Mills, R. Montero, P. Portella, and J. Telesman, eds., pp. $215-223$.

[46] Mughrabi, H., and Tetzlaff, U., 2000. "Microstructure and High-Temperature Strength of Monocrystalline Nickel-Base Superalloys". Advanced Engineering Materials, 2(6), pp. 319-326.

[47] Draper, S., Hull, D., and Dreshfield, R., 1989. "Observations of Directional Gamma Prime Coarsening During Engine Operation". Metallurgical and Materials Transactions A, 20, pp. 683-688.

[48] Gordon, A. P., Neu, R. W., and McDowell, D. L., 2009. "Effect of pre-exposure on crack initiation life of a directionally solidified Ni-base superalloy". International Journal of Fatigue, 31(2), pp. 393 - 401.

[49] Kupkovits, R. A., Smith, D. J., and Neu, R. W., 2010. "Influence of minimum temperature on the thermomechanical fatigue of a directionally-solidified Ni-base superalloy". Procedia Engineering, 2(1), pp. 687 - 696.

[50] Harris, K., Erickson, G., and Schwer, R., 1984. "MAR-M247 DerivativeCM247LC-DS Alloy CMSX Single Crystal Alloys Properties and Performance". In Superalloys 1984, pp. 221-230.

[51] , 2012. ASTM E606-12 Standard Practice for Strain-Controlled Fatigue Testing. Tech. rep., ASTM International.

[52] , 2010. ASTM E2368-10 Standard Practice for Strain Controlled Thermomechanical Fatigue Testing. Tech. rep., ASTM International.

[53] Gandy, D., and Scheibel, J., 2006. Life Management System for Advanced E Class Gas Turbines. Tech. Rep. 1010477, Electric Power Research Institute.

[54] Kirka, M. M., 2014. "Thermomechanical Behavior of a Directionally Solidified Nickel-base Superalloy in the Aged State". PhD thesis, Georgia Institute of Technology. 
[55] Buffiere, J., and Ignat, M., 1995. "A Dislocation Based Criterion for the Raft Formation in Nickel-based Superalloys Single Crystals". Acta Metallurgica et Materialia, 43(5), pp. 1791-1797.

[56] Kupkovits, R., 2008. "Thermomechanical Fatigue Behavior of the DirectionallySolidified Nickel-Base Superalloy CM24\%'. Master's thesis, Georgia Institute of Technology.

[57] Tien, J., and Caulfield, T., eds., 1989. Superalloys, Supercomposites, and Superceramics. Academic Press.

[58] Pessah-Simonetti, Caron, M. P., and Khan, T., 1993. "Effect of a Long-Term Prior Aging on the Tensile Behaviour of a High-Performance Single Crystal Superalloy". Journal de Physique IV, 3, pp. 347-351.

[59] Private Communication with Siemens Energy.

[60] Neuner, F. C., Tetzlaff, U., and Mughrabi, H., 2002. "Enhancement of Thermomechanical Fatigue Resistance of a Monocrystalline Nickel-base Superalloy by Pre-rafting". In Thermomechanical Fatigue Behavior of Materials, A. McGaw, S. Kalluri, J. Bressers, and S. D. Peteves, eds., Vol. 4 of ASTM STP 1428. ASTM International.

[61] Pineau, A., and Antolovich, S. D., 2009. "High Temperature Fatigue of Nickelbase Superalloys - A Review with Special Emphasis on Deformation Modes and Oxidation". Engineering Failure Analysis, 16(8), pp. 2668-2697.

[62] Trexler, M. D., 2007. "The Relationship of Microstructure to Fracture and Corrosion Behavior of a Directionally Solidified Superalloy". PhD thesis, Georgia Institute of Technology.

[63] Saxena, A., 1998. Nonlinear Fracture Mechanics for Engineers. CRC Press.

[64] Leverant, G. R., and M.Gell, 1969. "The Elevated Temperature Fatigue of a NickelBase Superalloy, MAR-M200, in Conventually-Cast and Directionally-Solidified Forms". Transactions of the Metallurgical Society of AIME, 245, pp. 1167-1173.

[65] Trexler, M. D., and Sanders, T. H., 2008. "Quantitative Characterization of Features Affecting Crack Path in a Directionally Solidified Superalloy". In Superalloys 2008, S. . R. C. Reed, K. A. Green, P. Caron, T. Gabb, M. G. Fahrmann, E. S. Huron, and S. A. Woodard, eds.

[66] Karamched, P. S., and Wilkinson, A. J., 2011. "High Resolution Electron Backscatter Diffraction Analysis of Thermally and Mechanically Induced Strains Near Carbide Inclusions in a Superalloy". Acta Materialia, 59(1), pp. 263-272. 
[67] McHugh, S., 1990. "Modelling the Thermo-mechanical bBhavior of a Carbide Inclusion in a Nickel Superalloy Including Residual Stress Effects with a Simple Finite-element Model'. Mathematical and Computer Modelling, 14(0), pp. 933941.

[68] Yu-ichi, K., Hidenori, T., and Xinfang, Z., 2012. "Hybrid System for In-situ Observation of Microstructure Evolution in Steel Materials". Transactions of JWRI, 41(2), pp. 412-418.

[69] Kamaraj, M., 2003. "Rafting in Single Crystal Nickel-base Superalloys- An Overview". Sadhana, 28, pp. 115-128.

[70] Kirka, M. M., Brindley, K. A., Neu, R. W., Antolovich, S. D., Shinde, S. R., and Gravett, P. W. "Influence of Coarsened and Rafted Microstructures on the Thermomechanical Fatigue of a Ni-base Superalloy". Submitted for Review to the International Journal of Fatigue. 


\section{List of Tables}

1 Nominal chemical compositions of the DS Ni-base superalloy used in this work given as weight percent [50]. . . . . . . . . . . . . . . 4 4

2 Summary of TMF Findings. . . . . . . . . . . . . . . . . 28 


\section{List of Figures}

1 Initial cuboidal $\gamma^{\prime}$ microstructure within the dendritic core. . . . . . . . 5

2 Influence of $T_{\min }$ on IP $R_{\epsilon}=0$ TMF life in the L-orientation. Isothermal results are for $R_{\epsilon}=-1[33] \ldots \ldots \ldots \ldots$. . . . . . . . 8

3 Influence of $T_{\min }$ on $\mathrm{OP} R_{\epsilon}=-\infty$ TMF life in the L-orientation. Isothermal results are for $R_{\epsilon}=-1[33] \ldots \ldots \ldots \ldots$

4 Half-life hysteresis curves for material undergoing IP, $R_{\epsilon}=0$ and OP, $R_{\epsilon}=-\infty$ showing the effect of $T_{\min }$ upon the stress-strain response in relation to the material's isothermal behavior at $950^{\circ} \mathrm{C} . \ldots . . . .10$

5 Stress amplitude curves for (a) IP TMF experiments with $R_{\epsilon}=0$ (b) OP TMF experiments with $R_{\epsilon}=-\infty \ldots \ldots . \ldots 10$

$6 \quad$ Fatigue crack propagating from an oxidation spike in material exposed to OP TMF $R_{\epsilon}=-\infty$ TMF $\left(T=100-950^{\circ} \mathrm{C}\right.$ and $\left.\Delta \epsilon_{m e c h}=1.0 \%\right) \ldots .12$

$7 \quad$ Fatigue cracks linking between debonded and cracked carbides in material exposed to IP $R_{\epsilon}=0 \mathrm{TMF}\left(\Delta T=100-750^{\circ} \mathrm{C}\right.$ and $\left.\Delta \epsilon_{\text {mech }}=1.2 \%\right) . \quad 13$

8 Optical images showing the fracture surfaces of material in the L-orientation exposed to TMF conditions. Crack initiation sites are indicated by the white arrows: (a) $\mathrm{OP}, R_{\epsilon}=-\infty, \mathrm{T}=100-950^{\circ} \mathrm{C}$, and $\Delta \epsilon_{m e c h}=1.0 \%$ (b) IP, $R_{\epsilon}=0, \mathrm{~T}=100-950^{\circ} \mathrm{C}$, and $\Delta \epsilon_{m e c h}=1.0 \% \ldots \ldots \ldots$

9 Resultant cubodial primary $\gamma^{\prime}$ precipitates in failed material exposed to OP $R_{\epsilon}=-\infty \operatorname{TMF}\left(T=100-950^{\circ} \mathrm{C}\right.$ and $\left.\Delta \epsilon_{m e c h}=1.0 \%\right)$ indicating negligible changes in precipitate size and morphology. . . . . . . . . . . 14

10 Life curves for TMF experiments for material in the L-orientation conducted in the $500-950^{\circ} \mathrm{C}$ temperature range under IP $R_{\epsilon}=-1$ and $R_{\epsilon}=0$ loading conditions and $\mathrm{OP} R_{\epsilon}=-1$ and $R_{\epsilon}=-\infty$ conditions in comparison to the strain-life at $950^{\circ} \mathrm{C}$ under fully-reversed loading conditions. . . . . . . . . . . . . . . . . . . . 16

11 IP TMF results with $T=500-950^{\circ} \mathrm{C}$ comparing the effect of mean strain on (a) First cycle response (b) Half-life hysteresis response (c) Mean stress evolution. . . . . . . . . . . . . . . . . . . . 17

12 OP TMF results with $T=500-950^{\circ} \mathrm{C}$ comparing the effect of mean strain on (a) First cycle response (b) Half-life hysteresis response (c) Mean stress evolution. . . . . . . . . . . . . . . . . . 18

13 Slip band emination on a $M_{23} C_{6}$ carbide occurring as a result of OP $R_{\epsilon}=-\infty \mathrm{TMF}$ exposure within a interdendritic region $\left(T=100-950^{\circ} \mathrm{C}\right.$ $\left.\Delta \epsilon_{\text {mech }}=0.8 \%\right) \ldots \ldots \ldots \ldots \ldots \ldots \ldots$ 
14 IP-OP TMF strain-life curves for material in the L-orientation for CC and CF TMF cycling a) $T=500-950^{\circ} \mathrm{C}$ and b) $T=100-750^{\circ} \mathrm{C} \ldots \ldots 21$

15 IP $R_{\epsilon}=0 \mathrm{TMF}$ results for $T=100-750^{\circ} \mathrm{C}$ comparing $\mathrm{CC}$ to $\mathrm{CF}$ in the L-orientation on the (a) Half-life hysteresis response (b) Mean stress evolution. . . . . . . . . . . . . . . . . . 22

16 Representative initial and half-life hysteresis responses for material subjected to $T=100-950^{\circ} \mathrm{C} \mathrm{CC} \mathrm{TMF} \mathrm{(a)} \mathrm{IP} R_{\epsilon}=0$ and (b) OP $R_{\epsilon}=-\infty .22$

17 IP $R_{\epsilon}=0 \mathrm{TMF}$ results for $T=100-950^{\circ} \mathrm{C}$ comparing $\mathrm{CC}$ to $\mathrm{CF}$ in the L-orientation on the (a) Half-life hysteresis response (b) Mean stress evolution. . . . . . . . . . . . . . . . . . . 23

18 OP $R_{\epsilon}=-\infty$ TMF results for $T=100-950^{\circ} \mathrm{C}$ comparing $\mathrm{CC}$ to $\mathrm{CF}$ in the L-orientation on the (a) Half-life hysteresis response (b) Mean stress

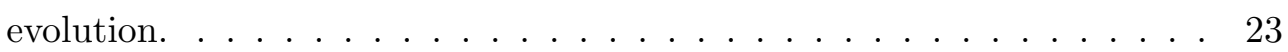

19 Rafted microstructures at material failure after exposure to $\mathrm{CF}$ conditions a) IP TMF, $R_{\epsilon}=0 \mathrm{~T}=100-950^{\circ} \mathrm{C}, \Delta \epsilon_{\text {mech }}=0.7 \%$ b) OP TMF, $R_{\epsilon}=-\infty \mathrm{T}=100-950^{\circ} \mathrm{C}, \Delta \epsilon_{\text {mech }}=0.8 \% \ldots \ldots \ldots 24$

20 IP-OP TMF strain-life curves for material in the T-orientation a) Depicting the effect of $T_{\min }$ and $\mathrm{b}$ ) the effect of $\mathrm{CF}$ in the $100-950^{\circ} \mathrm{C}$ temperature range. . . . . . . . . . . . . . . . 25

21 IP TMF results for $T=100-950^{\circ} \mathrm{C}$ comparing $\mathrm{CC}$ to $\mathrm{CF}$ in the T-orientation on the (a) Half-life hysteresis response (b) Mean stress evolution. . . . . 26

22 Comparison of the failed gage surfaces exposed to OP TMF, $T=100$ $950^{\circ} \mathrm{C}$ and $\Delta \epsilon_{\text {mech }}=0.55 \%$ in the T-orientation (a) under CC conditions (b) under $\mathrm{CF}$ conditions. . . . . . . . . . . . . . . . . 26

23 Transgranular cracking occurring under IP $R_{\epsilon}=0$ TMF conditions $\left(T=100-950{ }^{\circ} \mathrm{C}\right.$ and $\left.\Delta \epsilon_{m e c h}=0.55 \%\right) \ldots \ldots \ldots 27$

24 Fatigue crack emanating from a carbide along a grain boundary in material tested under IP $R_{\epsilon}=0, \mathrm{CC}$ TMF conditions $\left(T=100-950^{\circ} \mathrm{C}\right.$ and

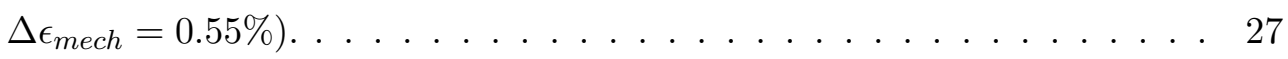


1

2

3

\title{
Parameters Influencing Thermomechanical Fatigue of a Directionally-solidified Ni-base Superalloy
}

\author{
by \\ M. M. Kirka ${ }^{1, a}$, K. A. Brindley ${ }^{1}$, R. W. Neu ${ }^{1,2 *}$, S. D. Antolovich ${ }^{1,2}$, S. R. Shinde ${ }^{3}$, P. W. \\ Gravett $^{3}$, \\ ${ }^{1}$ The George W. Woodruff School of Mechanical Engineering \\ ${ }^{2}$ School of Materials Science and Engineering \\ Georgia Institute of Technology, Atlanta, GA, USA \\ ${ }^{3}$ Siemens Energy Inc., Orlando, FL 32826, United States \\ ${ }^{a}$ Current address: Oak Ridge National Laboratory, One Bethel Valley Road, Oak Ridge, \\ TN 37831, USA. \\ *corresponding author: email: rick.neu@gatech.edu, tel: 1-404-894-3074
}

\begin{abstract}
Thermomechanical fatigue (TMF) is a low cycle fatigue process in which material life is correlated to the mechanical strain amplitude. However, it is well known that several other factors influence this life. This paper examines several of these parameters and their influence on life using experiments conducted on a second generation directionally-solidified (DS) Ni-base superalloy. The parameters considered include the influence of the temperature extremums $\left(T_{\max }\right.$ of either 750 or $950^{\circ} \mathrm{C}$ and $T_{\min }$ of either 100 or $500^{\circ} \mathrm{C}$ ), strain ratio $\left(R_{\epsilon}\right)$, the strain-temperature phasing (in-phase (IP) and out-of-phase $(\mathrm{OP})$ ), the influence of dwells at the high temperature end of the cycle resulting in a creep-fatigue $(\mathrm{CF})$ interaction, and material anisotropy associated with the grain growth direction (longitudinal versus transverse). Results suggest that the phasing has a primary role in controlling the mechanism of degradation. IP TMF is dominated by crack formation in volumes surrounding debonded carbides for both continuously cycling (CC) and $\mathrm{CF}$ at 950 and $750^{\circ} \mathrm{C}$, while $\mathrm{OP}$ TMF is dominated by surface oxidation and repetitive cracking of the oxide that reforms at the crack tip at $950^{\circ} \mathrm{C}$. Decreasing the $T_{\max }$ to $750^{\circ} \mathrm{C}$ the environmental and creep effects are reduced resulting in virtually pure fatigue exposure under OP conditions. With decreasing $T_{\min }$ from $500^{\circ} \mathrm{C}$ to $100^{\circ} \mathrm{C}$ was observed an increase in inelastic strain amplitude and
\end{abstract}


corresponding decrease in life. Variations in $R_{\epsilon}$ were found to have no significant influence on life or stabilized stress behavior. TMF loading in the transverse orientation resulted in life reductions over the longitudinal orientation due to cracks propagating in a transgranular manner. Lastly, only in material exposed to $\mathrm{CF}$ with a $T_{\max }$ of $950^{\circ} \mathrm{C}$ rafting of the $\gamma^{\prime}$ precipitates was observed.

Keywords: thermomechanical fatigue, nickel-base superalloy, strain-life, directional solidification 


\section{Introduction}

Nickel-base (Ni-base) superalloys find widespread use as blade materials for airfoils used in the hot sections of gas turbine engines due to their ability to withstand extreme temperature conditions while maintaining excellent fracture toughness [1]. Much effort has been invested in understanding the creep [2-9] and fatigue [10-15] responses of Ni-base superalloys. However, understanding the effects of thermomechanical fatigue (TMF) on the life of Ni-base superalloys is paramount because the deformation and damage mechanisms observed in creep and fatigue typically do not directly transfer to the behavior of Ni-base superalloys under TMF loadings [16,17]. Additionally, the deformation mechanisms that do occur are not the same for single-crystal, directionally solidified, and polycrystalline Ni-base superalloys undergoing identical loadings due to the microstructure, orientation sensitivity, and grain size [18].

Because of the complexities associated with TMF cycles, attempts have been made to propose the use of an equivalent temperature at which to conduct isothermal LCF such that the material life values are similar to the corresponding TMF experiment. However, this has been shown only to work in practices when the deformation mechanisms are similar between the isothermal and TMF experiment [19]. At low temperatures $\left(<750^{\circ} \mathrm{C}\right)$ dislocations shear the $\gamma^{\prime}$ precipitates and at high temperatures $\left(>850^{\circ} \mathrm{C}\right)$ the $\gamma^{\prime}$ precipitates are by-passed by dislocations. This occurs as a result of the increase in hardness of the $\gamma^{\prime}$ precipitates with increasing temperature [20]. Further, previous studies on the influence of IP and OP TMF on the damage mechanisms have shown that OP TMF failure primarily occurs through environmental desegregation $[?, 21-26]$.

Overall, no single set of TMF conditions can be considered truly representative of those that impact hot section components. As a result, idealized TMF cycles are used in which meaningful damage interactions can be studied $\left[.{ }^{1}\right]$ to. Two of the most common $\left[.{ }^{2}\right.$ ]are in-phase (IP) TMF where the maximum temperature $\left(T_{\max }\right)$ and strain occur at the same time, and out-of-phase (OP) TMF where the maximum temperature occurs at the minimum strain. Further realism can be included through the introduction of stress or strain holds at peak temperature to promote creep-fatigue $(\mathrm{CF})$ interactions. To summarize, there are several considerations that can influence TMF life of Ni-base superalloys:

i) Temperature-strain phasing (IP or OP TMF) [23]

\footnotetext{
${ }^{1}$ removed: ..

${ }^{2}$ removed: being
} 
ii) Maximum temperature extreme $[21,24,27,28]$

iii) Minimum temperature extreme $[21,24,27,28]$

iv) Mean Strain $[29,30]$

v) Creep-fatigue interactions due to long dwells coupled with periodic TMF cycles $[24,31-41]$

vi) Elastic anisotropy due to crystal orientation [12,14, 21,32, 42-45]

vii) Over-aging of the microstructure during service conditions [18, 46-49].

The goal of this work is to evaluate the significance of these various considerations on TMF life behavior through an extensive experimental program. The effects of aging of the microstructure on fatigue life will be considered in a follow-on work. Within this work a second generation directionally-solidified (DS) Ni-base superalloy used in industrial gas turbine applications is the focus of this investigation.

\section{Material and Experimental Procedure}

\subsection{Material}

TMF tests were performed on a second-generation directionally solidified (DS) Ni-base superalloy of chemical composition shown in Table 1 provided in the form of cast slabs having dimensions $127 \times 228 \times 25.4 \mathrm{~mm}$ and cast by PCC Airfoils (Minerva, OH). From the as-cast condition, the material $\left[.{ }^{3}\right.$ ]was given a proprietary two-step heat treatment. The heat treatment is meant to promote elemental homogenization and precipitation of the $\gamma^{\prime}$ precipitates. As a result of the composition and heat treatment, the alloy is comprised of $65 \% \gamma^{\prime}$ by volume fraction, with the $\gamma^{\prime}$ being cubic in shape and having an average side length of $0.7 \mu \mathrm{m}$ and the $\gamma$ channels having an average thickness of $0.17 \mu \mathrm{m}$ in the dendritic core (Figure 1). The average grain diameter in the material is $2 \mathrm{~mm}$, with the primary dendrites being $500 \mu \mathrm{m}$, and the secondary dendrite arm spacing being $100 \mu \mathrm{m}$. Present are intermittent script grain boundary MC type carbides and blocky type $M_{23} C_{6}$ carbides within the interdendiritc regions of the alloy. The carbides $\left[.{ }^{4}\right]$ ranged in size from a few microns to $25 \mu \mathrm{m}$.

\footnotetext{
${ }^{3}$ removed: is

${ }^{4}$ removed: range
} 
Table 1: Nominal chemical compositions of the DS Ni-base superalloy used in this work given as weight percent [50].

\begin{tabular}{cccccccccccc}
\hline $\mathrm{Cr}$ & $\mathrm{Co}$ & $\mathrm{Mo}$ & $\mathrm{W}$ & $\mathrm{Al}$ & $\mathrm{Ti}$ & $\mathrm{Ta}$ & $\mathrm{Hf}$ & $\mathrm{C}$ & $\mathrm{B}$ & $\mathrm{Zr}$ & $\mathrm{Ni}$ \\
\hline 8.1 & 9.2 & 0.5 & 9.5 & 5.6 & 0.7 & 3.2 & 1.4 & 0.07 & 0.015 & 0.01 & $\mathrm{Bal}$
\end{tabular}

\subsection{TMF Test Procedure}

TMF experiments were performed on cylindrical dog-bone specimens fabricated from the cast slabs in accordance with ASTM E606-12 [51] having a gage section length of $13.2 \mathrm{~mm}$ (0.52 in) and diameter of $6.35 \mathrm{~mm}$ (0.25 in). The TMF experiments were performed on computer controlled closed loop servohydraulic test systems equipped with MTS FlexTest 40 controllers. Induction heating was used to heat the specimens with a 26 gage K-type thermocouple spot welded near the end of the specimen gage section for reading the temperature. The temperature gradient over the gage section was minimized by optimization of the induction coil configuration to be within the $+/-5^{\circ} \mathrm{C}$ 
requirements mandated by ASTM standard E2368-12 [52]. Total strain, $\epsilon_{\text {tot }}=\epsilon_{\text {mech }}+\epsilon_{\text {th }}$ was measured over the gage length with a $12.7 \mathrm{~mm}$ MTS high temperature axial extensometer utilizing alumina rods. All experiments were conducted in mechanical strain control, where the mechanical strain was calculated through subtraction of the thermal strain from the total strain measured by the extensometer, $\epsilon_{m e c h}=\epsilon_{t o t}-\epsilon_{t h}$. The thermal strain was determined through polynomial fit to free thermal expansion measured before the start of each test.

TMF experiments were conducted on specimens with longitudinal (L-orientation) and transverse (T-orientation) orientations with respect to the direction of solidification. Generally, the experimental conditions were chosen such that the TMF life was on the order of a few thousand cycles, which is representative of the number of start-up and shutdown cycles of a land-based gas turbine [53]. Continuous cycling (CC) and creep-fatigue $(\mathrm{CF}) \mathrm{TMF}$ experiments were conducted for the temperature ranges of $100-750^{\circ} \mathrm{C}$ and $100-950^{\circ} \mathrm{C}$ in both the L-orientation and T-orientation for both the IP, $R_{\epsilon}=0$ and $\mathrm{OP}, R_{\epsilon}=-\infty \mathrm{TMF}$ waveforms. The $\mathrm{CC}$ cycle time for the large temperature range of $100-950^{\circ} \mathrm{C}$ was $600 \mathrm{~s}$ and that for the temperature range of $100-750^{\circ} \mathrm{C}$ was $480 \mathrm{~s}$. The differences in cycle time were done to maintain a near constant heating and cooling rate amongst the different temperature ranges. All CF experiments were conducted with the 1200 second strain hold occurring at the peak temperature of the cycle. Additionally, CC TMF experiments were conducted with a higher minimum temperature and three different maximum temperatures $\left(500-750^{\circ} \mathrm{C}, 500-850^{\circ} \mathrm{C}\right.$, and $500-950^{\circ} \mathrm{C}$ ) in the L-orientation under both IP and OP waveforms. In these cases the cycle times were 120, 150, and 180 seconds. The criterion for crack initiation was defined as a $5 \%$ load drop from the peak of the stabilized hysteresis response. This failure criterion corresponds to a crack in the range of 0.5 and $1.0 \mathrm{~mm}$ [33].

\section{Results and Discussion}

\subsection{Influence of Temperature Extremum}

The minimum temperature $\left(T_{\min }\right)$ experienced by material within gas turbine engines relates to the length of the engine's shutdown. Short shutdowns are associated with minimum temperatures of 500 and $100^{\circ} \mathrm{C}$ with long ones. Most often it is desirable to conduct TMF experiments in laboratories with a minimum cycle temperature as low as possible to replicate long-term shutdowns conditions; however, to accelerate testing by increasing the frequency of the cycle, a higher minimum temperature is often used. 

processes occurring during the high temperature excursions in the cycle, while the yield strength for most Ni-base superalloys remains nearly constant below $500^{\circ} \mathrm{C}$. The reductions in the $T_{\min }$ of the cycle have two possible impacts on the material. First $\left[. .^{5}\right]$ there can be a reduction in the fatigue resistance, due to an increase in the inelastic strain range arising from increases in the elastic modulus with the decreasing temperature [27]. Second, the aging of the $\gamma^{\prime}$ microstructure has been reported to be observed at elevated temperatures [27]. However, in light of these observations, extension of these trends to $T_{\max }$ below $950^{\circ} \mathrm{C}$ when aging is insignificant is unclear.

TMF experiments were conducted under both IP, $R_{\epsilon}=0$ and OP, $R_{\epsilon}=-\infty$ phasing conditions with a $T_{\min }$ of 100 or $500^{\circ} \mathrm{C}$ on specimens with an L-orientation. The $T_{\max }$ investigated for each phasing condition were 750,850 , and $950^{\circ} \mathrm{C}$, with the corresponding mechanical strain amplitudes of 1.2,1.1, and 1.0\% respectively. Through reducing not only the $T_{\min }$, but also the $T_{\max }$, the various damage mechanisms thought to be associated with this reduced $T_{\min }$ effect can be isolated. For $T_{\max }$ of $750^{\circ} \mathrm{C}$, one can expect the failure mechanisms to be dominated by pure fatigue, when $T_{\max }$ is $850^{\circ} \mathrm{C}$ a mixture of creep-fatigue, and when $T_{\max }$ is $950^{\circ} \mathrm{C}$, a combination of microstructure evolution, creep, and fatigue damage is occurring.

Through the introduction of a reduced $T_{\min }$, the number of cycles required for crack initiation was observed to successively decrease with increasing temperature differential for both IP and OP TMF. Using the isothermal life results at the $T_{\max }$ of interest as a reference, a $T_{\min }$ of $500^{\circ} \mathrm{C}$ resulted in a $4 \mathrm{x}$ reduction in the cycle to crack initiation on average, with a $T_{\min }$ of $100^{\circ} \mathrm{C}$ further decreasing the life by $20 \mathrm{x}$ on average for IP TMF. This is depicted in Figure 2. OP TMF exhibited similar trends with reductions in the number of cycles being 2.5 and $8 \mathrm{x}$ on average for $T_{\min }$ of 500 and $100^{\circ} \mathrm{C}$ respectively as shown in Figure 3.

\footnotetext{
${ }^{5}$ removed: being
} 


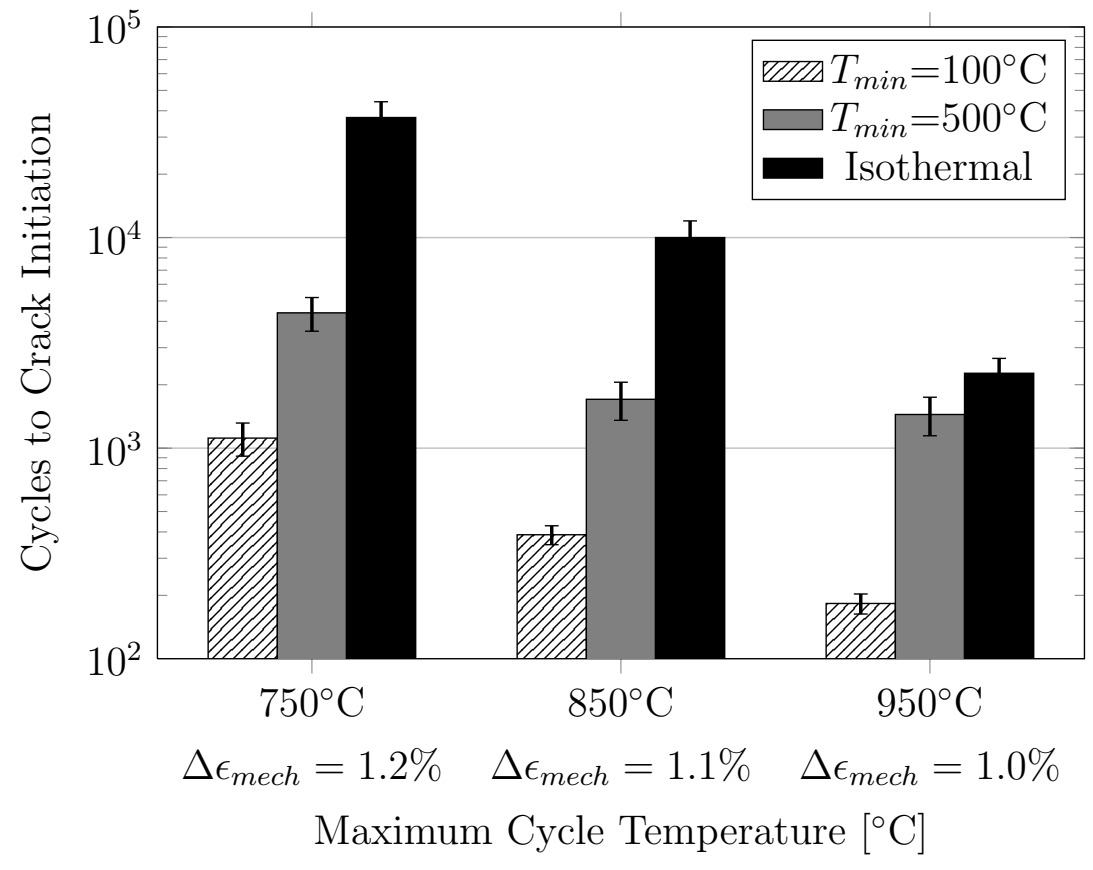

Figure 2: Influence of $T_{\min }$ on IP $R_{\epsilon}=0 \mathrm{TMF}$ life in the L-orientation. Isothermal results are for $R_{\epsilon}=-1$ [33]. 


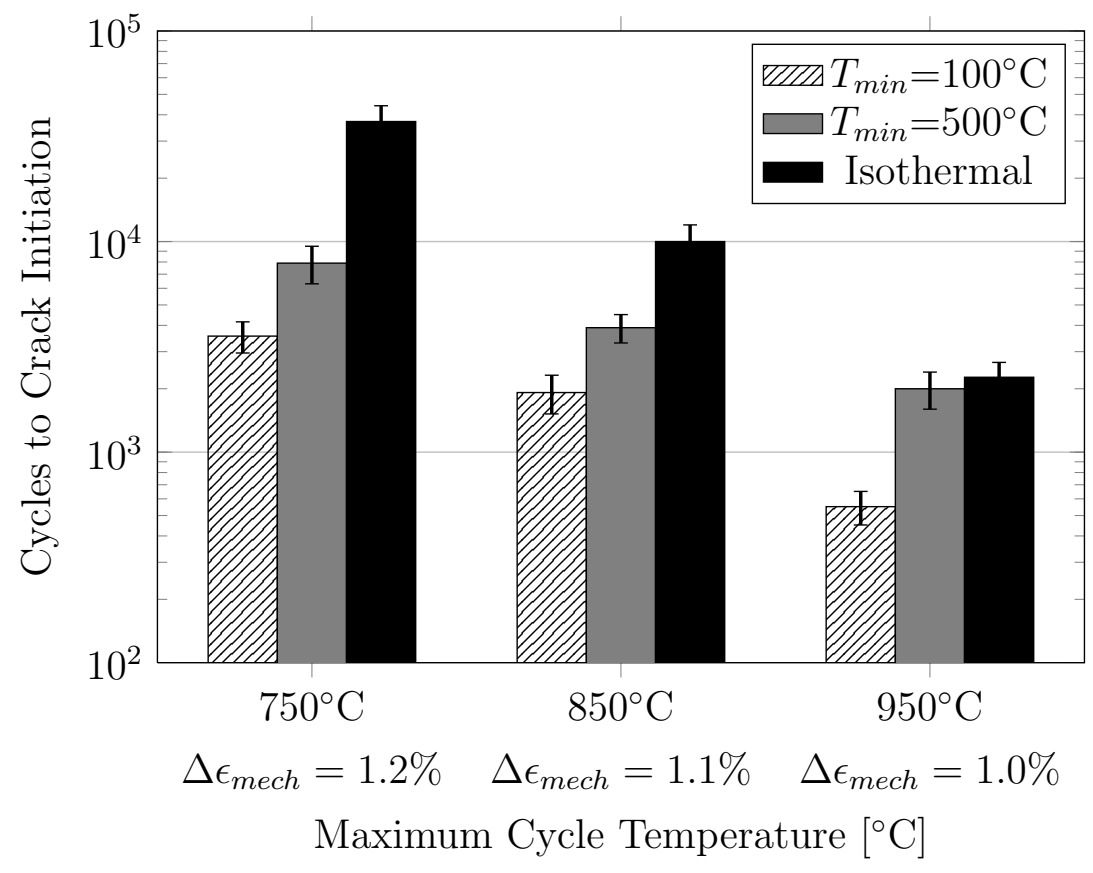

Figure 3: Influence of $T_{\text {min }}$ on OP $R_{\epsilon}=-\infty$ TMF life in the L-orientation. Isothermal results are for $R_{\epsilon}=-1$ [33].

The respective hysteresis responses at half-life were compared. All reduced $T_{\min }$ experiments exhibited increases in the inelastic strain range compared to the higher $T_{\text {min }}$ responses under both IP and OP TMF loadings as shown by the representative results in Figure 4 at half-life. In addition, the stress amplitude of the reduced $T_{\min }$ is greater. While the yield strength remains nearly constant in the $100-650^{\circ} \mathrm{C}$ temperature range, the elastic modulus increases nearly $20 \%$ when temperature decreases from 500 to $100^{\circ} \mathrm{C}$ [54]. For a given mechanical strain range, when the temperature is lower, the elastic strain range is reduced resulting in a greater inelastic strain range. 


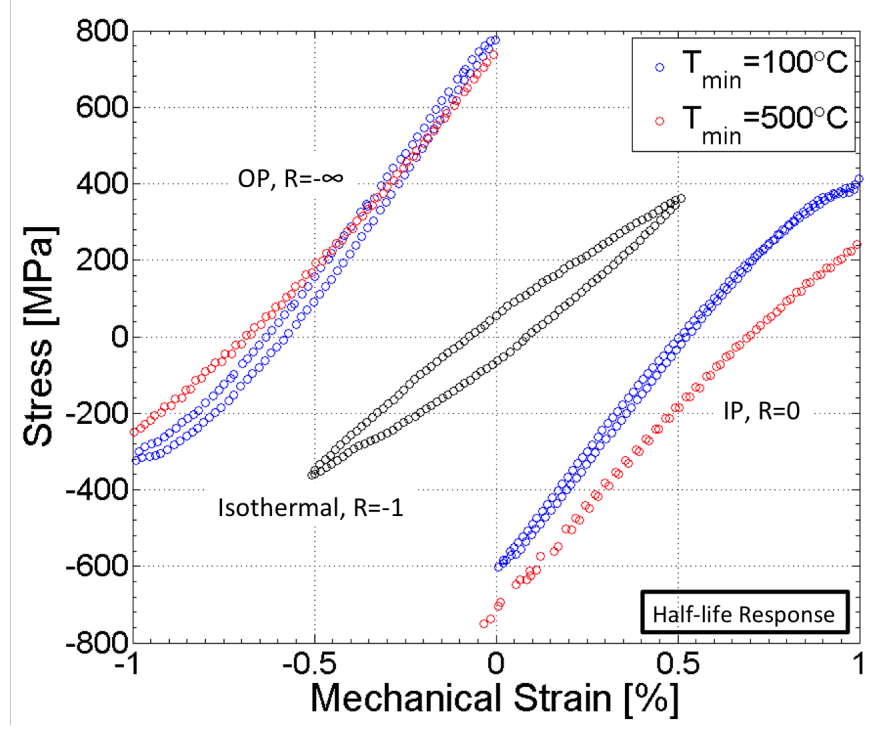

Figure 4: Half-life $\left[.{ }^{7}\right.$ ]hysteresis curves for material undergoing IP, $R_{\epsilon}=0$ and OP, $R_{\epsilon}=$ $-\infty$ showing the effect of $T_{\min }$ upon the stress-strain response in relation to the material's isothermal behavior at $950^{\circ} \mathrm{C}$.

The reduced $T_{\min }$ experiments exhibit a 10-20\% higher stress amplitude than $T_{\min }=500^{\circ} \mathrm{C}$ as shown in Figure 5 from the onset of cycling. In most cases, the specimens were observed to have achieved stabilized hysteresis within the first $10 \mathrm{cy}-$ cles; however, the IP TMF $100-850^{\circ} \mathrm{C}$ experiment and the IP TMF experiments with a $T_{\max }$ of $950^{\circ} \mathrm{C}$ exhibited cyclic softening with the peak tensile stress occurring on the first cycle.
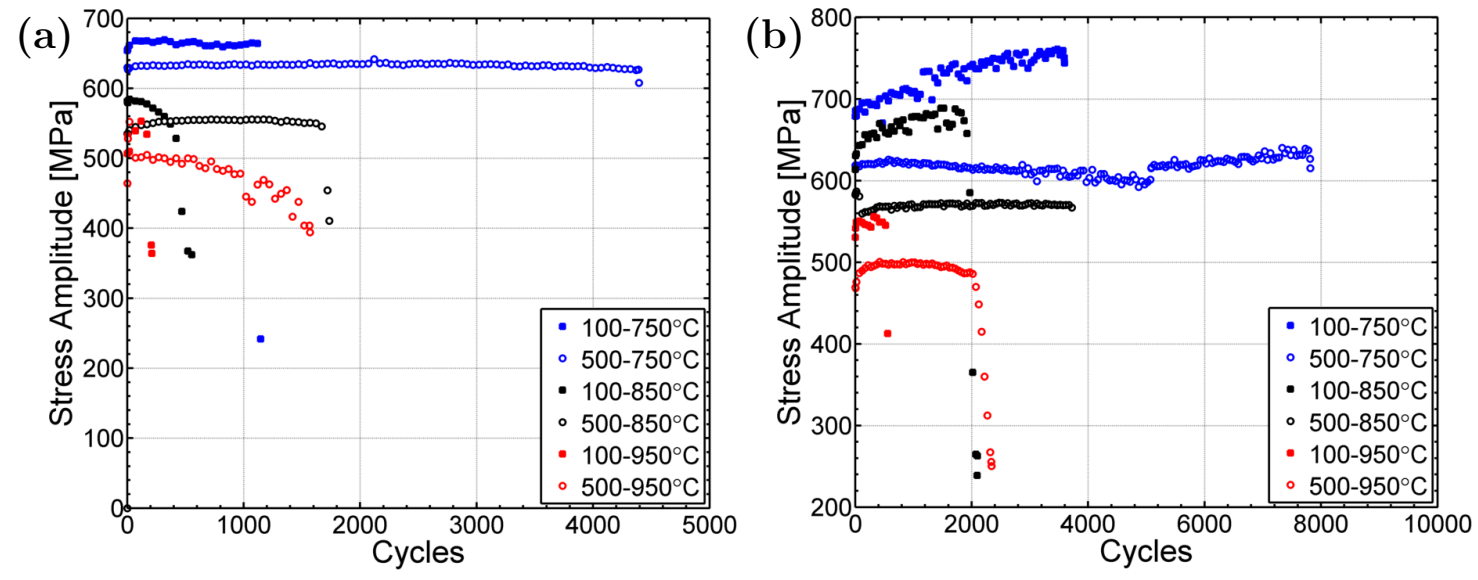

Figure 5: Stress amplitude curves for (a) IP TMF experiments with $R_{\epsilon}=0$ (b) OP TMF experiments with $R_{\epsilon}=-\infty$. 
In the case of IP TMF experiments with $T_{\max }=950^{\circ} \mathrm{C}$, the cyclic softening can be attributed to extensive inelastic strains occurring in the $\gamma$ channels perpendicular to the loading axis at peak temperatures as a result of the alignment of the peak temperature with the peak tensile strain that occurs in IP TMF [55]. In the case of OP TMF, the greatest inelastic deformation occurs in the $\gamma$ channels parallel to the applied axial load [55]. In comparison, the cyclic softening observed in the 100$850^{\circ} \mathrm{C}$ IP experiments, is a combination of accumulation of plastic deformation in the $\gamma$ channels perpendicular to the load and shearing of the $\gamma^{\prime}$ that occurs at temperatures below $750^{\circ} \mathrm{C}$ during the TMF cycle $[1,55]$.

OP TMF failure was dominated by preferential cracking along the oxidation spikes (Figure 6) when $T_{\max }=850^{\circ} \mathrm{C}$ and $950^{\circ} \mathrm{C}$, but when $T_{\max }=750^{\circ} \mathrm{C}$ the mechanism of failure was pure fatigue, with the crack exhibiting macroscopic cube shear behavior. $\left[. .^{8}\right] \ln$ dropping the temperature from $950^{\circ} \mathrm{C}$ to $750^{\circ} \mathrm{C}$, a $80 \%$ reduction in the rate of oxidation occurs [56]. As a result, the $750^{\circ} \mathrm{C}$ behavior was attributed to stress concentrations on fewer slip planes and $\gamma^{\prime}$ shearing, whereas above $800^{\circ} \mathrm{C}$ the deformation becomes more homogeneous with damage being localized to the $\gamma$ channels [57]. On the fracture surface (Figure 8a) of material exposed to OP conditions are observed numerous crack initiation sites near the surface as evidence of increased environmental influence in the interdendritic regions. In contrast, fatigue cracks were observed to be emanating from carbide interfaces and the surrounding material in all IP TMF specimens as shown in Figure 7. Under IP conditions, typically a single primary crack is observed on the fracture surface (Figure 8b) emanating from the surface and linking with interior cracks from debonded carbides that allow for rapid propagation of the crack through the material. In the coming sections, this IP fatigue failure mechanism will be discussed in greater detail. Ultimately, no discernible influence of minimum cycle temperature was observed on the failure mechanisms, with the temperature-strain phasing controlling which degradation mechanism operates.

\footnotetext{
${ }^{8}$ removed: Further, in
} 


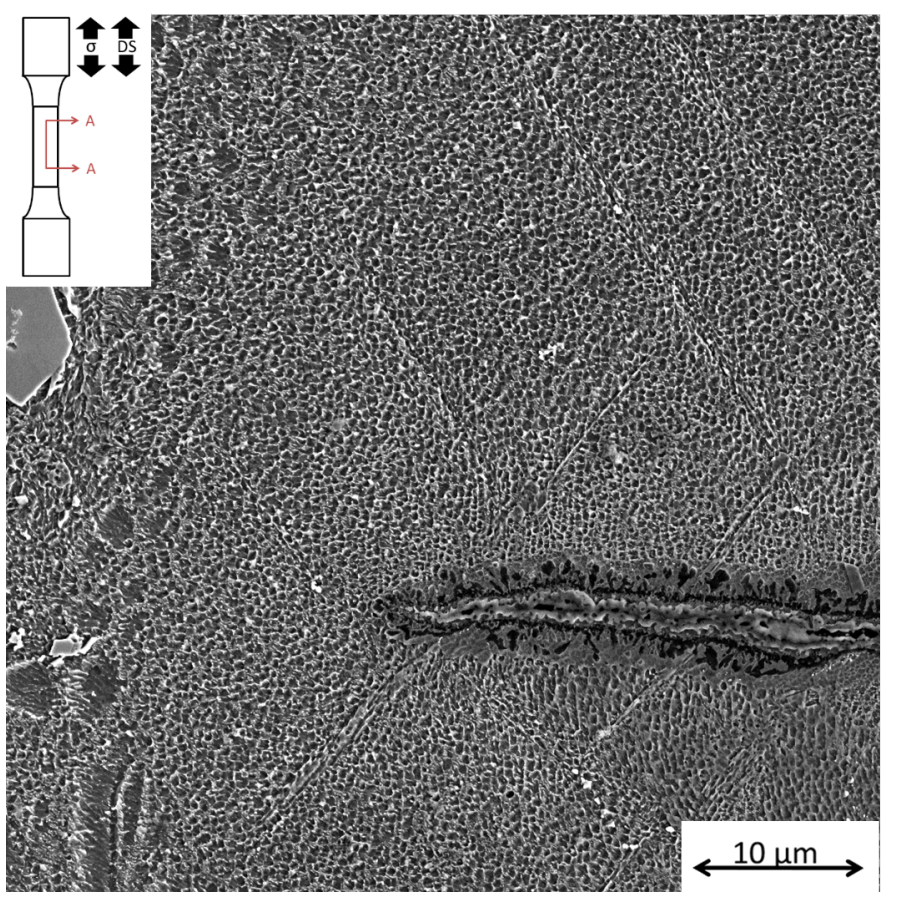

Figure 6: Fatigue crack propagating from an oxidation spike in material exposed to OP TMF $R_{\epsilon}=-\infty \operatorname{TMF}\left(\left[.{ }^{10}\right] T=100-950^{\circ} \mathrm{C}\right.$ and $\left.\Delta \epsilon_{m e c h}=1.0 \%\right)$. 


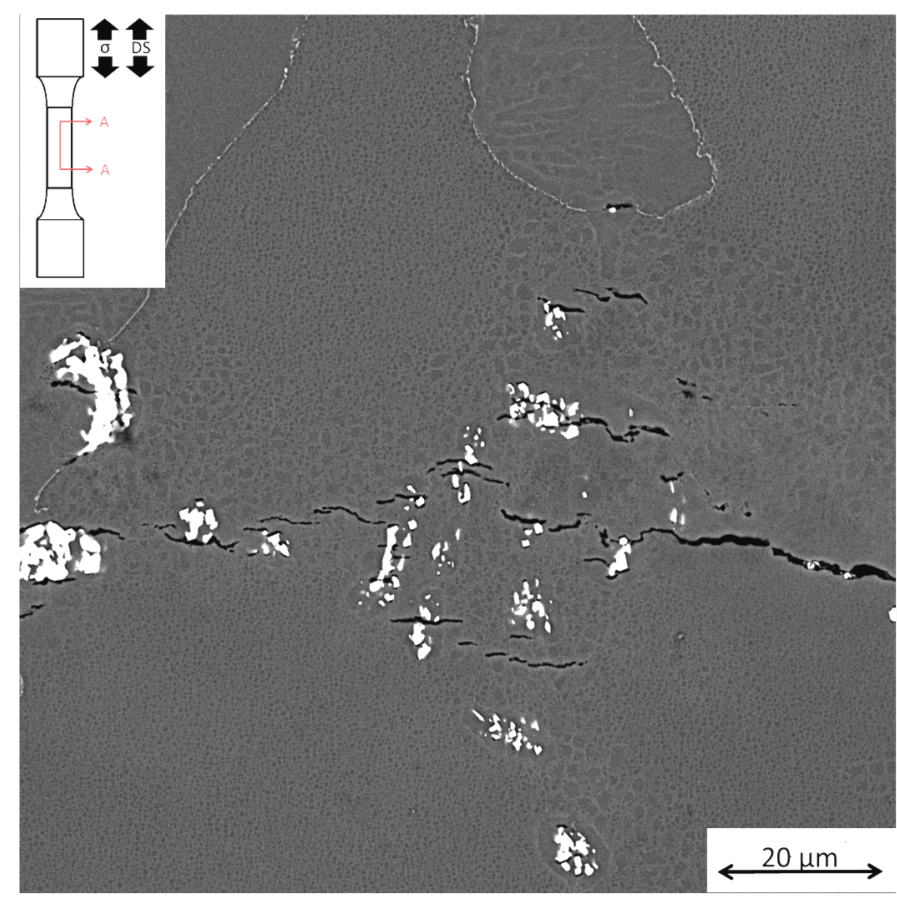

Figure 7: Fatigue cracks linking between debonded and cracked carbides in material exposed to IP $R_{\epsilon}=0 \mathrm{TMF}\left(\Delta T=100-750^{\circ} \mathrm{C}\right.$ and $\left.\Delta \epsilon_{m e c h}=1.2 \%\right)$.

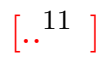

(a)

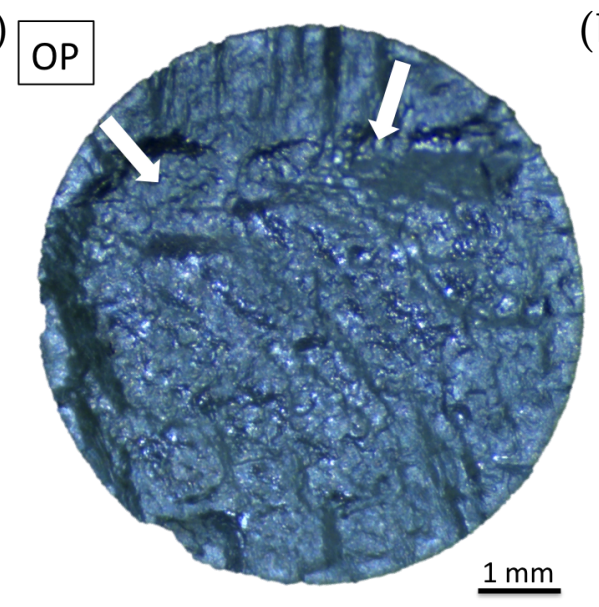

(b)

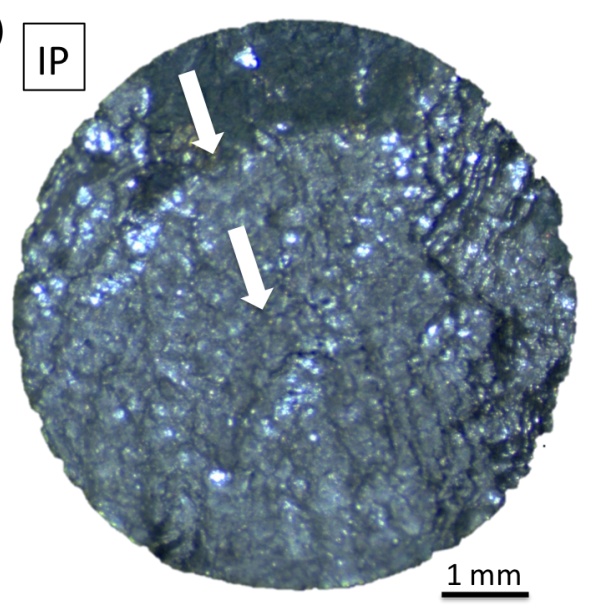

Figure 8: Optical images showing the fracture surfaces of material in the L-orientation exposed to TMF conditions. Crack initiation sites are indicated by the white arrows: (a) OP, $R_{\epsilon}=-\infty$, $\mathrm{T}=100-950^{\circ} \mathrm{C}$, and $\Delta \epsilon_{\text {mech }}=1.0 \%$ (b) $\mathrm{IP}, R_{\epsilon}=0, \mathrm{~T}=100-950^{\circ} \mathrm{C}$, and $\Delta \epsilon_{\text {mech }}=1.0 \%$

\footnotetext{
${ }^{11}$ removed: At the end of these experiments
} 
At failure of the material, the $\gamma^{\prime}$ precipitates were found to $\left[.{ }^{12}\right.$ ]not yet exhibit directional coarsening for specimens tested with a $T_{\max }$ of $950^{\circ} \mathrm{C}$ as shown by the primarily cuboidal primary $\gamma^{\prime}$ precipitates (Figure 9). No detectable microstructure evolution was observed in the experiments conducted at maximum temperatures of either $750^{\circ} \mathrm{C}$ or $850^{\circ} \mathrm{C}$. These findings are consistent with analytical model predictions for aging of the alloy where directional coarsening was only observed at temperatures above $900^{\circ} \mathrm{C}$ [54]. Further, the cumulative exposure time for the $T_{\max }=950^{\circ} \mathrm{C}$ specimens during the TMF experiment is too short to bring about a fully rafted structure, even though the thermodynamic driving force for directional coarsening is sufficient.

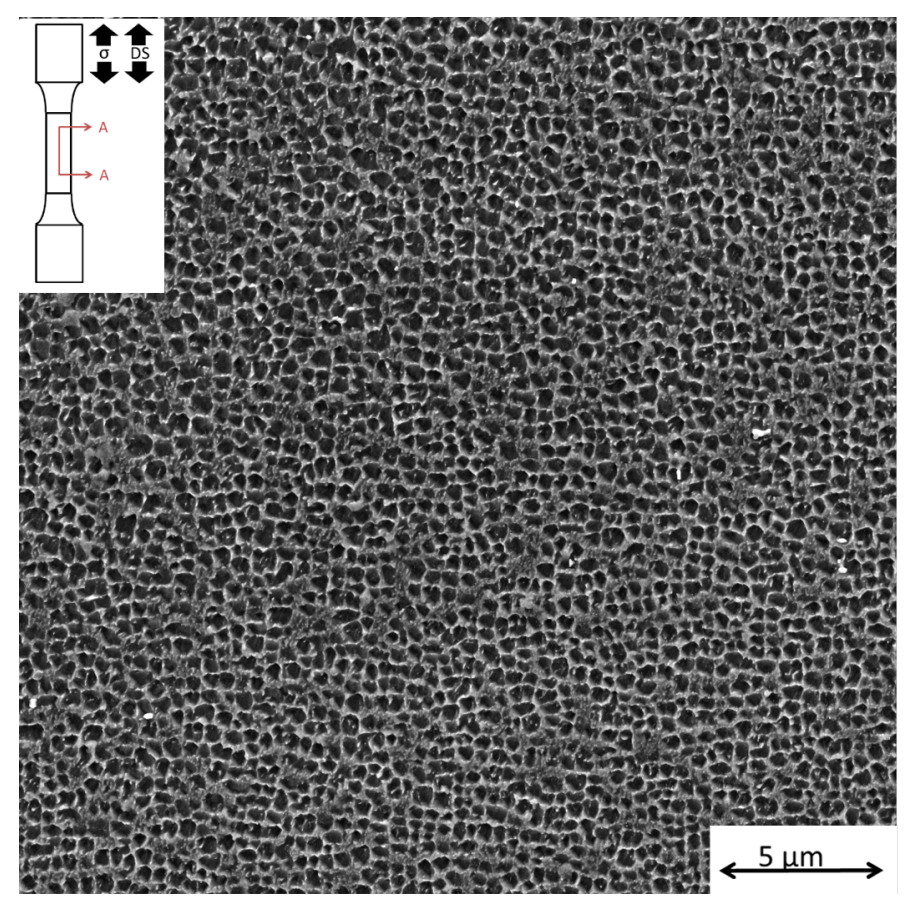

Figure 9: Resultant cubodial primary $\gamma^{\prime}$ precipitates in failed material exposed to OP $R_{\epsilon}=-\infty \operatorname{TMF}\left(\left[.{ }^{14}\right] T=100-950^{\circ} \mathrm{C}\right.$ and $\left.\Delta \epsilon_{m e c h}=1.0 \%\right)$ indicating negligible changes in precipitate size and morphology.

As a result of the experiential findings, the following can be stated about the potential life limiting mechanisms:

1) Microstructural analysis determined coarsening to be a non-factor in the TMF experiments conducted at all $T_{\max }$ considered [58].

2) Continuous cracking and re-oxidizing of the specimen surfaces and subsurface $\gamma^{\prime}$

\footnotetext{
${ }^{12}$ removed: still be in the early stages of
} 

factors for $\mathrm{OP}$ TMF life. At $T_{\max }$ of $750^{\circ} \mathrm{C}$ the rate of oxidation is reduced $80 \%$ due to limiting the oxidation kinetics having an exponential dependence on temperature [56].

3) Accumulated creep damage can be considered the contributing factor for TMF with a $T_{\max }$ of $850^{\circ} \mathrm{C}$ and $950^{\circ} \mathrm{C}$ as evidenced by the cyclic softening in the stress amplitude curves.

4) With a $T_{\max }$ of $750^{\circ} \mathrm{C}$ and under both IP and OP conditions, the observed reduction in life when the minimum cycle temperature is reduced can be attributed to the greater inelastic strain that occurs from an increase in the elastic modulus in the sub- $500^{\circ} \mathrm{C}$ temperature regime. The peak stresses do not allow for creep damage, and environmental and aging effects are mitigated [59].

\subsection{Effect of Mean Strain}

While the loading conditions in service components are typically associated with OP $R_{\epsilon}=-\infty$ TMF and IP $R_{\epsilon}=0$ TMF loadings, variations in mean strains do occur within service components. To examine the influence of mean strain on strain-life behavior in the L-orientation, OP $R_{\epsilon}=-\infty$ and $R_{\epsilon}=-1$ TMF experiments in the 500$950^{\circ} \mathrm{C}$ temperature range were conducted. Similarly, IP experiments were conducted for both $R_{\epsilon}=0$ and $R_{\epsilon}=-1$ in the $500-950^{\circ} \mathrm{C}$ range. The strain-life curves for each set of mean strain conditions is shown in Figure 10 with the isothermal LCF behavior at $950^{\circ} \mathrm{C}$ under fully-reversed conditions as a reference to the upper strain-life limit. 

the $500-950^{\circ} \mathrm{C}$ temperature range under IP $R_{\epsilon}=-1$ and $R_{\epsilon}=0$ loading conditions and OP $R_{\epsilon}=-1$ and $R_{\epsilon}=-\infty$ conditions in comparison to the strain-life at $950^{\circ} \mathrm{C}$ under fully-reversed loading conditions.

Specimens tested under both IP and OP $R_{\epsilon}=-1$ TMF generally exhibited shorter fatigue lives than the TMF experiments with a mean strain. However, the results are well within the experimental scatter of the material and the allowable variations for grain misorientation. Through repetition of the TMF experiments, a $+\backslash-20 \%$ range in the life from the mean value was found.

Comparative sets of initial cycle and half-life stress-train curves with the corresponding mean stress evolution curves for both IP and OP TMF are shown in Figures 11 and $12\left[.{ }^{15}\right]$. Aside from the shift in strain associated with the difference in strain ratios, the half-life hysteresis behavior under both IP and OP conditions with a mean strain result in statistically identical peak stresses as the corresponding fully-reversed experiments at half-life. In addition the accumulated inelastic strains were also equivalent between the cycles. From the evolution of the non-zero mean stress it is observed that IP and OP experiments conducted with a mean strain exhibited nearly symmetric loading on the initial cycle, with the material ultimately reaching stabilized hysteresis at approximately $15 \%$ life, whereas the fully-reversed experiments stabilized within $10 \%$ of the life value. Further, both IP and OP experiments with $R_{\epsilon}=-1$ experi-

\footnotetext{
${ }^{15}$ removed: are
} 
enced higher stresses in the cold portion of their respective TMF cycles early in life controlling the rate of stress stabilization.
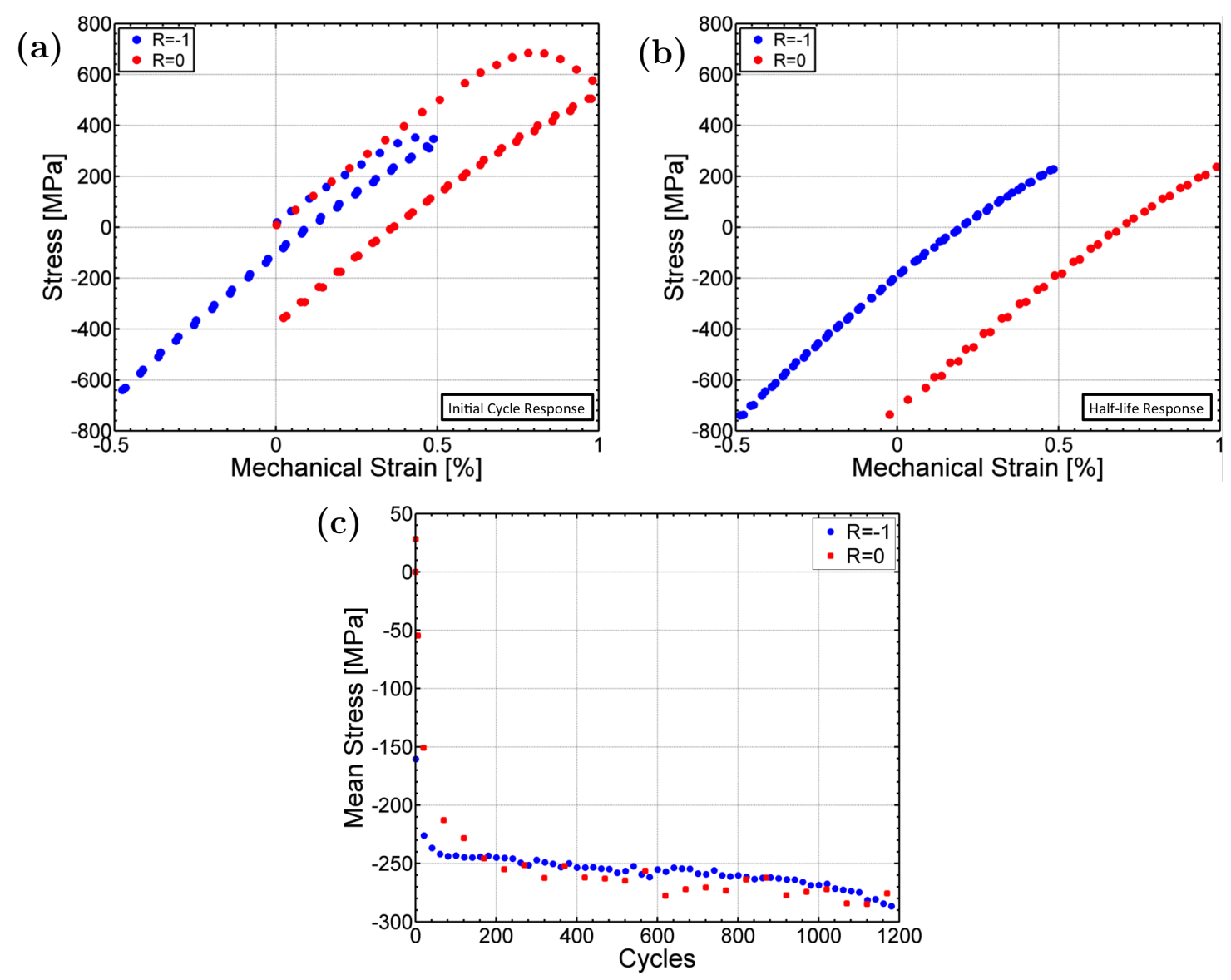

Figure 11: IP TMF results with $\left[.{ }^{17}\right] T=500-950^{\circ} \mathrm{C}$ comparing the effect of mean strain on (a) First cycle response (b) Half-life hysteresis response (c) Mean stress evolution. 

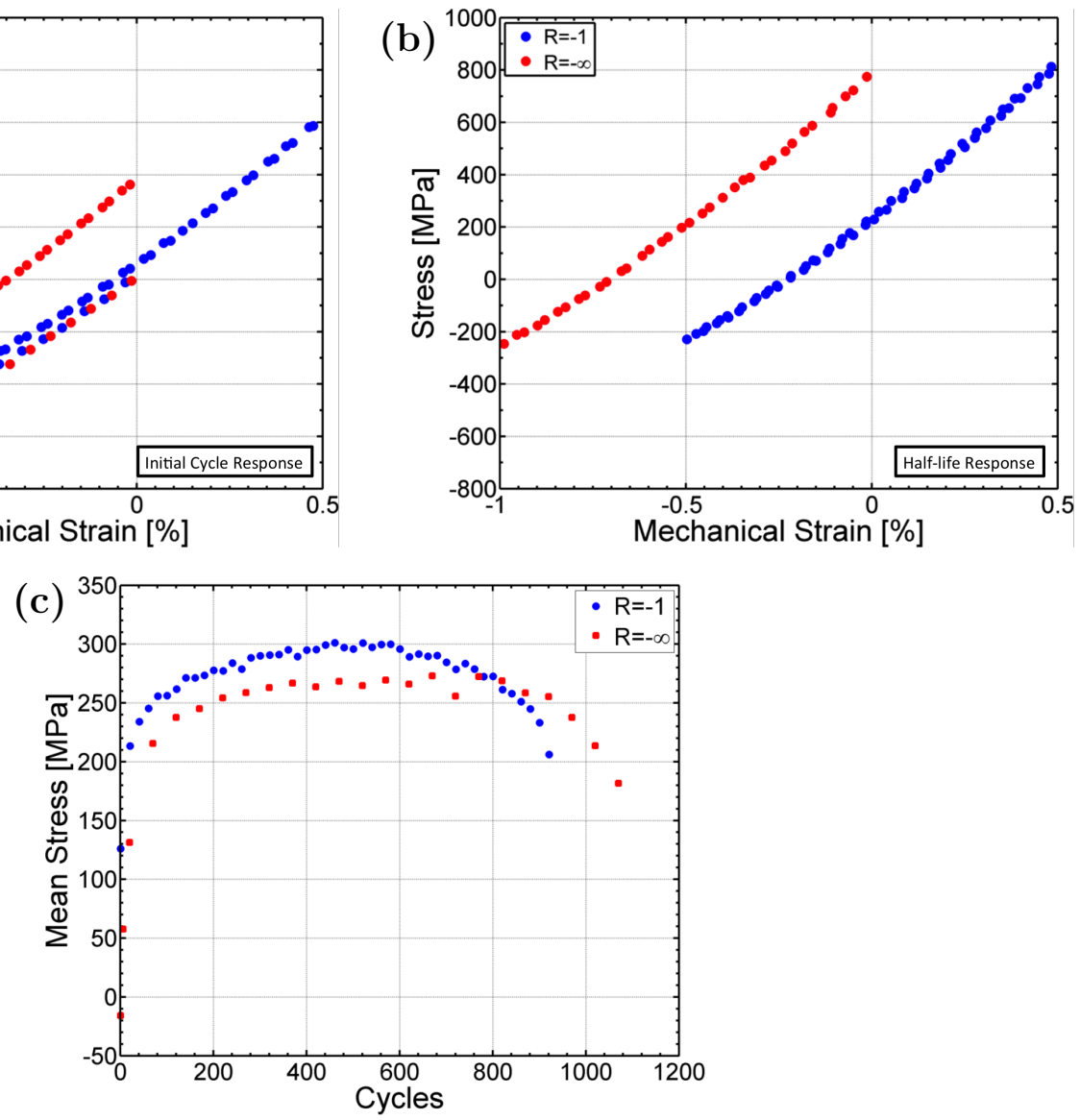

Figure 12: OP TMF results with $\left[.{ }^{19}\right] T=500-950^{\circ} \mathrm{C}$ comparing the effect of mean strain on (a) First cycle response (b) Half-life hysteresis response (c) Mean stress evolution.

While differences exist in the stress evolution, consideration of the known variation in the strain-life results and the similarities of the resultant strain-life and stress response, the TMF response independent of mean strain. As a result, the mechanical strain amplitude can be considered to control the strain-life under TMF conditions where different mean strains are of concern. These findings are consistent with the behavior of other Ni-base superalloys under various mean strain conditions [30].

\subsection{Temperature-Force Interactions}

Amongst TMF loadings, OP TMF loadings generally become the life limiting cycle type $[48,57,60]$. This is attributed to the material degradation that occurs from the the continuous cracking of oxide layers and re-oxidation in the areas surrounding a growing fatigue crack $[21,61]$. For the cases where a maximum cycle temperature of 
$1223 \mathrm{~K}\left(950^{\circ} \mathrm{C}\right)$ was used;

1. An IP-OP TMF crossover was observed

2. IP behavior is life limiting at high $\Delta \epsilon_{m e c h}$ and OP TMF at low mechanical strain amplitudes

3. A shift in the $T_{\min }$ is observed a shift in the IP-OP mechanical strain from a $\Delta \epsilon_{\text {mech }} \approx 0.9 \%$ for $500-950^{\circ} \mathrm{C}$ to a $\Delta \epsilon_{\text {mech }} \approx 0.7 \%$ for $\Delta \mathrm{T}=100-950^{\circ} \mathrm{C}$.

4. In the case of the IP-OP curves in the $100-750^{\circ} \mathrm{C}$ temperature range, an IP-OP crossover is not observed and the OP TMF behavior always exhibits a greater life than that of the IP cycle

Similar IP-OP crossovers have also been reported for the Ni-base superalloys MarM247LC-DS and GTD-111 undergoing TMF with a $T_{\max }$ in the $871-971^{\circ} \mathrm{C}$ range $[17$, $22,48]$

Examination of specimens exposed to IP TMF conditions above the cross-over point revealed that a large majority of the $M_{23} C_{6}$ carbides within the microstructure had fatigue cracks either emanating from their interfaces with the $\gamma-\gamma^{\prime}$ matrix or in the matrix material directly surrounding them as shown in Figure 7. Due to the three-dimensional sub-surface nature of the carbides, the cracks in the matrix are most likely the result of below carbide debonding [62]. In addition, the minority of carbides with chord lengths greater than $20 \mu \mathrm{m}$ were themselves observed to have cracked; most likely on the initial cycle $[10,63]$. Similar microstructural observations have been reported for IP TMF of other Ni-base superalloys where the $T_{\max }$ values used were in the $870-970^{\circ} \mathrm{C}$ range; however, these occurrences were primarily attributed creep and casting porosity $[17,22,48]$. For IP $500-950^{\circ} \mathrm{C}$ experiments conducted below the mechanical strain crossover point, fatigue cracks were still observed to be emanating from debonded carbides and the surrounding regions.

The preferred fatigue crack growth and propagation mechanisms were observed to be the linking-up of cracks with neighboring carbides as shown in Figure 7. While creep interactions between the carbides and surrounding matrix can be assumed to most $\left[.{ }^{20}\right.$ ]certainly occur for TMF tests conducted with high mechanical strain amplitudes and $T_{\text {max }} s$ of either $750^{\circ} \mathrm{C}$ and $850^{\circ} \mathrm{C}$, the presence of debonded carbides in specimens tested under IP TMF conditions with a $T_{\max }=750^{\circ} \mathrm{C}$ and low mechanical strain amplitude (relatively speaking) is indicative that this is a creep moderated mechanism for TMF cycles with a $T_{\max }$ above $850^{\circ} \mathrm{C}$. Under OP TMF conditions carbide decohesion is not

\footnotetext{
${ }^{20}$ removed: certainty
} 
observed. However, the carbides can still be seen to be stress $\left[.{ }^{21}\right]$ concentrators as indicated by slip bands $\left[.{ }^{22}\right]$ eminating from the carbides as shown in Figure 13.

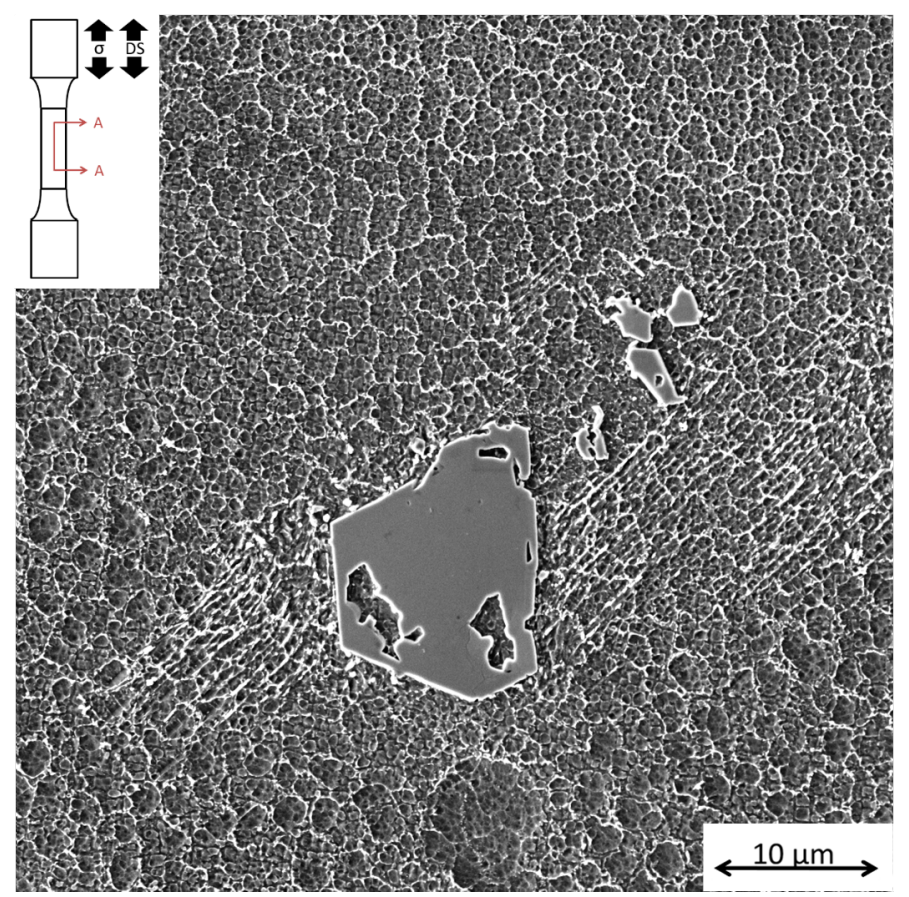

Figure 13: Slip band emination on a $M_{23} C_{6}$ carbide occurring as a result of OP $R_{\epsilon}=-\infty$ TMF exposure within a interdendritic region $\left(\left[.{ }^{24}\right] T=100-950^{\circ} \mathrm{C} \Delta \epsilon_{\text {mech }}=0.8 \%\right)$.

For Mar-M200 undergoing isothermal $\mathrm{LCF}$ in the $20-800^{\circ} \mathrm{C}$ temperature range, the primary fatigue crack propagation mechanism was determined to be the linking of cracks emanating from debonded carbides [10,64]. Above, $850^{\circ} \mathrm{C}$ it was reported that the fatigue crack propagation mechanism changed to that of cracks initiating at casting porosity in Mar-M200 [10,64]. However, in the case of of the presently tested CM247LC-DS there is no significant casting porosity. Additionally, quantitative fractography measurements of failed tensile surfaces tested in the $20-880^{\circ} \mathrm{C}$ range revealed the carbide area fraction was found to average $10 \%$, while the average volume fraction of carbides within the bulk was determined to be less than $2 \%$ [65]. Further, the expected thermal strain mismatch between the bulk superalloy and the $\mathrm{MC} / M_{23} C_{6}$ carbides is $\approx 1.0 \%$ resulting in compressive strains developing in the material surrounding the carbides at room temperature [66-68].

\footnotetext{
${ }^{21}$ removed: concentrator

${ }^{22}$ removed: impinging
} 
Overall, the IP-OP mechanical strain-life crossover point and the associated temperature dependence can be linked with the microscopic TMF conditions in the material surrounding the carbides and the associated interfaces. When accounting for the strains induced by the thermal strain mismatch, the matrix material in regions in the immediate vicinity of the carbides experiences a local mechanical strain amplitude that is a combination of the thermal misfit and the applied mechanical strain amplitude for a given TMF cycle that ultimately results in extensive fatigue damage accumulation in these localized regions. Ultimately, below the IP-OP crossover point, fatigue damage accumulation in regions near the debonded carbides under IP TMF continues to occur, however the damage accumulation is at a reduced rate compared to the OP TMF experiments which is the reason for the OP TMF being the life limiting cycle [22]. Further, rafting was not observed for CC conditions with a $T_{\max }$ of $950^{\circ} \mathrm{C}$.

\subsection{Creep-Fatigue Interactions}

The life comparisons between CC TMF and CF TMF experiments in the L-orientation were shown previously in Figure 14. On average, the inclusion of a dwell period resulted in a $2 \mathrm{x}$ or greater reduction in TMF life, with the greatest life reductions occurring for IP TMF conditions. On average, the inclusion of a strain hold resulted in a $5 \mathrm{x}$ reduction in life for both IP and OP TMF with a $T_{\max }$ of $950^{\circ} \mathrm{C}$. For CF with a $T_{\text {max }}$ of $750^{\circ} \mathrm{C}$, the life reduction associated with the dwell conditions resulted in a temperature-strain phasing dependent effect, with OP CF exhibiting an increasing life knockdown factor with decreasing strain amplitude, while IP CF exhibited a decreasing knockdown when compared to CC conditions. This IP life reduction can be attributed to the rapid debonding of the carbides and fatigue crack nucleation in the surrounding matrix material through the accumulation of voids. In the case of OP TMF, the increase in cyclic inelastic strain coupled with the accelerated environmental damage is the primary reason for the life reduction. 


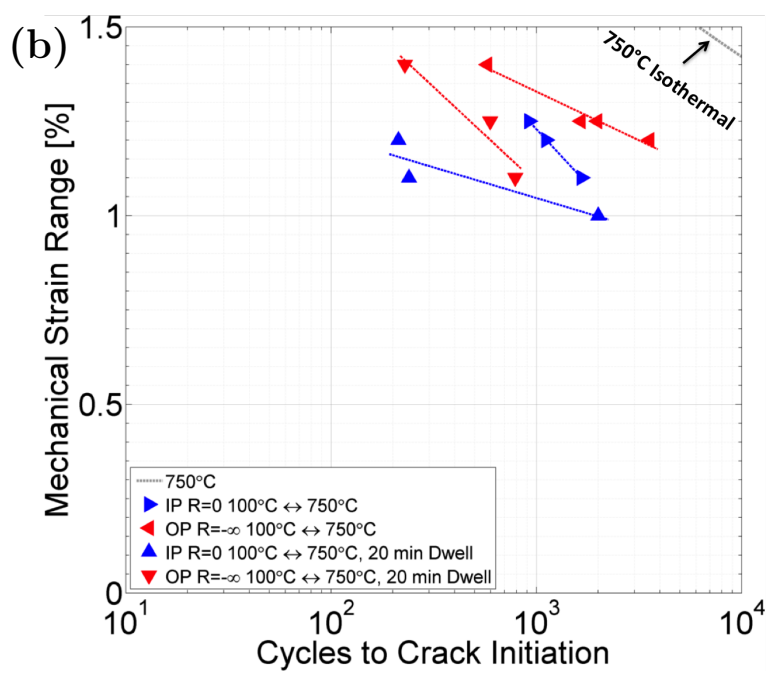

Figure 14: IP-OP TMF strain-life curves for material in the L-orientation for $\mathrm{CC}$ and $\mathrm{CF}$ TMF cycling a) $T=500-950^{\circ} \mathrm{C}$ and b) $\left[.{ }^{26}\right] T=100-750^{\circ} \mathrm{C}$.

The half-life hysteresis and mean stress evolution curves are shown in Figures 15-18 comparing the $\mathrm{CC}$ and $\mathrm{CF}$ responses for the life results in Figure 14. The dwell periods were generally found to result in an increase in the amount of accumulated inelastic strain, with nearly complete stress relaxation occurring for CF TMF cycles with $T_{\max }$ of 850 and $950^{\circ} \mathrm{C}$. At a $T_{\max }$ of $750^{\circ} \mathrm{C}$, minimal stress relaxation is observed to occur as a result of the limited ductility at intermediate temperatures. This is consistent with trends observed for DS Ni-base superalloys under isothermal CF conditions [30].
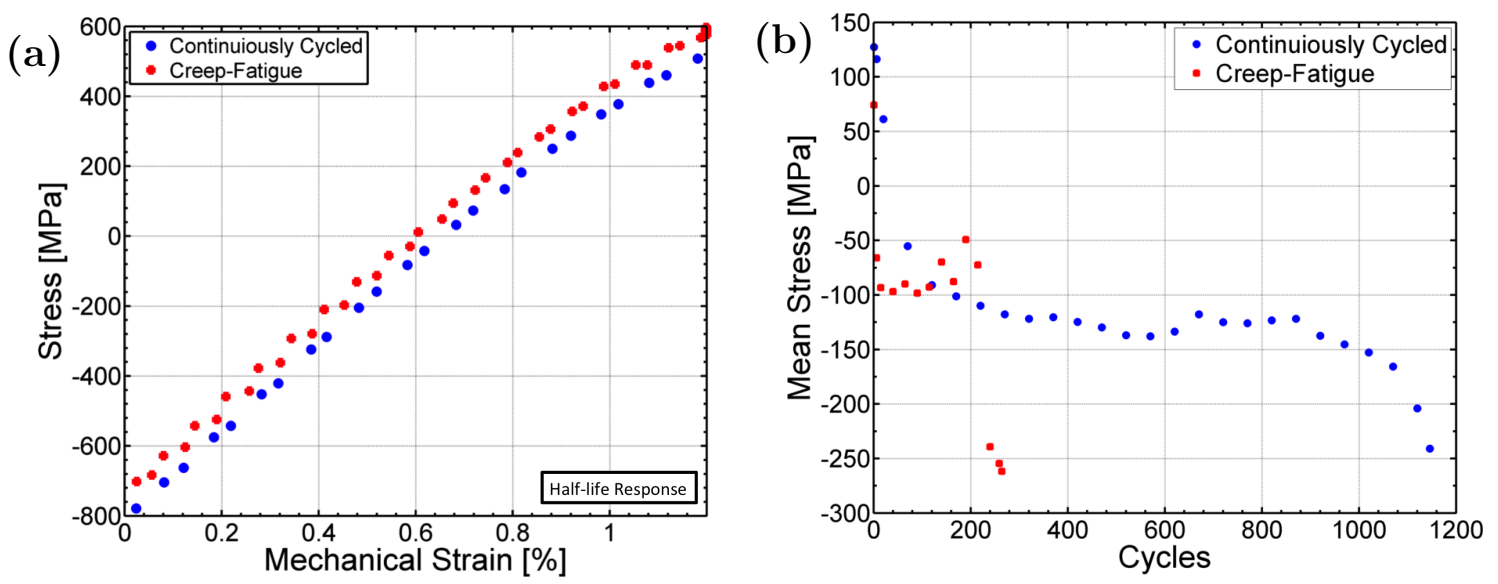

Figure 15: IP $R_{\epsilon}=0 \mathrm{TMF}$ results for $\left[.{ }^{28}\right] T=100-750^{\circ} \mathrm{C}$ comparing $\mathrm{CC}$ to $\mathrm{CF}$ in the L-orientation on the (a) Half-life hysteresis response (b) Mean stress evolution. 
(a)

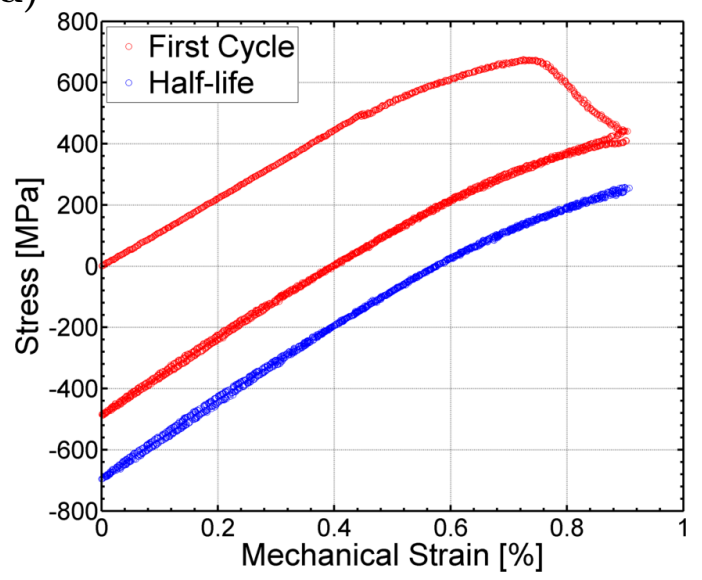

(b)

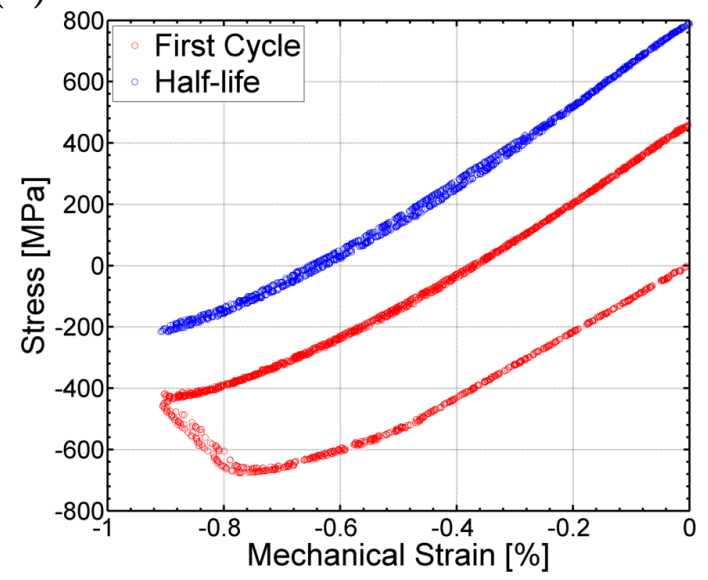

Figure 16: Representative initial and half-life hysteresis responses for material subjected to $T=100-950^{\circ} \mathrm{C} \mathrm{CC} \mathrm{TMF} \mathrm{(a)} \mathrm{IP} R_{\epsilon}=0$ and (b) OP $R_{\epsilon}=-\infty$

(a)

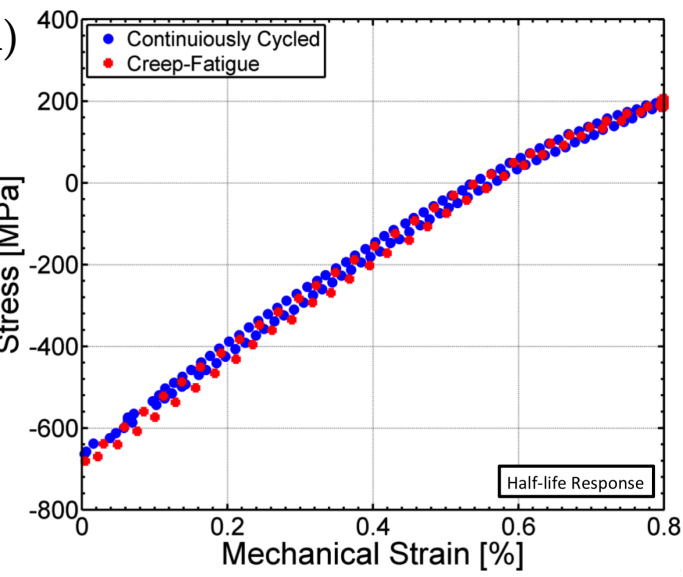

(b)

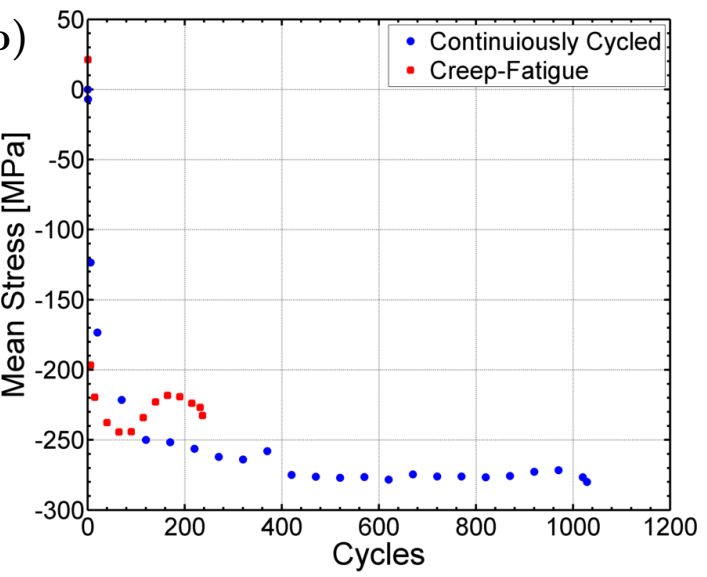

Figure 17: IP $R_{\epsilon}=0$ TMF results for $\left[. .^{30}\right] T=100-950^{\circ} \mathrm{C}$ comparing $\mathrm{CC}$ to $\mathrm{CF}$ in the L-orientation on the (a) Half-life hysteresis response (b) Mean stress evolution. 


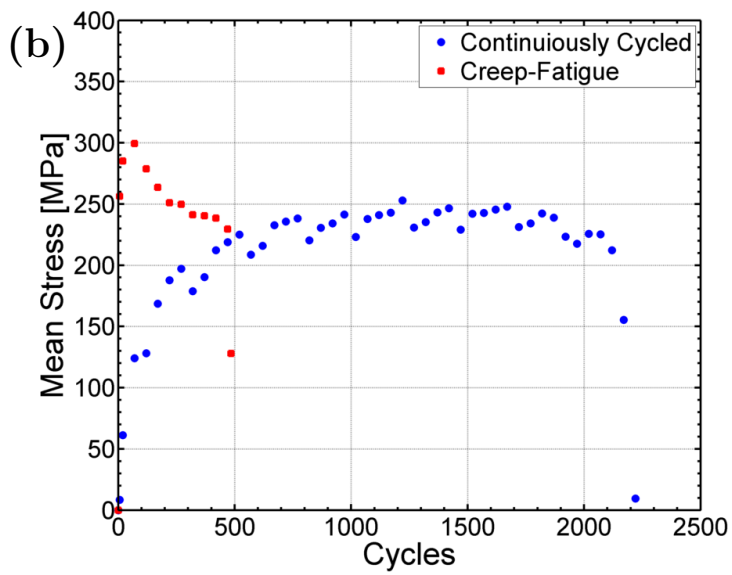

Figure 18: OP $R_{\epsilon}=-\infty$ TMF results for $\left[.{ }^{32}\right] T=100-950^{\circ} \mathrm{C}$ comparing $\mathrm{CC}$ to $\mathrm{CF}$ in the L-orientation on the (a) Half-life hysteresis response (b) Mean stress evolution.

Shown in Figures 15-18 are representative half-life hysteresis and mean stress evolution curves comparing the $\mathrm{CC}$ and $\mathrm{CF}$ responses for the life results in Figure 14. For cycle with a $T_{\max }$ of $950^{\circ} \mathrm{C}$ and large strain amplitudes, the addition of a strain hold resulted in an increase in the accumulated inelastic strain, however, at lower applied strains and for $\mathrm{CF}$ with a $T_{\max }$ of $750^{\circ} \mathrm{C}$ no measurable differences in accumulated inelastic strain were observed when compared to corresponding CC cycles.

Under IP CF with a $T_{\max }$ of $950^{\circ} \mathrm{C}$, the mean stress was observed to initially [.. ${ }^{33}$ ]decrease before stabilizing at a value $20 \%$ above the peak mean stress. Whereas, in the OP CF case, the mean stress initially [.. ${ }^{34}$ ]decreased about $20 \%$ before increasing again, being indicative that a change in the internal stress state of the $\gamma-\gamma^{\prime}$ microstructure $\left[.{ }^{35}\right.$ ]occurred. Microstructural analysis of the failed material indicated rafting of the $\gamma^{\prime}$ only occurred in CF experiments at mechanical strain amplitudes below $0.7 \%$ for IP TMF and $0.8 \%$ for $\mathrm{OP}$ TMF with a $T_{\max }$ of $950^{\circ} \mathrm{C}$. This is shown in Figure 19. The temporal findings are consistent with the aging kinetics determined through characterization of the microstructure via two-point correlation statistics [54]. In all IP TMF cases, cracks were observed to be emanating from debonded carbides similar to the CC IP cases. Similarly, OP TMF crack propagation was observed to occur along oxidation spikes similar to that of the CC OP TMF cases. For both IP and OP CF conducted with a $T_{\max }$ of $750^{\circ} \mathrm{C}$, stabilized hysteresis $\left[.{ }^{36}\right.$ ]and mean stress were observed to rapidly occur within $10 \%$ of the material's life. In the IP case, the

\footnotetext{
${ }^{33}$ removed: decreases

${ }^{34}$ removed: decrease

${ }^{35}$ removed: is occurring

${ }^{36}$ removed: (mean stress ) was
} 
(a)

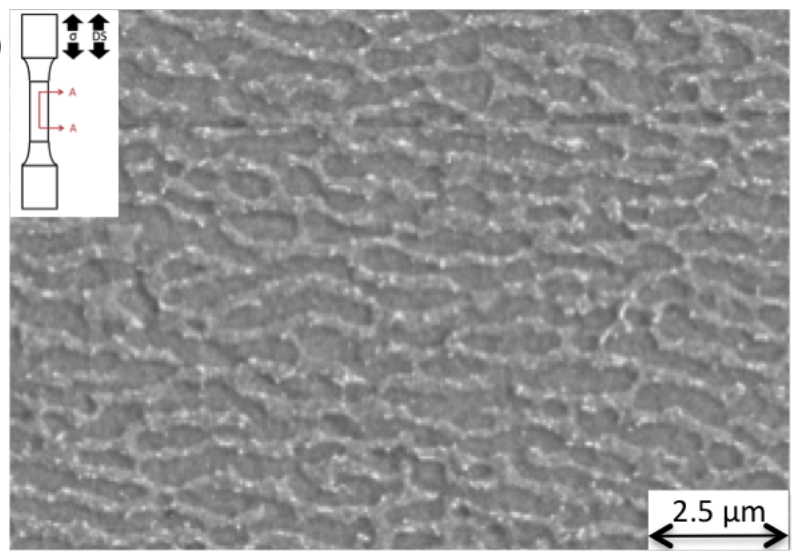

(b)

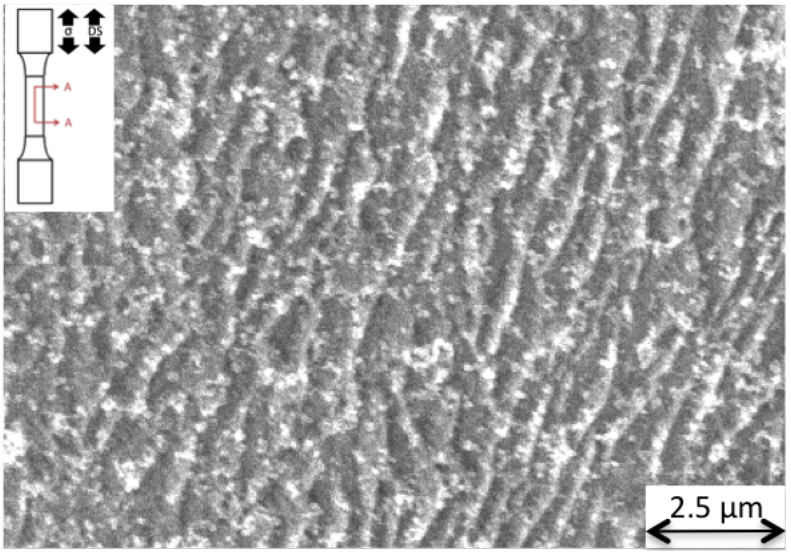

Figure 19: Rafted microstructures at material failure after exposure to CF conditions a) IP TMF, $R_{\epsilon}=0 \mathrm{~T}=100-950^{\circ} \mathrm{C}, \Delta \epsilon_{\text {mech }}=0.7 \%$ b) OP TMF, $R_{\epsilon}=-\infty \mathrm{T}=100-950^{\circ} \mathrm{C}, \Delta \epsilon_{\text {mech }}=0.8 \%$.

While other studies concerning the high temperature LCF behavior of Ni-base superalloys have reported rafting to occur under CC TMF conditions, in those particular cases the TMF cycles involved $T_{\max }>950^{\circ} \mathrm{C}$ or stress concentrators [21,23,27]. Additionally, other studies have noted rafting results in a softening effect which ultimately leads to premature failure [27]. In the present work, cyclic softening and hardening were observed, however, these occurrences did not directly relate to the presence of a rafted microstructure. Rather, fluctuations in the mean stress were observed to relate to the occurrence of a rafted microstructure.

\subsection{Material Anisotropy}

Many of the life trends observed for TMF loadings in the L-orientation, $\left[.{ }^{38}\right.$ ]were observed in the transverse orientation, however the transverse life [.. ${ }^{39}$ ]was generally reduced from that of the L-orientation as a result of increases in the elastic moduli. For the $500-950^{\circ} \mathrm{C}$ temperature range, the material life was found to be insensitive to temperature-force phasing when $T_{m i n}=500^{\circ} \mathrm{C}$ as shown in Figure $20 \mathrm{a}$. With a decrease

\footnotetext{
${ }^{37}$ removed: While,

${ }^{38}$ removed: are

${ }^{39}$ removed: is
} 


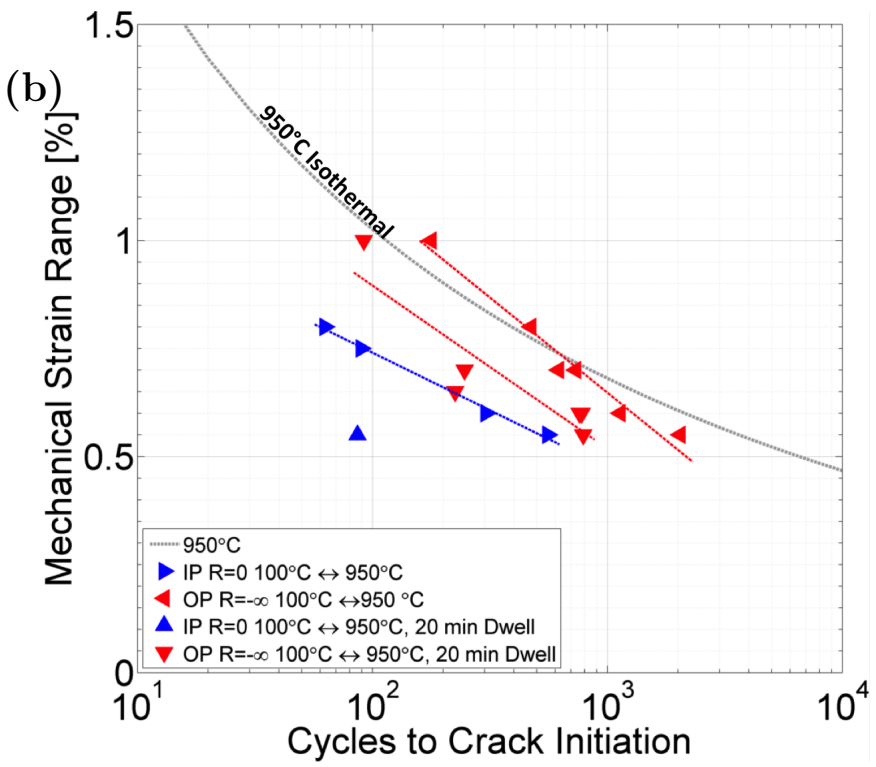

Figure 20: IP-OP TMF strain-life curves for material in the T-orientation a) Depicting the effect of $T_{\min }$ and $\mathrm{b}$ ) the effect of $\mathrm{CF}$ in the $100-950^{\circ} \mathrm{C}$ temperature range.

Similar to the L-orientation, CF fatigue conditions in the T-orientation result in a nearly $2 \mathrm{x}$ reduction in the fatigue life for OP TMF conditions and $10 \mathrm{x}$ for IP TMF as shown in Figure 20. Comparisons of the half-life behaviors between $\mathrm{CC}$ and $\mathrm{CF}$ reveal little difference in the mechanical response as shown in Figure 21. In the case of the failed gage sections exposed to OP TMF, $\left[.{ }^{42}\right]$ there were significant differences between the material exposed to $\mathrm{CC}$ and $\mathrm{CF}$ conditions as shown in Figure 22 where grain realignment can be observed in the $\mathrm{CF}$ exposed material.

\footnotetext{
${ }^{40}$ removed: As to

${ }^{41}$ removed: is unclear

${ }^{42}$ removed: can be seen
} 


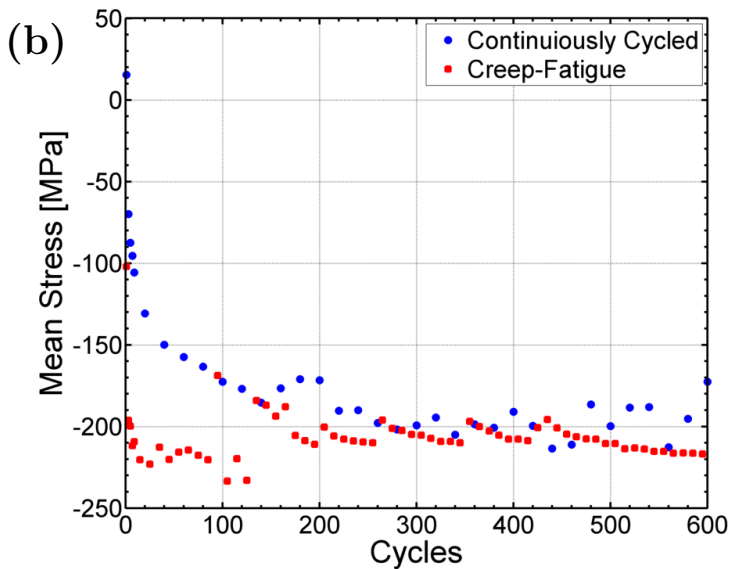

Figure 21: IP TMF results for $\left[.{ }^{44}\right] T=100-950^{\circ} \mathrm{C}$ comparing $\mathrm{CC}$ to $\mathrm{CF}$ in the T-orientation on the (a) Half-life hysteresis response (b) Mean stress evolution.
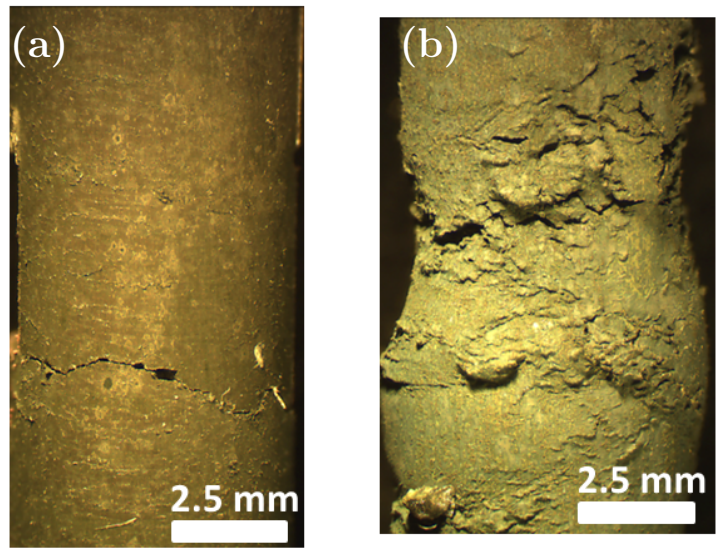

Figure 22: Comparison of the failed gage surfaces exposed to OP TMF, $\left[.{ }^{46}\right] \mathrm{T}=100-950^{\circ} \mathrm{C}$ and $\Delta \epsilon_{\text {mech }}=0.55 \%$ in the T-orientation (a) under CC conditions (b) under CF conditions.

Microscopy of the failed specimens indicates that under IP TMF conditions, fatigue crack propagation is dominated by intergranular cracking and cracks emanating from grain boundary carbides. This can be seen in the macroscopic micrograph in Figure 23 and the microscopic micrograph in Figure 24. The implications of the grain boundaries become significant in deciding the mode of fatigue crack growth and the materials susceptibility to environmental damage under TMF conditions. This behavior is similar to that reported for the DS Ni-base superalloy Mar-M247 [17,22]. Further, aging of the $\gamma-\gamma^{\prime}$ microstructure in the T-oriented specimens was not observed as a result of exposure to $\mathrm{CF}$ conditions as in the L-oriented $\left[. .^{47}\right]$. This can be attributed to the

\footnotetext{
${ }^{47}$ removed: , this
} 
sensitivity of the evolution kinetics to crystallographic orientation [69].

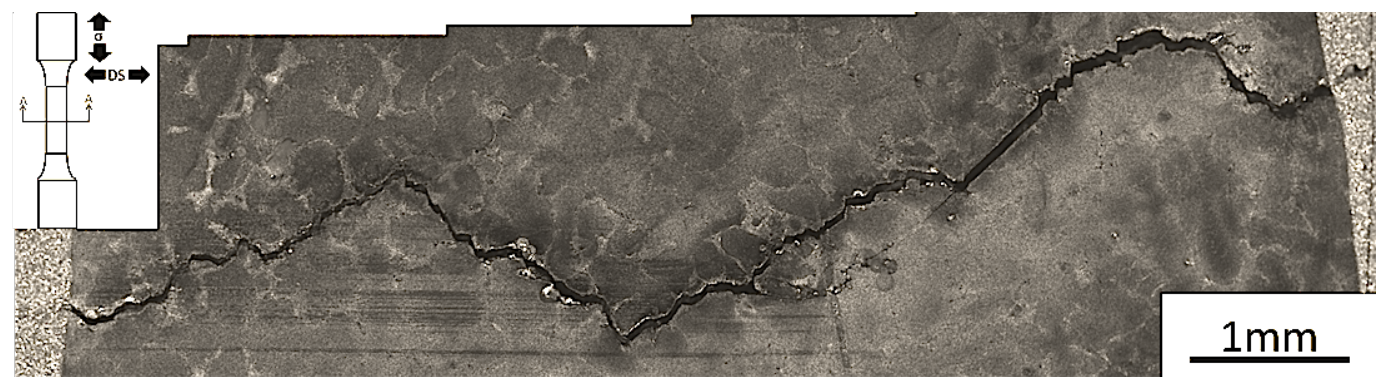

Figure 23: Transgranular cracking occurring under IP $R_{\epsilon}=0$ TMF conditions $\left(\left[. .{ }^{49}\right] T=100\right.$ $950^{\circ} \mathrm{C}$ and $\left.\Delta \epsilon_{\text {mech }}=0.55 \%\right)$.

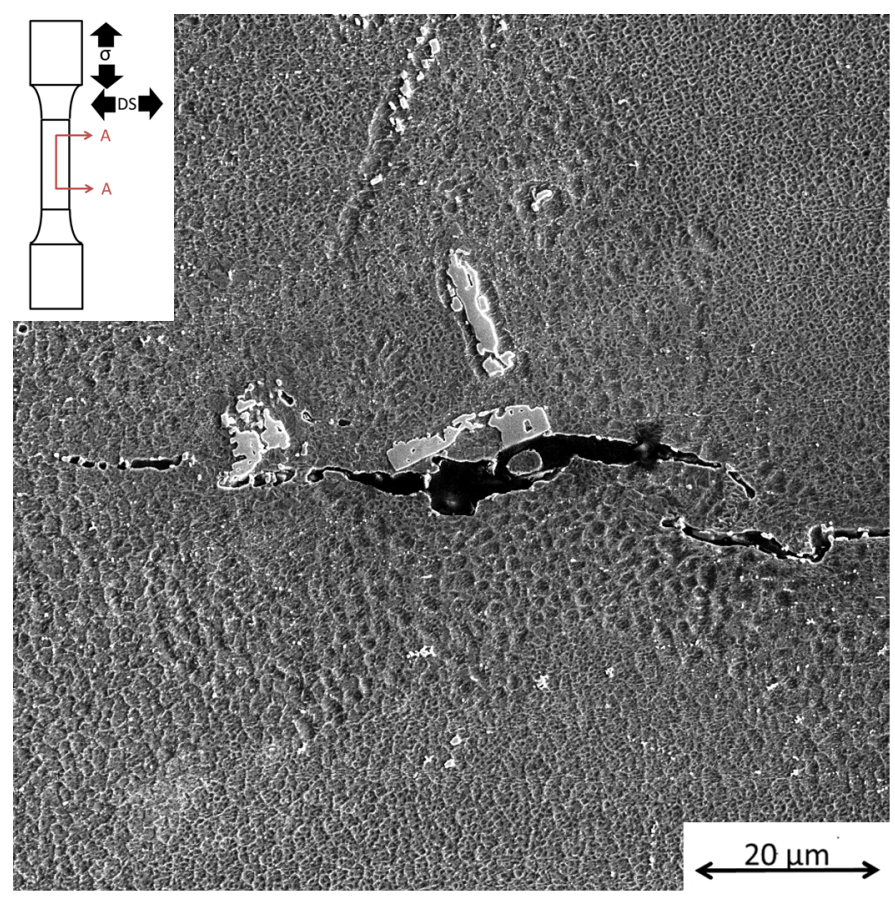

Figure 24: Fatigue crack emanating from a carbide along a grain boundary in material tested under IP $R_{\epsilon}=0$, CC TMF conditions $\left(\left[. .^{51}\right] T=100-950^{\circ} \mathrm{C}\right.$ and $\left.\Delta \epsilon_{\text {mech }}=0.55 \%\right)$.

\subsection{Review}

Based on the experimental findings of this work, the effects of TMF variables can be summarized as follows: 
Table 2: Summary of TMF Findings.

\begin{tabular}{|c|c|c|}
\hline TMF Cycle Variable & Material Effect & Life Effect \\
\hline$\downarrow T_{\min }$ & Increases inelastic strain & $\downarrow$ \\
\hline$\uparrow T_{\max }$ & Accelerated environment and creep interactions & $\downarrow$ \\
\hline$R_{\epsilon}$ & Stabilization at identical stress states & No effect \\
\hline IP/OP & Shifts dominant damage mechanism from carbide interactions for IP to environment interactions for OP TMF & Variable dependent \\
\hline Dwell & Enhanced inelastic strain accumulation and $\gamma^{\prime}$ rafting & $\downarrow$ \\
\hline Anisotropy & Transgranular crack propagation & $\downarrow$ \\
\hline
\end{tabular}

*Note: The summary table does not reflect effects of aged microsructure on strainlife. For microstructure influence refer to [70].

\section{Conclusions}

1) Experiments were conducted under both IP and OP TMF conditions with $T_{\min }$ of $100^{\circ} \mathrm{C}$ and $500^{\circ} \mathrm{C}$, while the $T_{\max }$ was varied between $750^{\circ} \mathrm{C}$ and $950^{\circ} \mathrm{C}$. Overall, experiments with the $T_{\min }=100^{\circ} \mathrm{C}$ were observed to have a $50-80 \%$ reduced TMF life over the TMF life of material exposed to identical mechanical strain amplitudes at the $T_{\min }=500^{\circ} \mathrm{C}$. Ultimately, due to the lack of observed microstructure evolution and creep interactions, especially with $T_{\max }=750^{\circ} \mathrm{C}$, the reduction in TMF life was related to the increase in the elastic properties with decreasing temperature from $500^{\circ} \mathrm{C}$ to $100^{\circ} \mathrm{C}$ resulting in an increase in the plastic strain amplitude.

2) TMF life was found to be independent of mean strain. This was determined through conducting TMF experiments under IP $R_{\epsilon}=-1$ and $R_{\epsilon}=0$ as well as OP $R_{\epsilon}=-1$ and $R_{\epsilon}=-\infty$. While the starting stresses and strain were different, the half-life, cyclic deformation response, and cycles to crack initiation were found to be within typical variations for TMF experiments conducted with the same temperature-load phasing and mean strains.

3) Above a threshold mechanical strain amplitude, IP TMF $\left[.{ }^{52}\right]$ loading was life limiting, while below OP TMF loading [.. $\left.{ }^{53}\right]$ was. Ultimately this occurrence was found to be associated with fatigue crack propagation from debonded carbides under IP TMF conditions within the interdendritic regions and along the grain boundaries in the L-orientation. Additionally, the transition between IP and OP TMF dominance was determined to be sensitive to the TMF cycle temperature range and material orientation.

\footnotetext{
${ }^{52}$ removed: loadings were

${ }^{53}$ removed: were
} 
4) $\mathrm{CF}$ interactions were found to result in a drastic life reduction over material exposed to identical conditions under CC conditions for both $\mathrm{T}=100-750\left[. .^{54}\right]^{\circ} \mathrm{C}$ and $\mathrm{T}=100-950^{\circ} \mathrm{C}$. Under low mechanical strain amplitude $(>0.7 \%)$ conditions, material exposed to both IP and OP CF TMF conditions with a $T_{\max }$ of $950^{\circ} \mathrm{C}$ was observed to have undergone directional coarsening. [.. $\left.{ }^{55}\right]$ Material exposed to large mechanical strain amplitudes did not directionally $\left[.{ }^{56}\right]$ coarsen as a result of insufficient time $\left[. .^{57}\right]$ for rafting to occur.

5) Experiments conducted in the T-orientation were found to exhibit the same TMF life traits as the longitudinal orientation, except that primary fatigue crack propagation mechanism was observed to be transgranular cracking and the life was reduced in comparison to the L-orientation.

\section{Acknowledgment}

The authors would like to thank Siemens Energy Inc., Orlando, FL for supporting this work through subcontract to DOE Award DE-FC26-05NT42644 on Advanced Hydrogen Turbine Development.

\footnotetext{
${ }^{54}$ removed: and

${ }^{55}$ removed: Whereas material

${ }^{56}$ removed: coarsened

${ }^{57}$ removed: for the formation of dislocation networks that allow
} 


\section{References}

[1] Reed, R. C., 2006. The Superalloys Fundamentals and Applications. Cambridge University Press.

[2] Caron, P., and Khan, T., 1983. "Improvement of Creep strength in a nickel-base single-crystal superalloy by heat treatment". Materials Science and Engineering, 61(2), pp. $173-184$.

[3] Caron, P., Henderson, P., Khan, T., and McLean, M., 1986. "On the Effects of Heat Treatments on the Creep Behaviour of a Single Crystal Superalloy". Scripta Metallurgica, 20, pp. 875-880.

[4] Nathal, M., 1987. "Effect of initial gamma prime size on the elevated temperature creep properties of single crystal nickel base superalloys". Metallurgical and Materials Transactions A, 18, pp. 1961-1970.

[5] Caron, P., Ohta, Y., Nakagawa, Y., and Khan, T., 1988. "Creep Deformation Anisotropy in Single Crystal Superalloys". In Superalloys 1988, S. Reichman, D. Duhl, G. Maurer, S. Antolovich, and C. Lund, eds., pp. 215-224.

[6] Nathal, M., MacKay, R., and Miner, R., 1989. "Influence of precipitate morphology on intermediate temperature creep properties of a nickel-base superalloy single crystal'. Metallurgical and Materials Transactions A, 20, pp. 133-141.

[7] Pollock, T., and Argon, A., 1992. "Creep Resistance of CMSX-3 Nickel base Superalloy Single Crystals". Acta Metallurgica et Materialia, 40(1), pp. 1-30.

[8] Mughrabi, H., Biermann, H., and Ungar, T., 1993. "Creep-induced local lattice parameter changes in a monocrystalline nickel-base superalloy". Journal of Materials Engineering and Performance, 2, pp. 557-564.

[9] Rowe, A., Wells, J., West, G., and Thomson, R., 2012. "Microstructural Evolution of Single Crystal and Directionally Solidified Rejuvinated Nickel Superalloys". In Superalloys 2012, E. Huron, R. Reed, M. Hardy, M. Mills, R. Montero, P. Portella, and J. Telesman, eds., pp. 245-254.

[10] Gell, M., and Leverant, G. R., 1968. "The Fatigue of the Nickel-Base Superalloy, Mar-M200, in Single-Crystal and Columnar-Grained Forms at Room Temperature". Transactions of the Metallurgical Society of AIME, 242(367-369).

[11] Antolovich, S., Domas, P., and Strudel, J., 1979. "Low cycle fatigue of René 80 as affected by prior exposure". Metallurgical and Materials Transactions A, 10, pp. 1859-1868. 
[12] Wright, P., and Anderson, A., 1980. "The Influence of Orientation on the Fatigue of Directionally Solidified Superalloys". In Superalloys 1980, J. Tien, ed., pp. 689 698.

[13] Antolovich, S. D., Rosa, E., and Pineau, A., 1981. "Low cycle fatigue of René 77 at elevated temperatures". Materials Science and Engineering, 47(1), pp. $47-57$.

[14] Gabb, T., Gayda, J., and Miner, R., 1986. "Orientation and temperature dependence of some mechanical properties of the single-crystal nickel-base superalloy René N4: Part II. Low cycle fatigue behavior". Metallurgical Transactions A, 17(3), pp. 497-505.

[15] Malpertu, J., and Rémy, L., 1990. "Influence of test parameters on the thermalmechanical fatigue behavior of a superalloy". Metallurgical Transactions A, 21(1), pp. 389-399.

[16] Sehitoglu, H., and Karasek, M., 1986. "Observations of Material Behavior Under Isothermal and Thermo-Mechanical Loading". Journal of Engineering Materials and Technology, 108(2), pp. 192-198.

[17] Boismier, D. A., and Sehitoglu, H., 1990. "Thermo-Mechanical Fatigue of MarM247: Part 1-Experiments". Journal of Engineering Materials and Technology, 112(1), pp. 68-79.

[18] Moverare, J. J., Johansson, S., and Reed, R. C., 2009. "Deformation and damage mechanisms during thermal-mechanical fatigue of a single-crystal superalloy". Acta Materialia, 57(7), pp. 2266 - 2276.

[19] Fleury, E., and Rémy, L., 1994. "Behavior of Nickel-base Superalloy Single Crystals Under Thermal-mechanical Fatigue". Metallurgical and Materials Transactions A, 25(1), pp. 99-109.

[20] Lall, C., Chin, S., and Pope, D., 1979. "The Orientation and Temperature Dependence of the Yield Stress of Ni3 (Al, Nb) Single Crystals". Metallurgical Transactions A, 10(9), pp. 1323-1332.

[21] Amaro, R. L., Antolovich, S. D., and Neu, R. W., 2012. "Mechanism-based Life Model for Out-of-phase Thermomechanical Fatigue in Single Crystal Ni-base Superalloys". Fatigue \& Fracture of Engineering Materials \& Structures, 35(7), pp. $658-671$.

[22] Sehitoglu, H., and Boismier, D. A., 1990. "Thermo-Mechanical Fatigue of MarM247: Part 2-Life Prediction". Journal of Engineering Materials and Technology, 112(1), pp. 80-89. 
[23] Kupkovits, R. A., and Neu, R. W., 2010. "Thermomechanical fatigue of a directionally-solidified Ni-base superalloy: Smooth and cylindrically-notched specimens". International Journal of Fatigue, 32(8), pp. 1330 - 1342.

[24] de la Yedra, A. G., Pedrejón, J. L., and Martín-Meizoso, A., 2013. "Thermomechanical Fatigue Tests on MarM-247 Nickel-based Superalloy Using the Direct Resistance Method". Materials at High Temperatures, 30(1), pp. 19 - 26.

[25] Huang, Z., Wang, Z., Zhu, S., Yuan, F., and Wang, F., 2006. "Thermomechanical fatigue behavior and life prediction of a cast nickel-based superalloy". Materials Science and Engineering: A, 432(1-2), pp. $308-316$.

[26] Okazaki, M., and Sakaguchi, M., 2008. "Thermo-mechanical fatigue failure of a single crystal Ni-based superalloy". International Journal of Fatigue, 30(2), pp. $318-323$.

[27] Arrell, D., Hasselqvist, M., Sommer, C., and Moverare, J., 2004. "On TMF Damage, Degradation Effects, and the Associated $T_{\text {min }}$ Influence on TMF Test Results in $\gamma / \gamma^{\prime}$ prime Alloys". In Superalloys 2004, K. Green, T. Pollock, H. Harada, T. Howson, R. Reed, J. Schirra, and S. Walston, eds., pp. 291-294.

[28] Kanesund, J., Moverare, J. J., and Johansson, S., 2011. "Deformation and damage mechanisms in IN792 during thermomechanical fatigue". Materials Science and Engineering: A, 528(13-14), pp. $4658-4668$.

[29] Fang, D., and Berkovits, A., 1994. "Mean stress models for low-cycle fatigue of a nickel-base superalloy". International Journal of Fatigue, 16(6), pp. 429 - 437.

[30] Gordon, A., 2006. "Crack Initiation Modeling of a Directionally-Solidified NickelBase Superalloy". PhD thesis, Georgia Institute of Technology.

[31] Zhou, H., Ro, Y., Koizumi, Y., Kobayashi, T., Harada, H., and Okada, I., 2004. "Thermomechanical Fatigue Behavior of the Third-generation, Single-crystal Superalloy TMS-75: Deformation Structure". Metallurgical and Materials Transactions A, 35(6), pp. 1779-1787.

[32] Okada, M., Tsutsumi, M., Kitamura, T., and Ohtani, R., 1998. "Initiation and Growth of Small Cracks in Directionally Solidified Mar-M247 Under Creep-Fatigue Part II: Effects of Angle Between Stress Axis and Solidification Direction". Fatigue \& Fracture of Engineering Materials \& Structures, 21(6), pp. 751-760.

[33] Moore, Z. J., and Neu, R. W., 2011. "Creep Fatigue of a Directionally Solidified Ni-base Superalloy - Smooth and Cylindrically Notched Specimens". Fatigue and Fracture of Engineering Materials and Structures, 34(1), pp. 17-31. 
[34] Filippini, M., 2011. "Creep-Fatigue at High Temperature of Notched Single Crystal Superalloys". Jounral of ASTM International, 8(6), pp. 1-19.

[35] le Graverend, J.-B., Cormier, J., Jouiad, M., Gallerneau, F., Paulmier, P., and Hamon, F., 2010. "Effect of fine precipitation on non-isothermal creep and creepfatigue behaviour of nickel base superalloy $\{M C 2\}$ ". Materials Science and Engineering: $A, \mathbf{5 2 7}(20)$, pp. $5295-5302$.

[36] Shi, D., Liu, J., Yang, X., Qi, H., and Wang, J., 2010. "Experimental investigation on low cycle fatigue and creep-fatigue interaction of DZ125 in different dwell time at elevated temperatures". Materials Science and Engineering: A, 528(1), pp. 233 $-238$.

[37] Beck, T., Lang, K.-H., Pitz, G., and Löhe, D., 2002. "The Influence of Superimposed Creep Loadings on the Thermal-Mechanical Fatigue Behaviour of the Ni-Base Superalloy IN 792 CC'. Mechanics of Time-Dependent Materials, 6(3), pp. $271-282$.

[38] Tong, J., Dalby, S., Byrne, J., Henderson, M., and Hardy, M., 2001. "Creep, fatigue and oxidation in crack growth in advanced nickel base superalloys". International Journal of Fatigue, 23(10), pp. 897 - 902.

[39] Okada, M., Tsutsumi, M., Kitamura, T., and Ohtani, R., 1998. "Initiation and Growth of Small Cracks in Directionally Solidified Mar-M247 Under Creep-Fatigue Part I: Effect of Microstructure". Fatige and Fracture of Engineering Materials and Structures, 21, pp. 741-750.

[40] Engler-Pinto, C., Noseda, C., Nazmy, M., and Rezai-Aria, F., 1996. "Interaction Between Creep and Thermo-mechanical Fatigue of CM24 ' $L C C$-DS'. In Superalloys 1996, R. Kissingerand, D. Deye, D. Anton, and A. Cetel, eds., TMS, pp. 319-325.

[41] Zhang, J., Harada, H., Ro, Y., Koizumi, Y., and Kobayashi, T., 2008. "Thermomechanical fatigue mechanism in a modern single crystal nickel base superalloy TMS-82". Acta Materialia, 56(13), pp. 2975 - 2987.

[42] Chieragatti, R., and Remy, L., 1991. "Influence of Orientation on the Low Cycle Fatigue of MAR-M 200 Single Crystals at $650^{\circ}$ C I: Fatigue Life Behaviour". Materials Science and Engineering: A, 141(1), pp. 1-9.

[43] Chieragatti, R., and Remy, L., 1991. "Influence of Orientation on the Low Cycle Fatigue of MAR-M 200 Single Crystals at $650^{\circ}$ C II: Cyclic Stress-strain Behaviour". Materials Science and Engineering: A, 141(1), pp. 11-22. 
[44] Hasebe, T., Sakane, M., and Ohnami, M., 1992. "High Temperature Low Cycle Fatigue and Cyclic Constitutive Relation of MAR-M247 Directionally Solidified Superalloy". International Journal of Engineering Materials Transactions, 114, pp. $162-167$.

[45] Segersall, M., Moverare, J. J., Simonsson, K., and Johansson, S., 2012. "Deformation and Damage MechanismsDuring Thermomechanical Fatigue of a Single Crystal Superalloy in the $\langle 001\rangle$ and $\langle 011\rangle$ Directions". In Superalloys 2012, E. Huron, R. Reed, M. Hardy, M. Mills, R. Montero, P. Portella, and J. Telesman, eds., pp. $215-223$.

[46] Mughrabi, H., and Tetzlaff, U., 2000. "Microstructure and High-Temperature Strength of Monocrystalline Nickel-Base Superalloys". Advanced Engineering Materials, 2(6), pp. 319-326.

[47] Draper, S., Hull, D., and Dreshfield, R., 1989. "Observations of Directional Gamma Prime Coarsening During Engine Operation". Metallurgical and Materials Transactions A, 20, pp. 683-688.

[48] Gordon, A. P., Neu, R. W., and McDowell, D. L., 2009. "Effect of pre-exposure on crack initiation life of a directionally solidified Ni-base superalloy". International Journal of Fatigue, 31(2), pp. 393 - 401.

[49] Kupkovits, R. A., Smith, D. J., and Neu, R. W., 2010. "Influence of minimum temperature on the thermomechanical fatigue of a directionally-solidified Ni-base superalloy". Procedia Engineering, 2(1), pp. 687 - 696.

[50] Harris, K., Erickson, G., and Schwer, R., 1984. "MAR-M247 DerivativeCM247LC-DS Alloy CMSX Single Crystal Alloys Properties and Performance". In Superalloys 1984, pp. 221-230.

[51] , 2012. ASTM E606-12 Standard Practice for Strain-Controlled Fatigue Testing. Tech. rep., ASTM International.

[52] , 2010. ASTM E2368-10 Standard Practice for Strain Controlled Thermomechanical Fatigue Testing. Tech. rep., ASTM International.

[53] Gandy, D., and Scheibel, J., 2006. Life Management System for Advanced E Class Gas Turbines. Tech. Rep. 1010477, Electric Power Research Institute.

[54] Kirka, M. M., 2014. "Thermomechanical Behavior of a Directionally Solidified Nickel-base Superalloy in the Aged State". PhD thesis, Georgia Institute of Technology. 
[55] Buffiere, J., and Ignat, M., 1995. "A Dislocation Based Criterion for the Raft Formation in Nickel-based Superalloys Single Crystals". Acta Metallurgica et Materialia, 43(5), pp. 1791-1797.

[56] Kupkovits, R., 2008. "Thermomechanical Fatigue Behavior of the DirectionallySolidified Nickel-Base Superalloy CM24\%'. Master's thesis, Georgia Institute of Technology.

[57] Tien, J., and Caulfield, T., eds., 1989. Superalloys, Supercomposites, and Superceramics. Academic Press.

[58] Pessah-Simonetti, Caron, M. P., and Khan, T., 1993. "Effect of a Long-Term Prior Aging on the Tensile Behaviour of a High-Performance Single Crystal Superalloy". Journal de Physique IV, 3, pp. 347-351.

[59] Private Communication with Siemens Energy.

[60] Neuner, F. C., Tetzlaff, U., and Mughrabi, H., 2002. "Enhancement of Thermomechanical Fatigue Resistance of a Monocrystalline Nickel-base Superalloy by Pre-rafting". In Thermomechanical Fatigue Behavior of Materials, A. McGaw, S. Kalluri, J. Bressers, and S. D. Peteves, eds., Vol. 4 of ASTM STP 1428. ASTM International.

[61] Pineau, A., and Antolovich, S. D., 2009. "High Temperature Fatigue of Nickelbase Superalloys - A Review with Special Emphasis on Deformation Modes and Oxidation". Engineering Failure Analysis, 16(8), pp. 2668-2697.

[62] Trexler, M. D., 2007. "The Relationship of Microstructure to Fracture and Corrosion Behavior of a Directionally Solidified Superalloy". PhD thesis, Georgia Institute of Technology.

[63] Saxena, A., 1998. Nonlinear Fracture Mechanics for Engineers. CRC Press.

[64] Leverant, G. R., and M.Gell, 1969. "The Elevated Temperature Fatigue of a NickelBase Superalloy, MAR-M200, in Conventually-Cast and Directionally-Solidified Forms". Transactions of the Metallurgical Society of AIME, 245, pp. 1167-1173.

[65] Trexler, M. D., and Sanders, T. H., 2008. "Quantitative Characterization of Features Affecting Crack Path in a Directionally Solidified Superalloy". In Superalloys 2008, S. . R. C. Reed, K. A. Green, P. Caron, T. Gabb, M. G. Fahrmann, E. S. Huron, and S. A. Woodard, eds.

[66] Karamched, P. S., and Wilkinson, A. J., 2011. "High Resolution Electron Backscatter Diffraction Analysis of Thermally and Mechanically Induced Strains Near Carbide Inclusions in a Superalloy". Acta Materialia, 59(1), pp. 263-272. 
[67] McHugh, S., 1990. "Modelling the Thermo-mechanical bBhavior of a Carbide Inclusion in a Nickel Superalloy Including Residual Stress Effects with a Simple Finite-element Model'. Mathematical and Computer Modelling, 14(0), pp. 933941.

[68] Yu-ichi, K., Hidenori, T., and Xinfang, Z., 2012. "Hybrid System for In-situ Observation of Microstructure Evolution in Steel Materials". Transactions of JWRI, 41(2), pp. 412-418.

[69] Kamaraj, M., 2003. "Rafting in Single Crystal Nickel-base Superalloys- An Overview". Sadhana, 28, pp. 115-128.

[70] Kirka, M. M., Brindley, K. A., Neu, R. W., Antolovich, S. D., Shinde, S. R., and Gravett, P. W. "Influence of Coarsened and Rafted Microstructures on the Thermomechanical Fatigue of a Ni-base Superalloy". Submitted for Review to the International Journal of Fatigue. 


\section{List of Tables}

1 Nominal chemical compositions of the DS Ni-base superalloy used in this work given as weight percent $[50] \ldots \ldots \ldots$. . . . . . . . 5

2 Summary of TMF Findings. . . . . . . . . . . . . . . . . . . 29 


\section{List of Figures}

1 Initial cuboidal $\gamma^{\prime}$ microstructure within the dendritic core. . . . . . . . 5

2 Influence of $T_{\min }$ on IP $R_{\epsilon}=0$ TMF life in the L-orientation. Isothermal results are for $R_{\epsilon}=-1[33] \ldots \ldots \ldots \ldots \ldots$. . . . . . . . 8

3 Influence of $T_{\min }$ on $\mathrm{OP} R_{\epsilon}=-\infty$ TMF life in the L-orientation. Isothermal results are for $R_{\epsilon}=-1[33] \ldots \ldots \ldots$. . . . . . . 9

4 Half-life [.. hysteresis curves for material undergoing IP, $R_{\epsilon}=0$ and OP, $R_{\epsilon}=-\infty$ showing the effect of $T_{\min }$ upon the stress-strain response in relation to the material's isothermal behavior at $950^{\circ} \mathrm{C} . \ldots . . . .10$

5 Stress amplitude curves for (a) IP TMF experiments with $R_{\epsilon}=0$ (b) OP TMF experiments with $R_{\epsilon}=-\infty \ldots \ldots . \ldots 10$

$6 \quad$ Fatigue crack propagating from an oxidation spike in material exposed to OP TMF $R_{\epsilon}=-\infty$ TMF $\left([.] T=.100-950^{\circ} \mathrm{C}\right.$ and $\left.\Delta \epsilon_{m e c h}=1.0 \%\right) \ldots 12$

7 Fatigue cracks linking between debonded and cracked carbides in material exposed to IP $R_{\epsilon}=0 \mathrm{TMF}\left(\Delta T=100-750^{\circ} \mathrm{C}\right.$ and $\left.\Delta \epsilon_{\text {mech }}=1.2 \%\right) . \quad 13$

8 Optical images showing the fracture surfaces of material in the L-orientation exposed to TMF conditions. Crack initiation sites are indicated by the white arrows: (a) $\mathrm{OP}, R_{\epsilon}=-\infty, \mathrm{T}=100-950^{\circ} \mathrm{C}$, and $\Delta \epsilon_{\text {mech }}=1.0 \%$ (b) IP, $R_{\epsilon}=0, \mathrm{~T}=100-950^{\circ} \mathrm{C}$, and $\Delta \epsilon_{m e c h}=1.0 \% \ldots \ldots \ldots$

9 Resultant cubodial primary $\gamma^{\prime}$ precipitates in failed material exposed to OP $R_{\epsilon}=-\infty \operatorname{TMF}\left([.] T=.100-950^{\circ} \mathrm{C}\right.$ and $\left.\Delta \epsilon_{m e c h}=1.0 \%\right)$ indicating negligible changes in precipitate size and morphology. . . . . . . . . . 14

10 Life curves for TMF experiments for material in the L-orientation conducted in the $500-950^{\circ} \mathrm{C}$ temperature range under IP $R_{\epsilon}=-1$ and $R_{\epsilon}=0$ loading conditions and $\mathrm{OP} R_{\epsilon}=-1$ and $R_{\epsilon}=-\infty$ conditions in comparison to the strain-life at $950^{\circ} \mathrm{C}$ under fully-reversed loading conditions. . . . . . . . . . . . . . . . . . . . 10

11 IP TMF results with [.. $] T=500-950^{\circ} \mathrm{C}$ comparing the effect of mean strain on (a) First cycle response (b) Half-life hysteresis response (c) Mean stress evolution. . . . . . . . . . . . . . . . . . . . 17

12 OP TMF results with [.. $] T=500-950^{\circ} \mathrm{C}$ comparing the effect of mean strain on (a) First cycle response (b) Half-life hysteresis response (c) Mean stress evolution. . . . . . . . . . . . . . . . . . . 18

13 Slip band emination on a $M_{23} C_{6}$ carbide occurring as a result of OP $R_{\epsilon}=-\infty$ TMF exposure within a interdendritic region $([.] T=.100-$

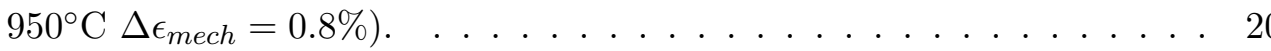


14 IP-OP TMF strain-life curves for material in the L-orientation for CC and CF TMF cycling a) $T=500-950^{\circ} \mathrm{C}$ and b) $[.] T=.100-750^{\circ} \mathrm{C} . \quad \ldots .22$

15 IP $R_{\epsilon}=0 \mathrm{TMF}$ results for $[.] T=.100-750^{\circ} \mathrm{C}$ comparing $\mathrm{CC}$ to $\mathrm{CF}$ in the L-orientation on the (a) Half-life hysteresis response (b) Mean stress evolution. . . . . . . . . . . . . . . . . . 22

16 Representative initial and half-life hysteresis responses for material subjected to $T=100-950^{\circ} \mathrm{C} \mathrm{CC} \mathrm{TMF} \mathrm{(a)} \mathrm{IP} R_{\epsilon}=0$ and (b) OP $R_{\epsilon}=-\infty .23$

17 IP $R_{\epsilon}=0 \mathrm{TMF}$ results for [.. $] T=100-950^{\circ} \mathrm{C}$ comparing $\mathrm{CC}$ to $\mathrm{CF}$ in the L-orientation on the (a) Half-life hysteresis response (b) Mean stress evolution. . . . . . . . . . . . . . . . . . 23

18 OP $R_{\epsilon}=-\infty$ TMF results for [.. $] T=100-950^{\circ} \mathrm{C}$ comparing $\mathrm{CC}$ to $\mathrm{CF}$ in the L-orientation on the (a) Half-life hysteresis response (b) Mean stress evolution. . . . . . . . . . . . . . . . . . . 24

19 Rafted microstructures at material failure after exposure to CF conditions a) IP TMF, $R_{\epsilon}=0 \mathrm{~T}=100-950^{\circ} \mathrm{C}, \Delta \epsilon_{m e c h}=0.7 \%$ b) OP TMF, $R_{\epsilon}=-\infty$

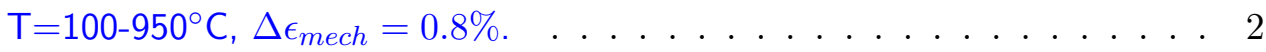

20 IP-OP TMF strain-life curves for material in the T-orientation a) Depicting the effect of $T_{\min }$ and $\mathrm{b}$ ) the effect of $\mathrm{CF}$ in the $100-950^{\circ} \mathrm{C}$ temperature range. . . . . . . . . . . . . . 26

21 IP TMF results for $[.] T=.100-950^{\circ} \mathrm{C}$ comparing $\mathrm{CC}$ to $\mathrm{CF}$ in the $\mathrm{T}$ orientation on the (a) Half-life hysteresis response (b) Mean stress evolution. . . . . . . . . . . . . . . . . . . . 27

22 Comparison of the failed gage surfaces exposed to OP TMF, [.. $] T=100-$ $950^{\circ} \mathrm{C}$ and $\Delta \epsilon_{\text {mech }}=0.55 \%$ in the T-orientation (a) under CC conditions (b) under CF conditions. . . . . . . . . . . . . . . . . . . 27

23 Transgranular cracking occurring under IP $R_{\epsilon}=0$ TMF conditions ([..

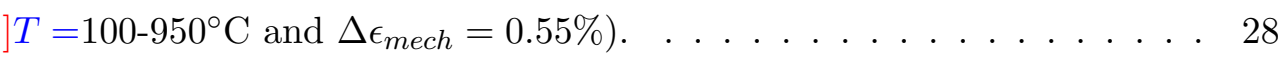

24 Fatigue crack emanating from a carbide along a grain boundary in material tested under IP $R_{\epsilon}=0, \mathrm{CC}$ TMF conditions $\left([.] T=.100-950^{\circ} \mathrm{C}\right.$

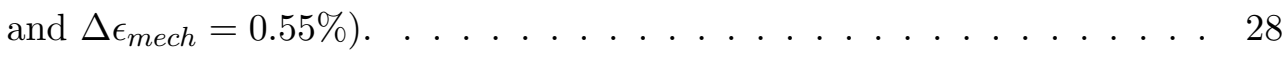


Figure 1

Click here to download high resolution image

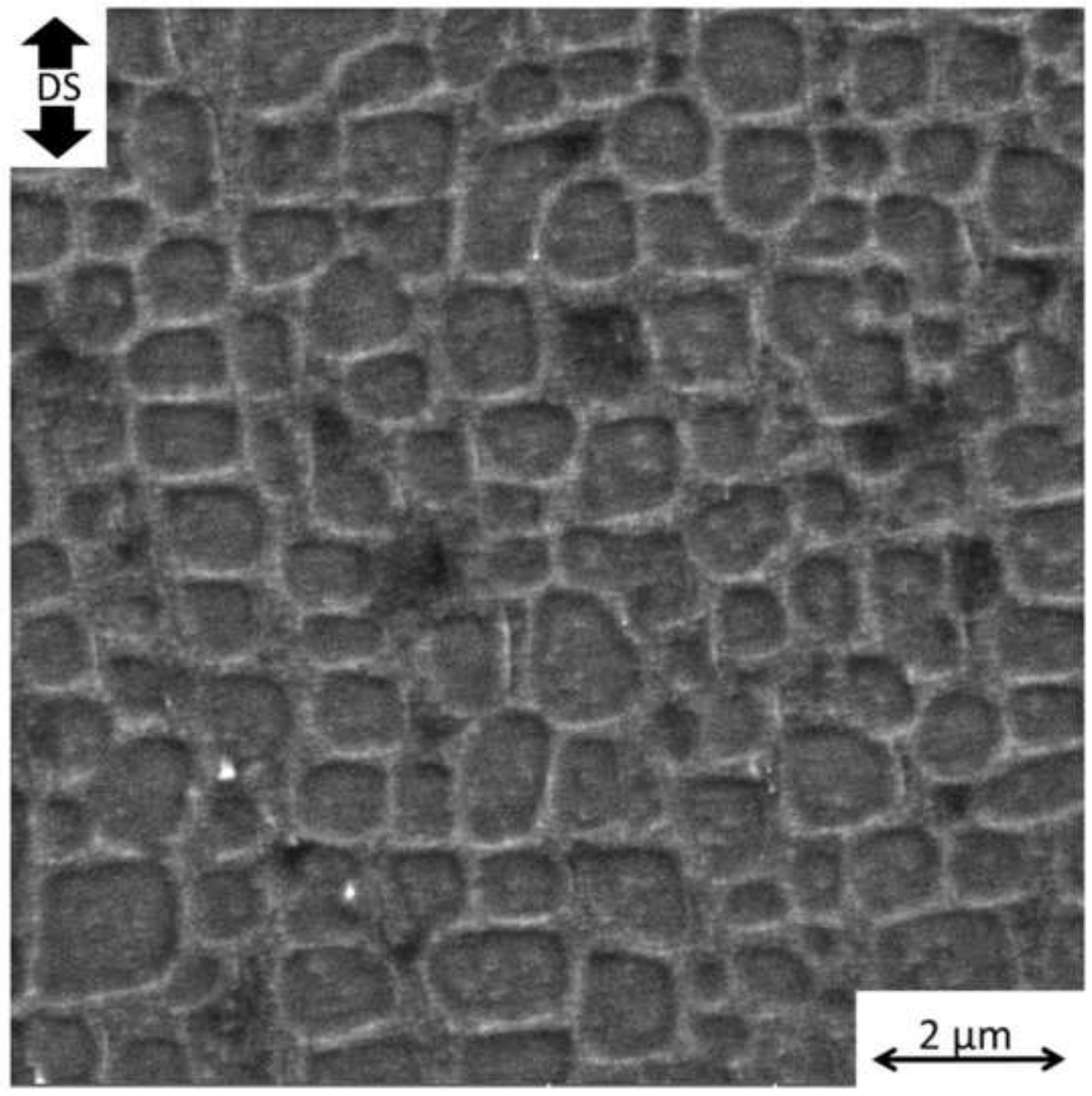


Click here to download high resolution image

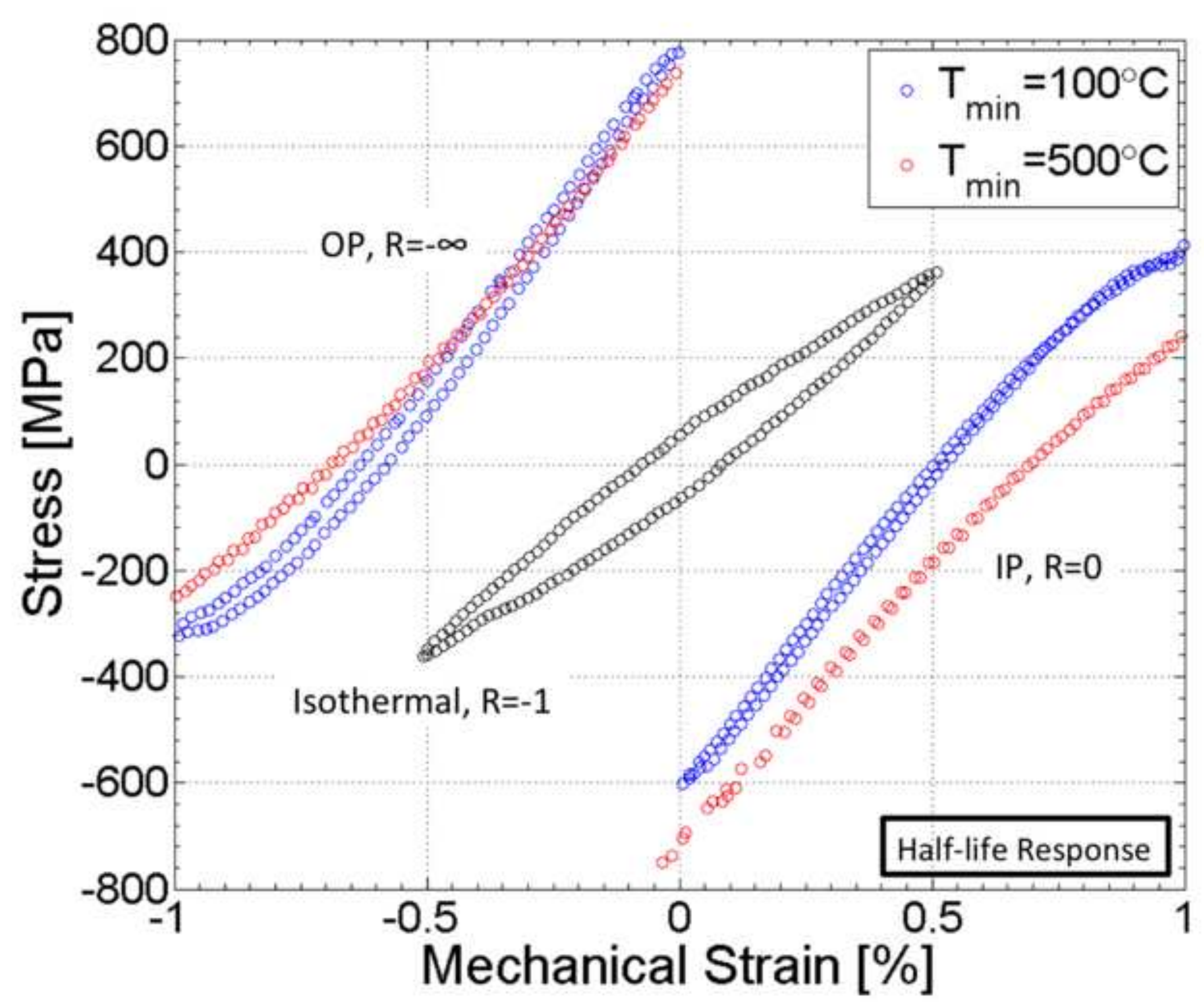




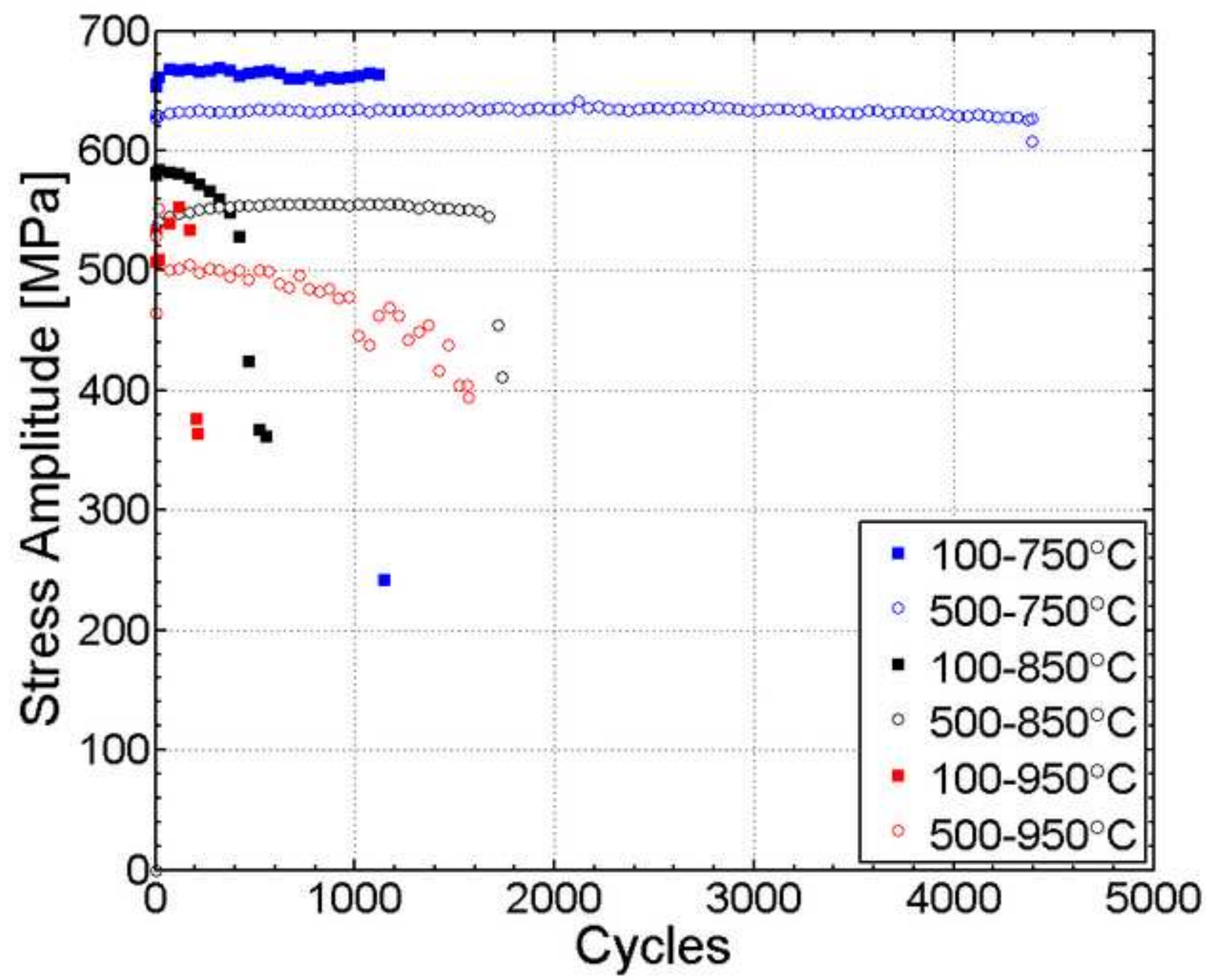




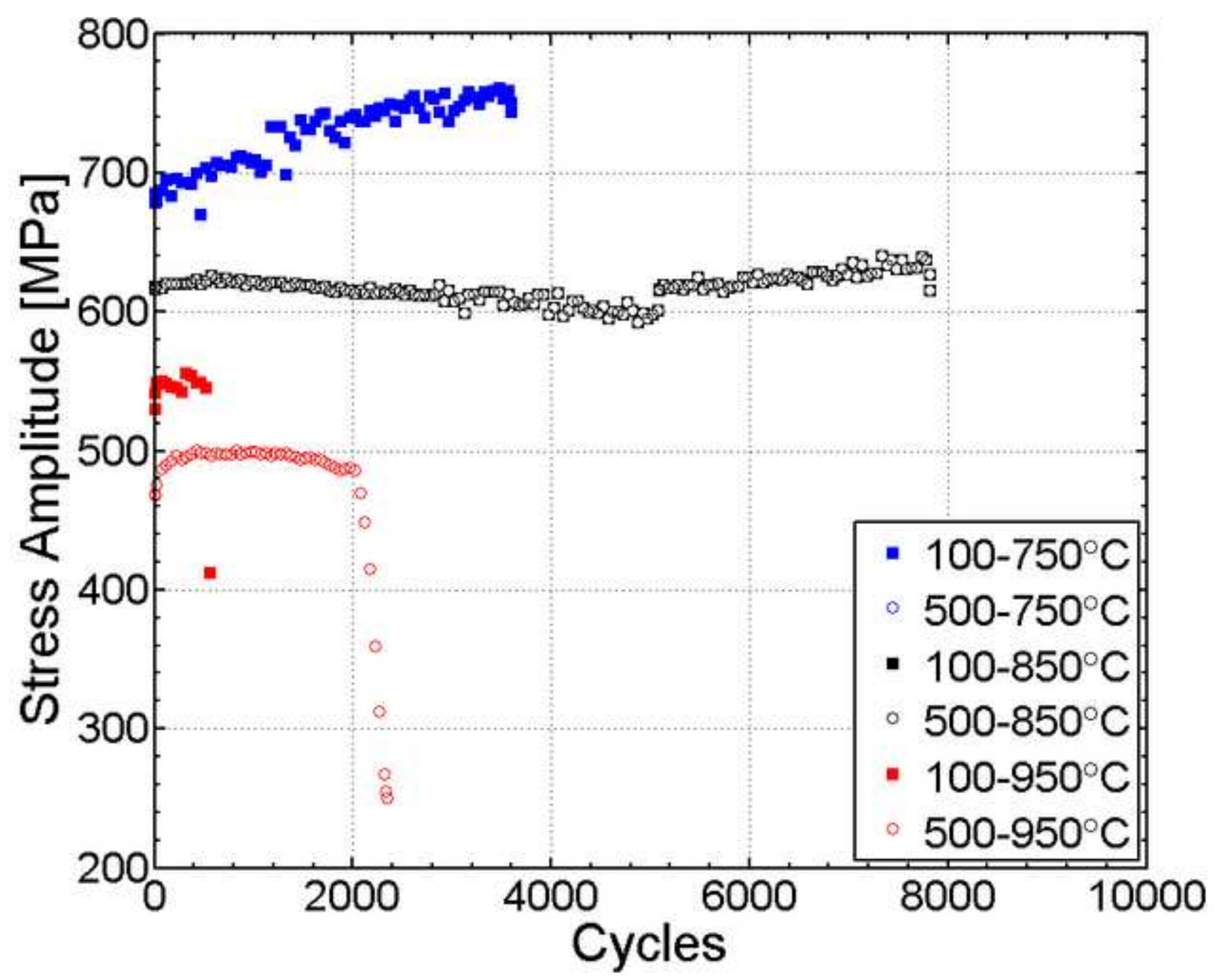




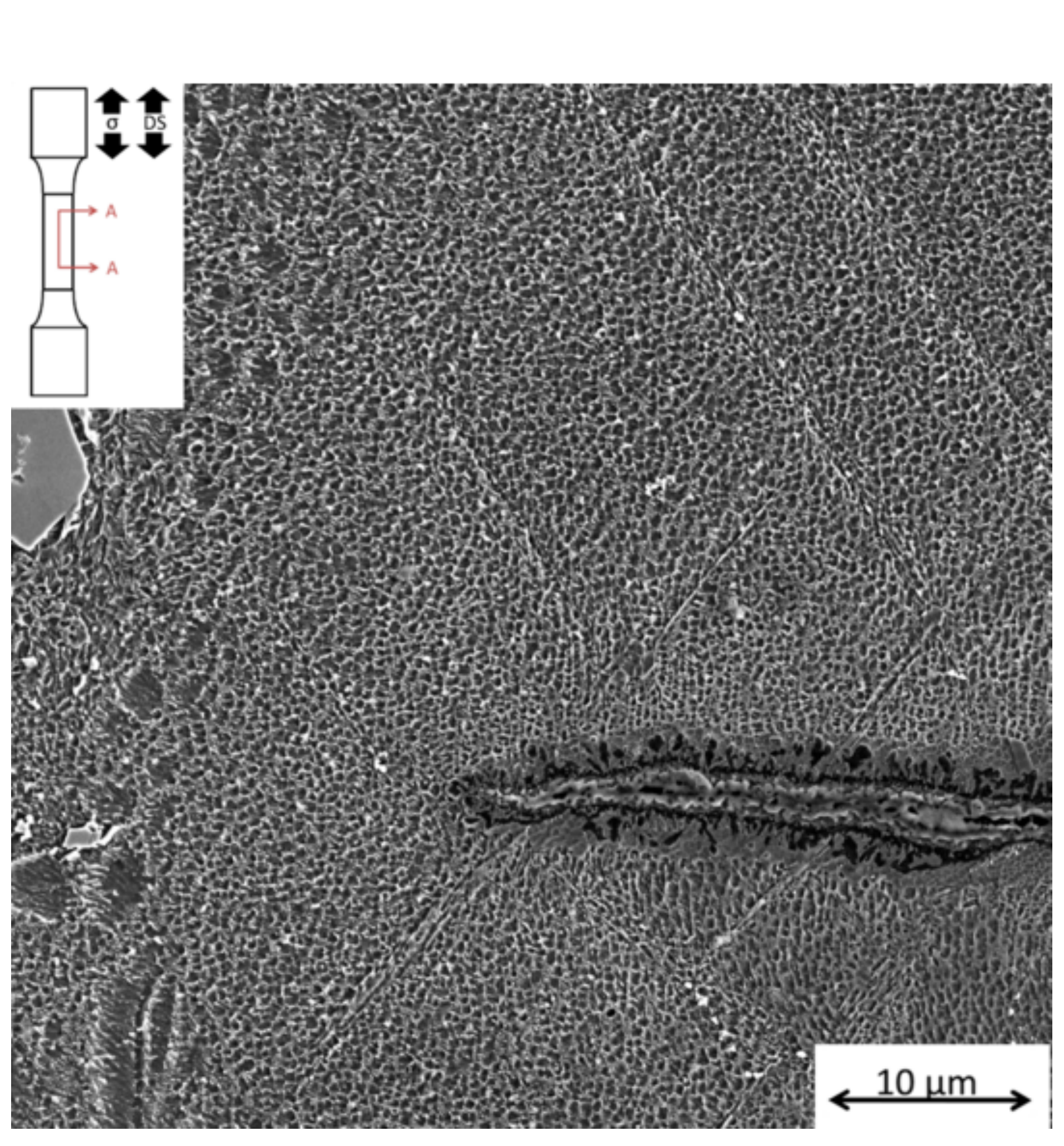
$1.5 \%$. 3.

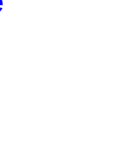

(1)

.

.

.

.
.

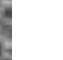
. .

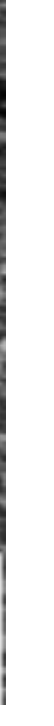


Figure 7

Click here to download high resolution image

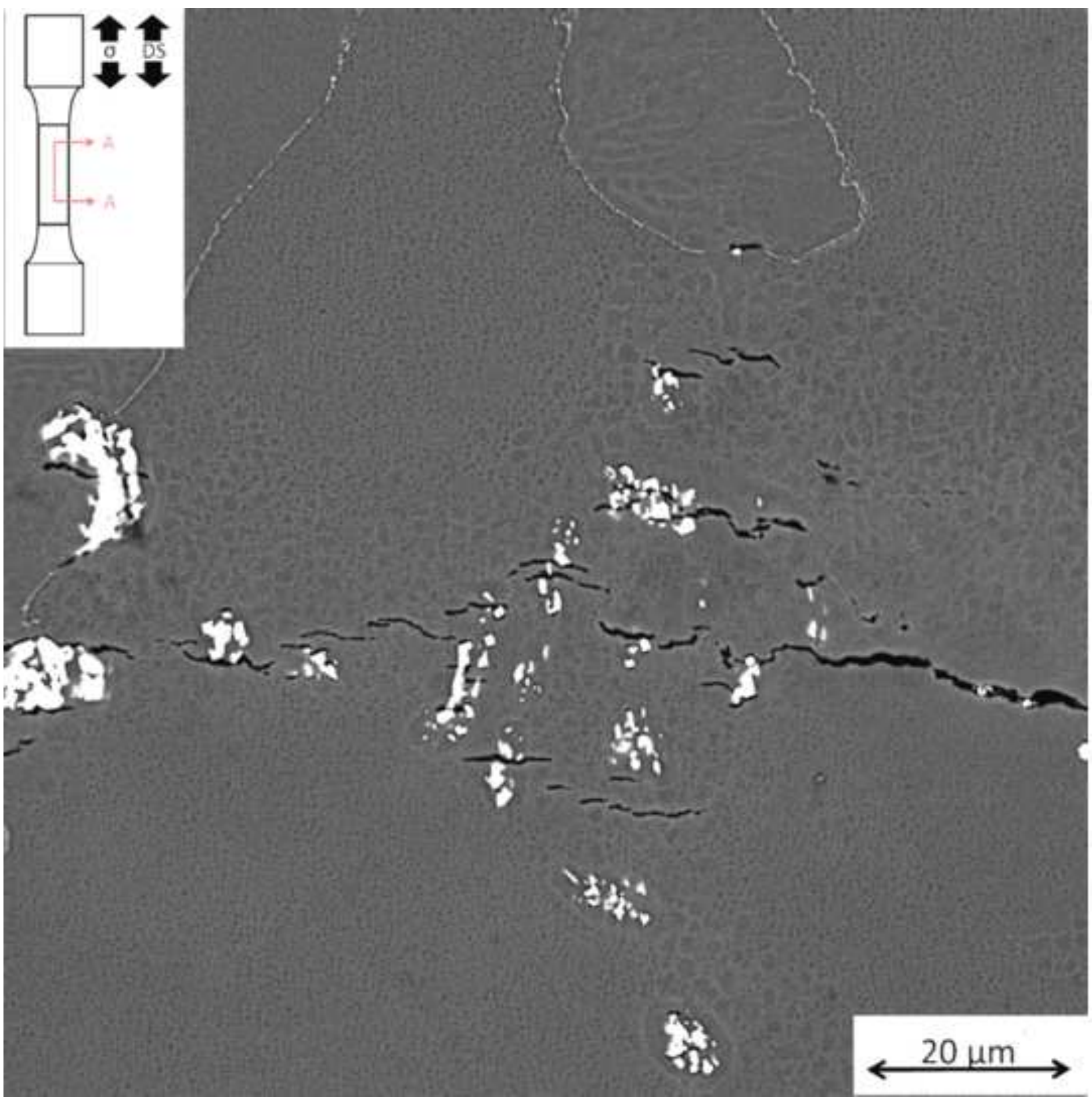


Figure 8a

Click here to download high resolution image

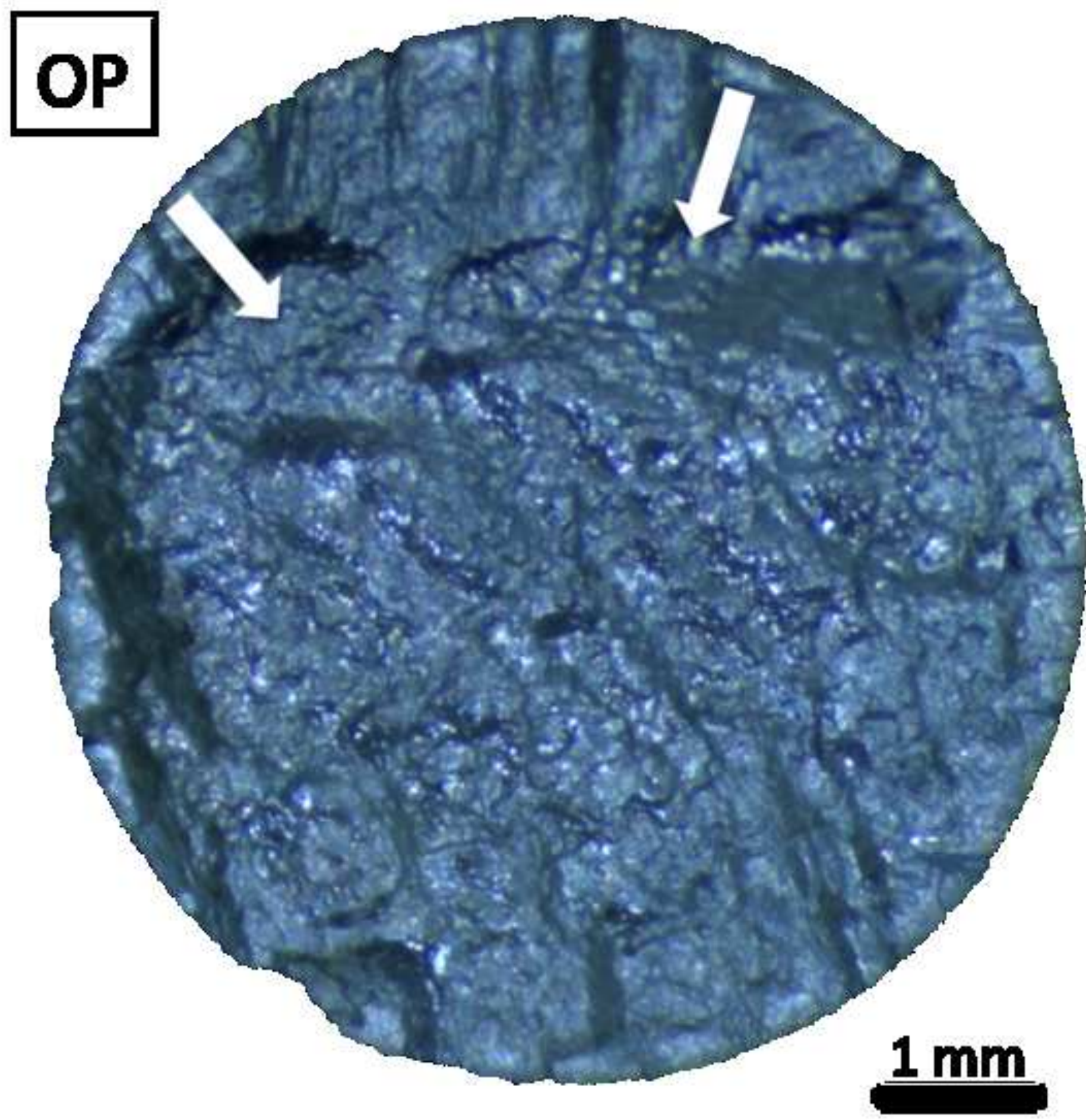

$1 \mathrm{~mm}$ 
Figure 8b

Click here to download high resolution image

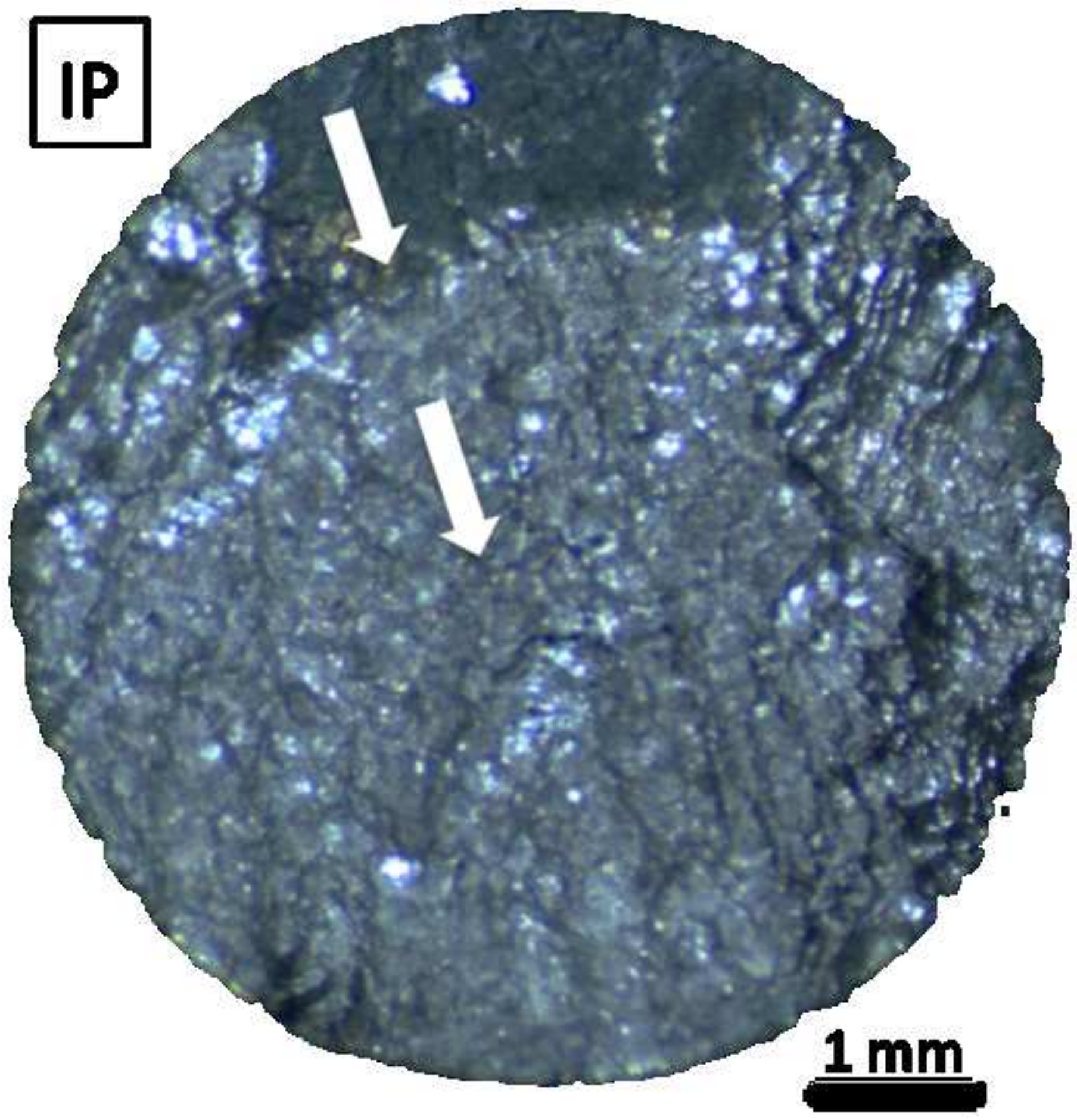


Click here to download high resolution image

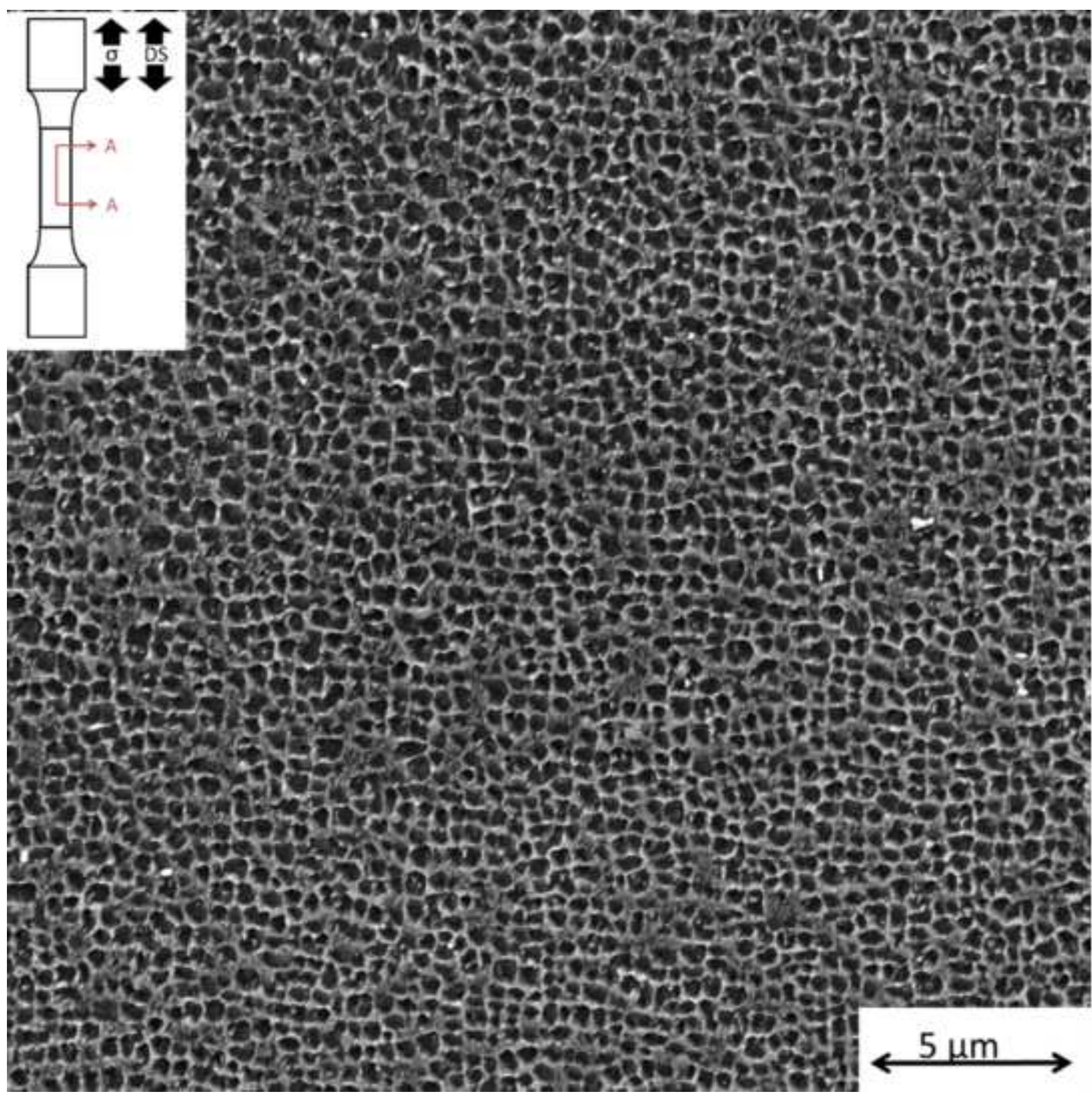

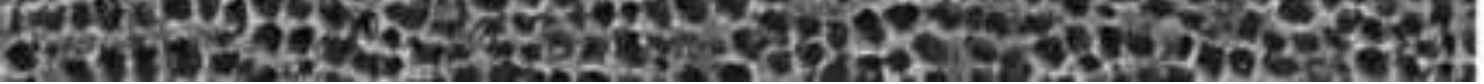

$5 \mu \mathrm{m}$ Fis. Fis. Fis. Fis. Fis. Fis. Fis. Fis. (n) .

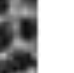

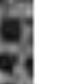

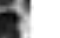
, .

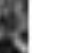

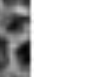

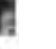

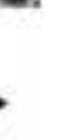

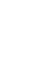

.

. 
Click here to download high resolution image

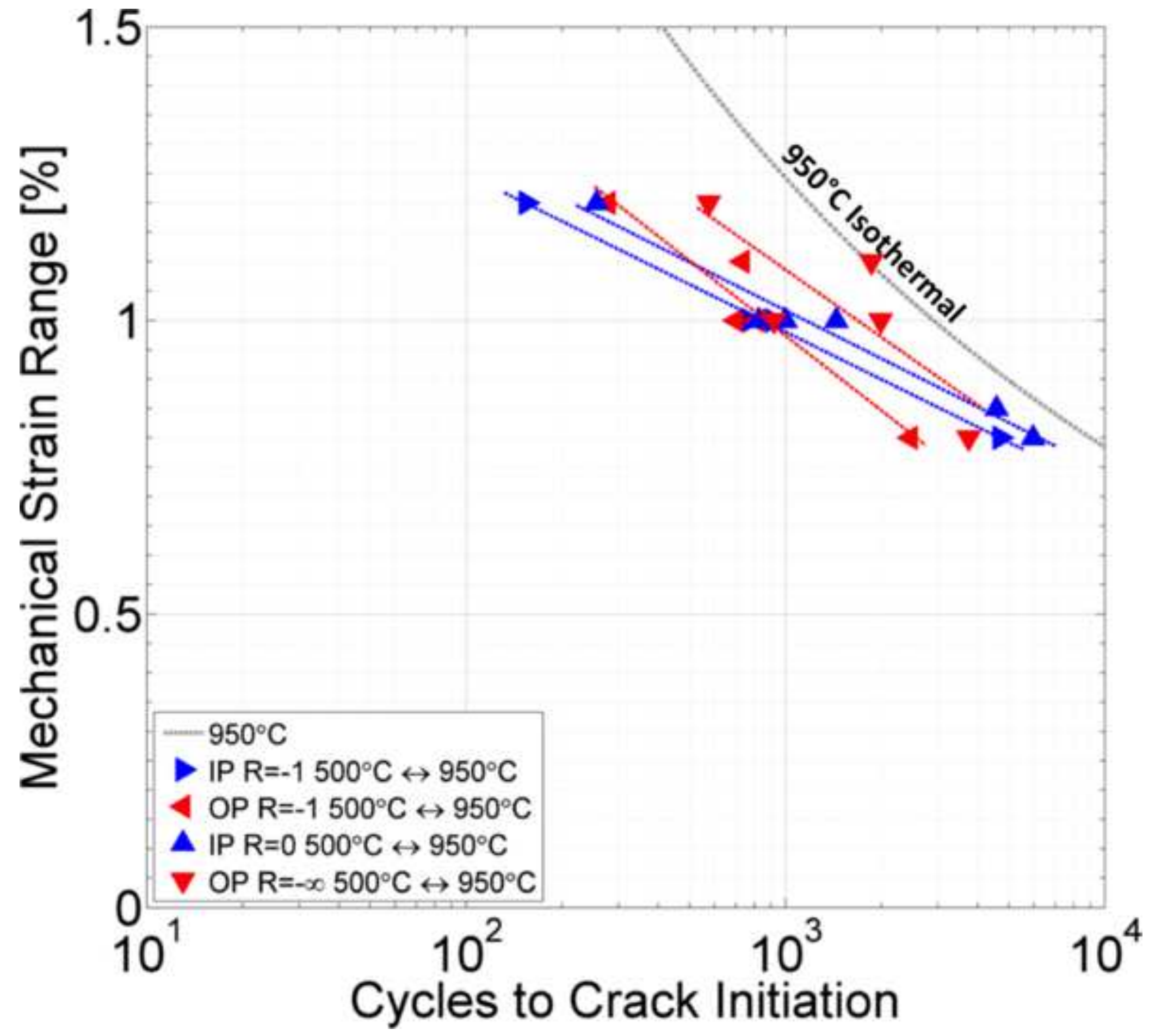




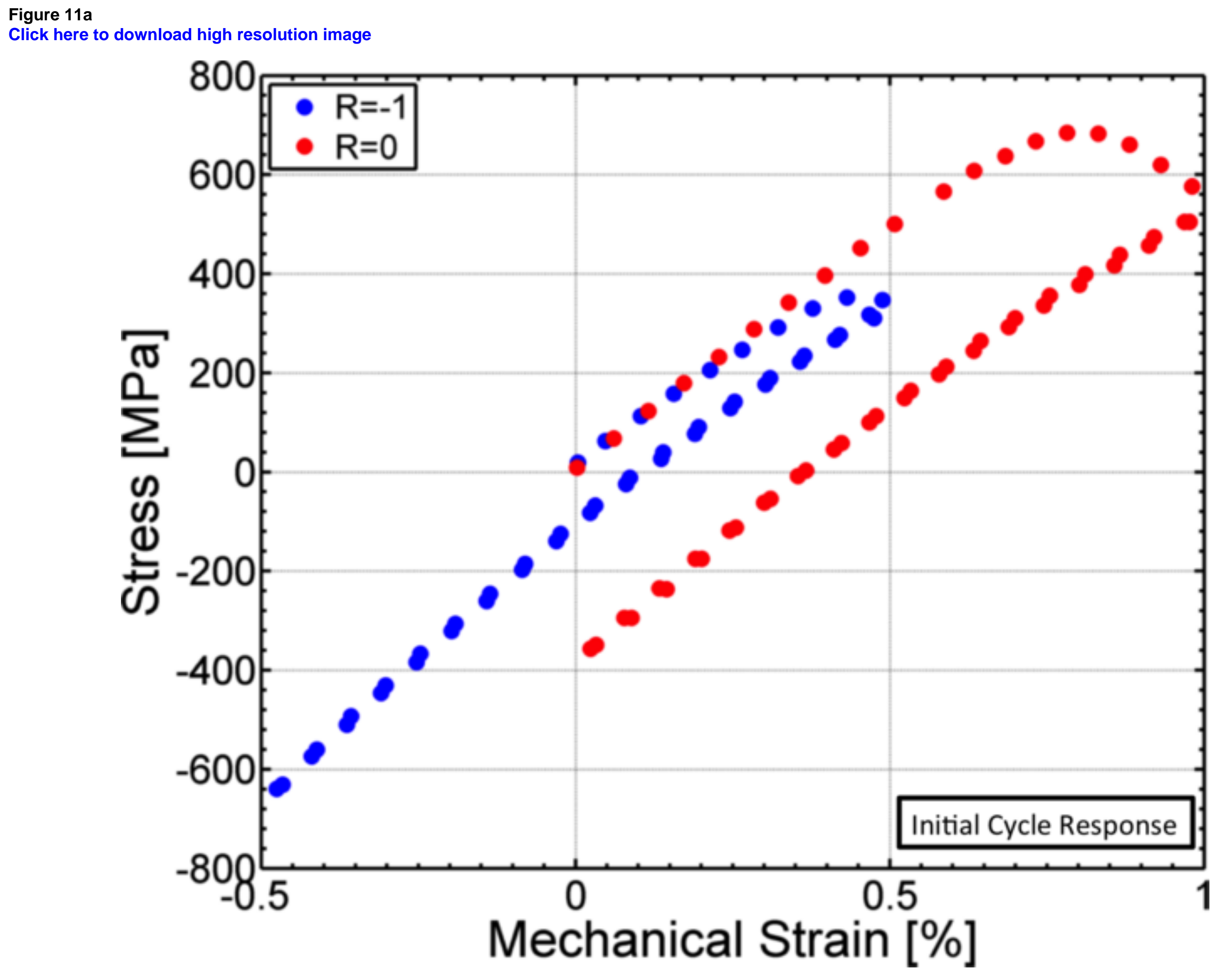


Figure 11c
Click here to download high resolution image

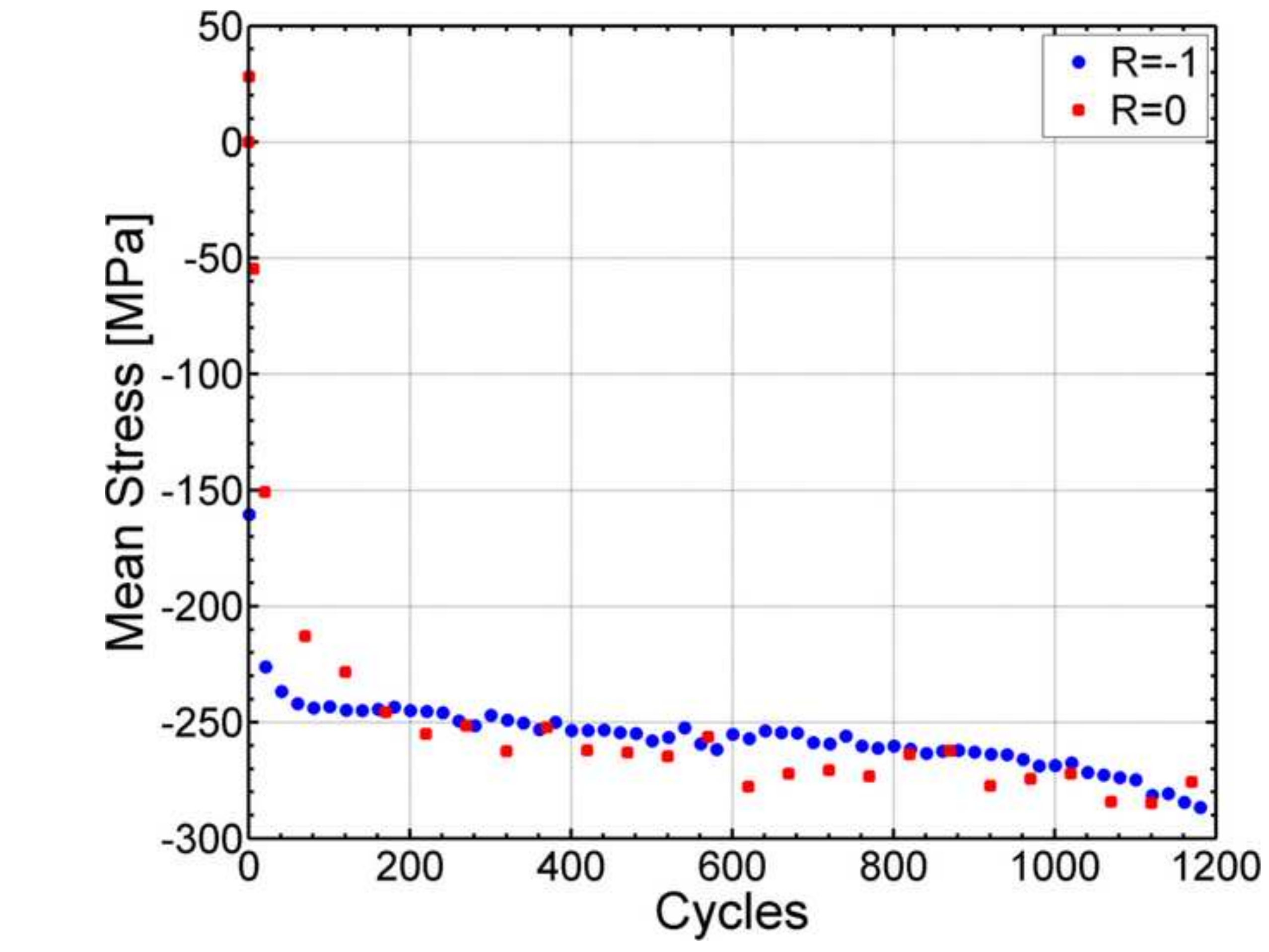


Click here to download high resolution image

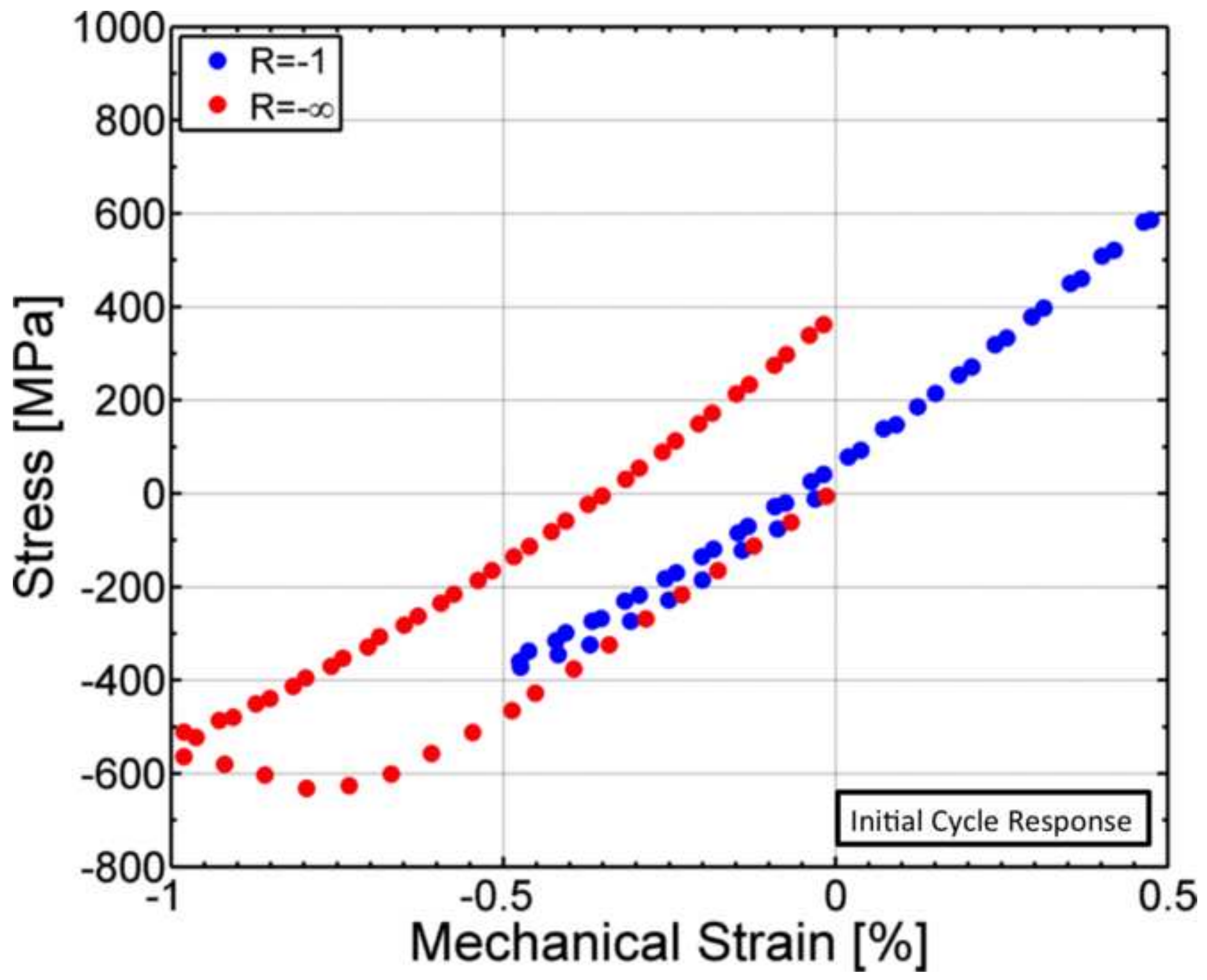


Figure $12 b$
Click here to download high resolution image

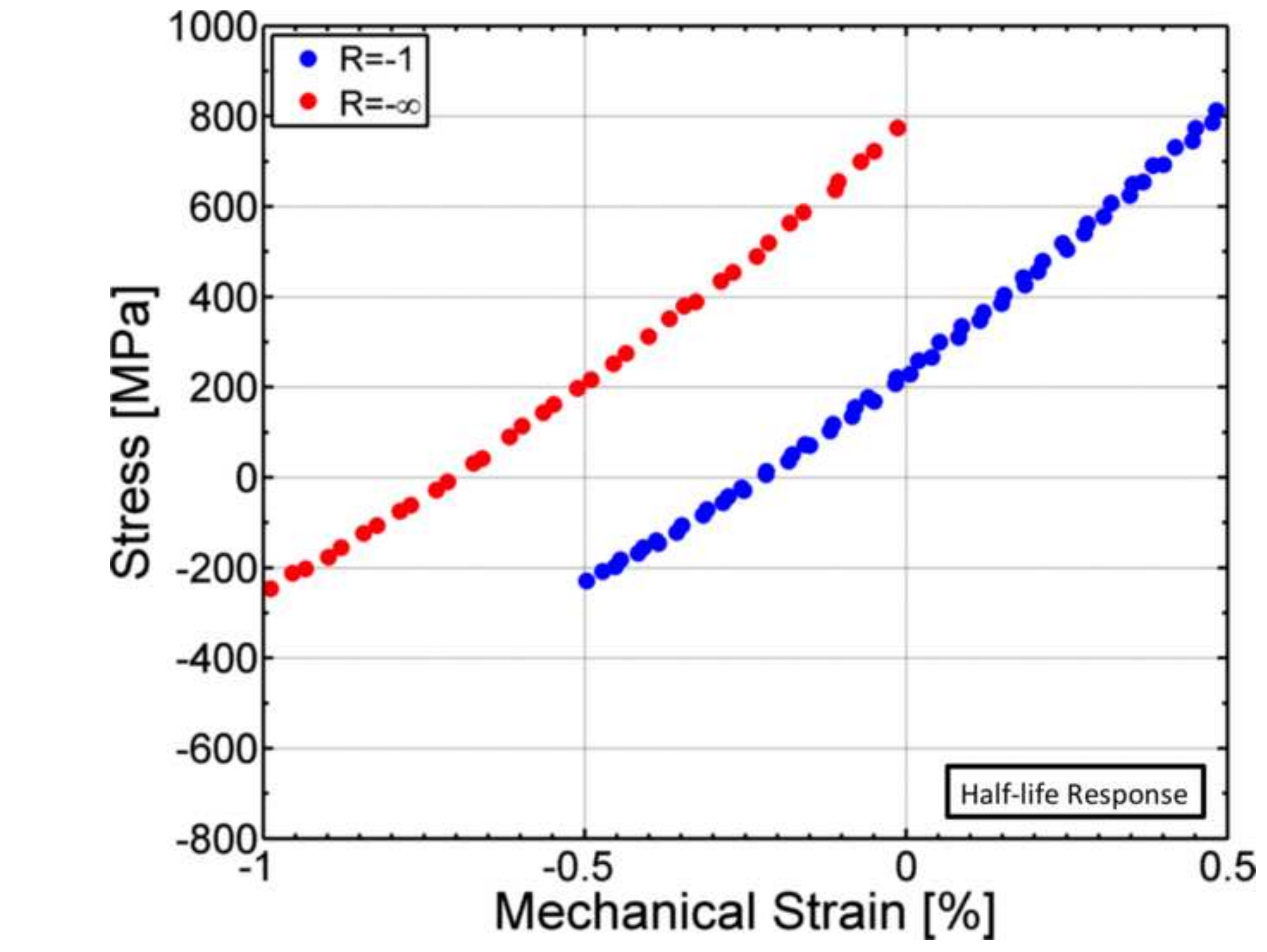


Click here to download high resolution image

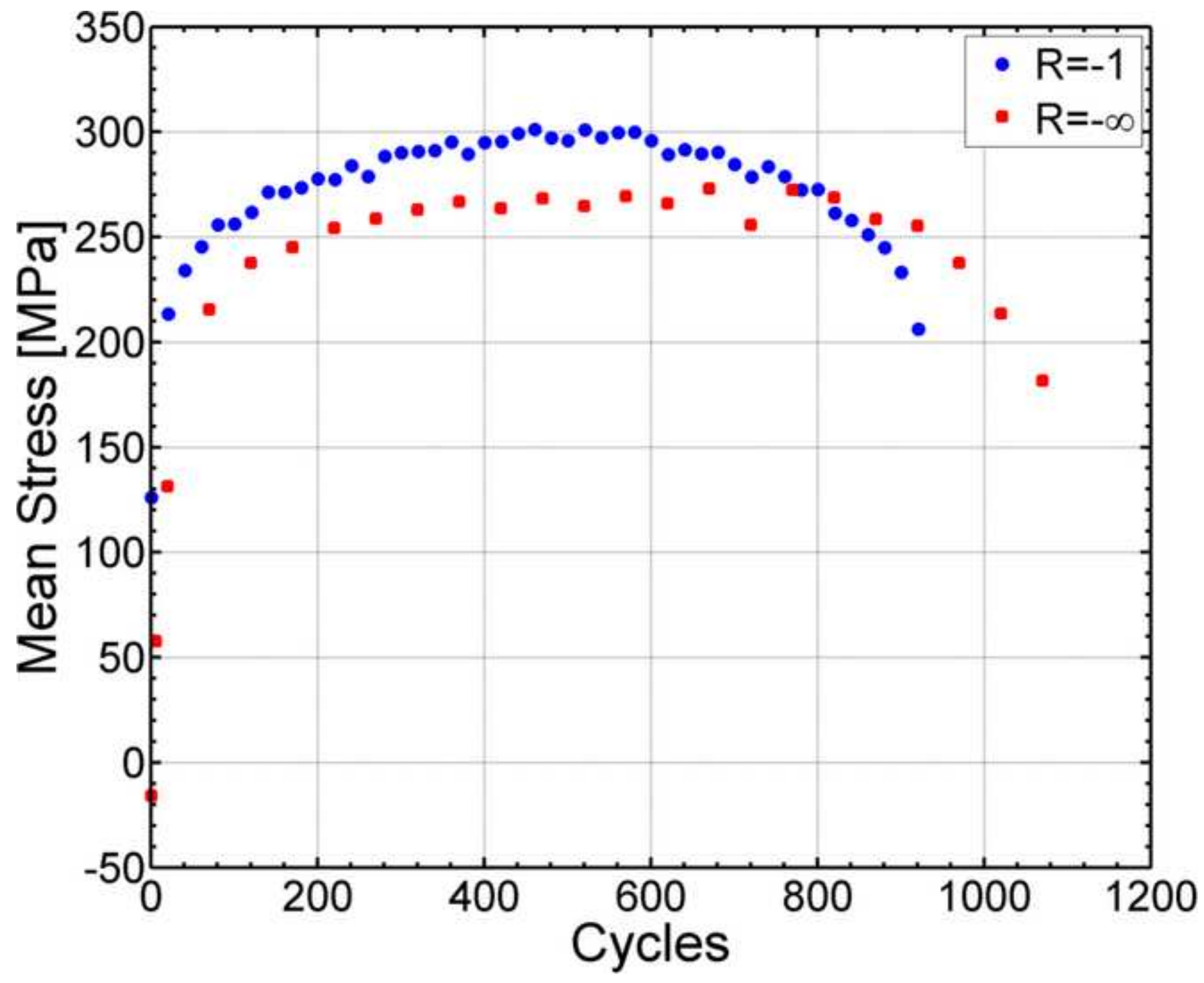


Click here to download high resolution image
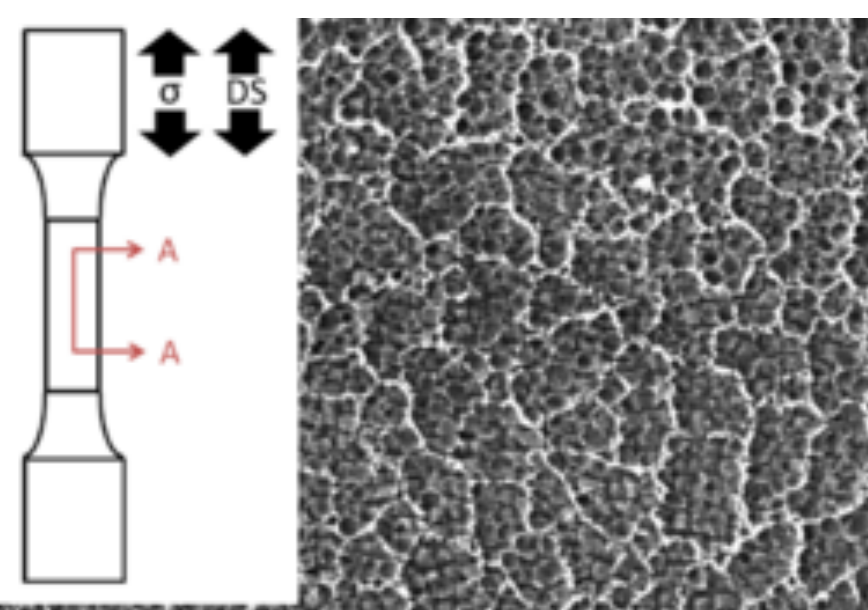

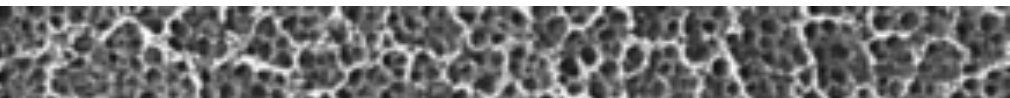

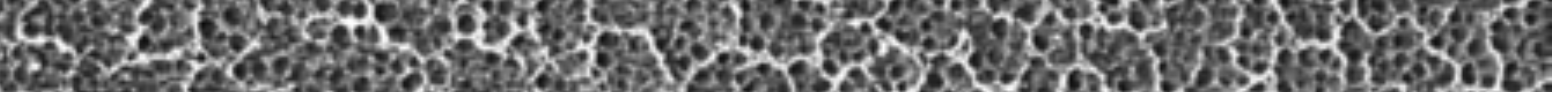

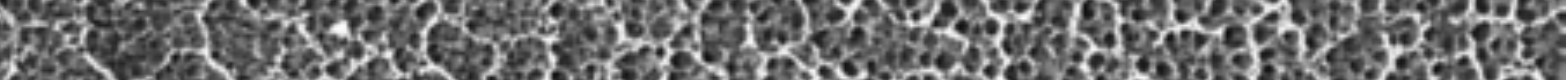
Y.8.

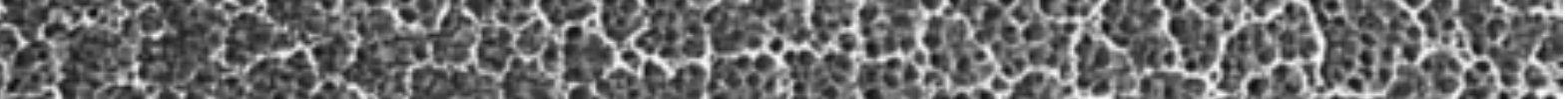

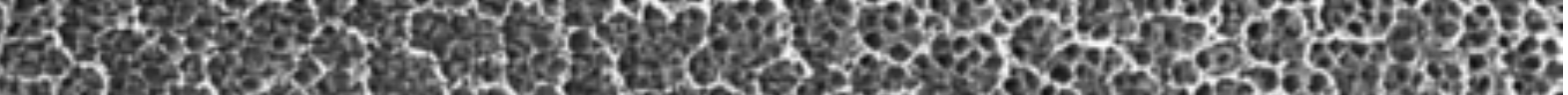

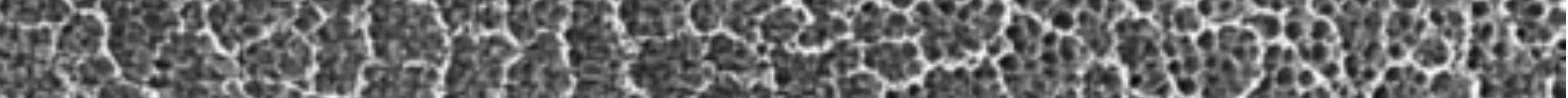
W 3.0 s.

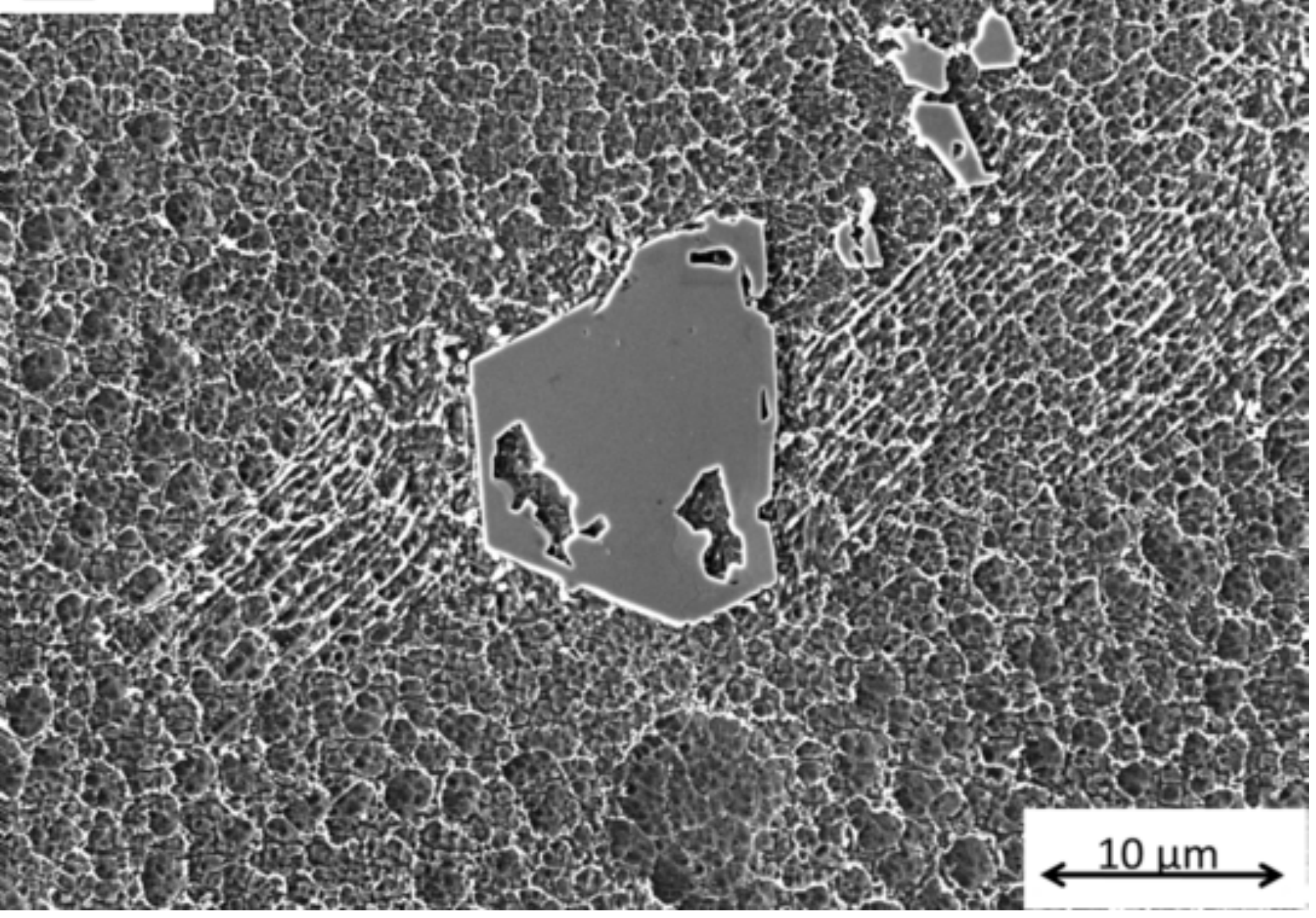




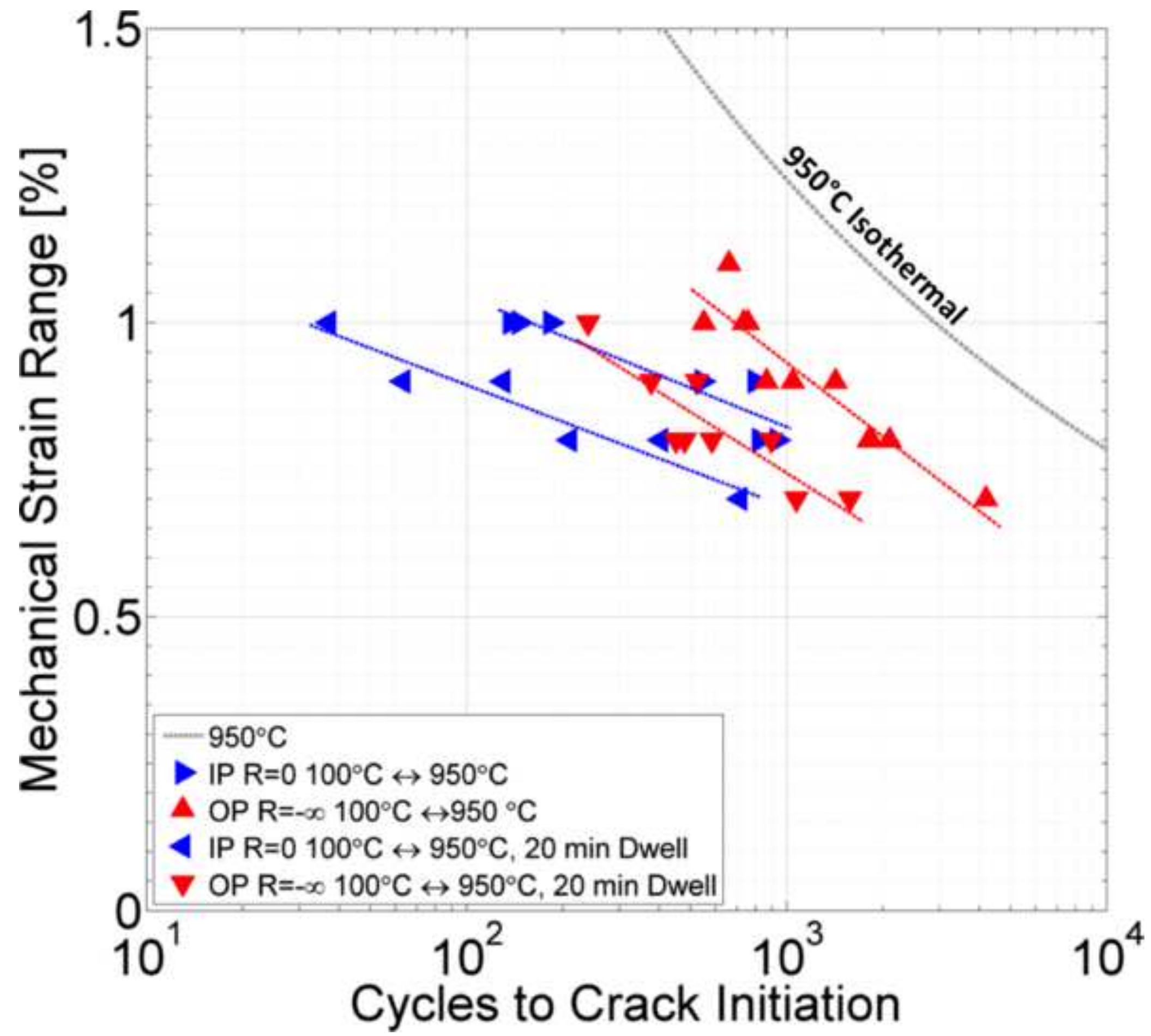




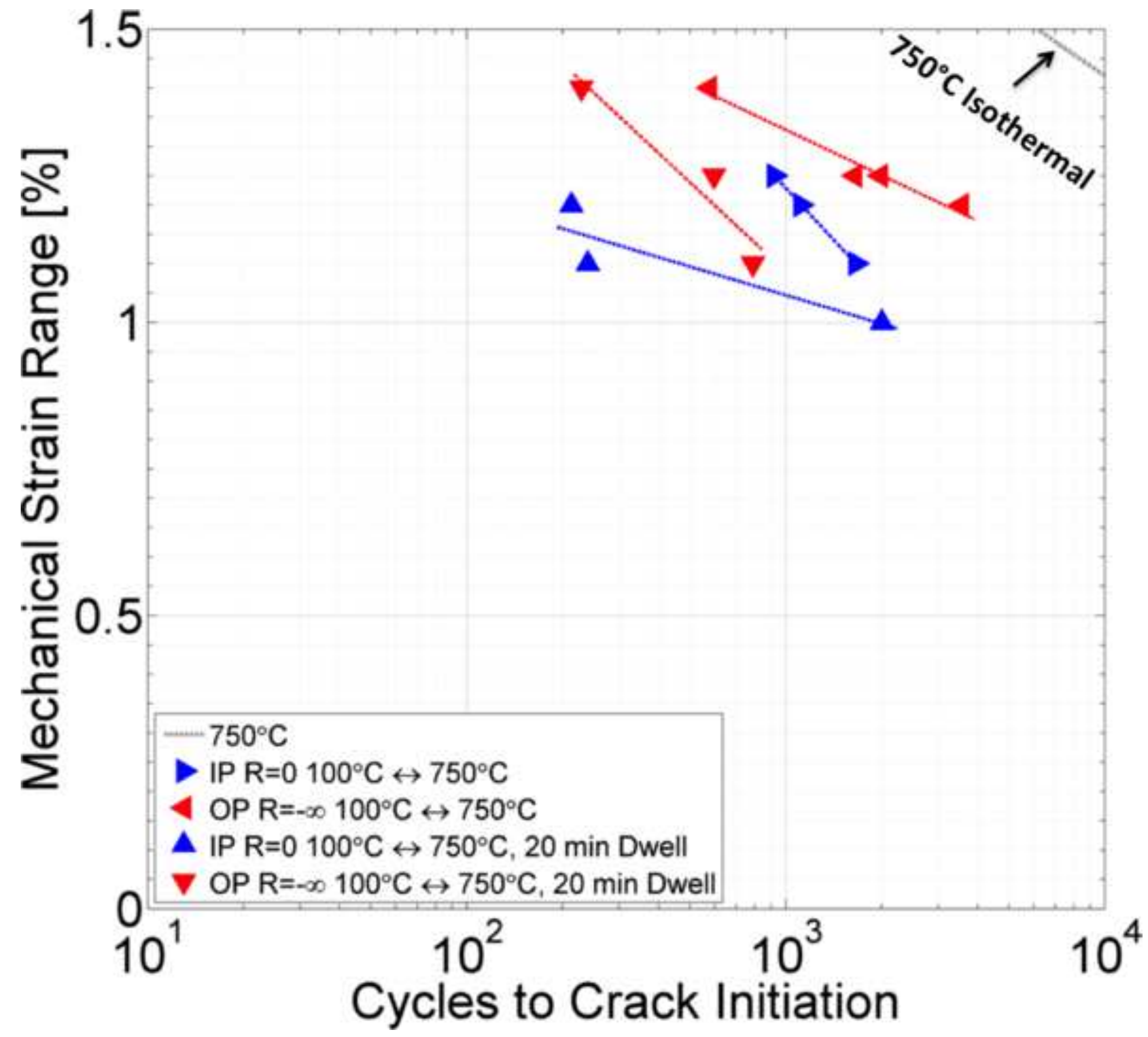




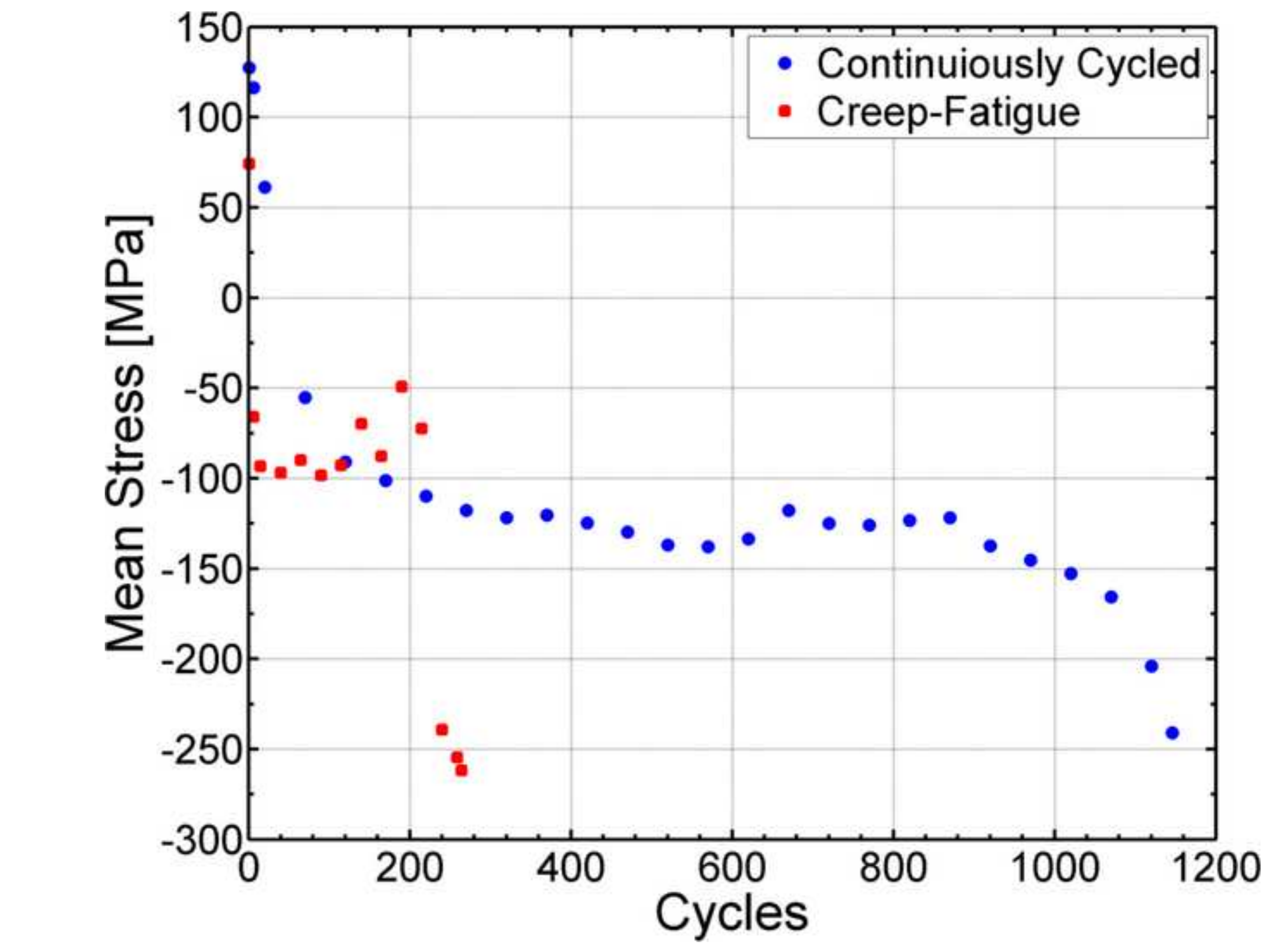

o download high resolution image 


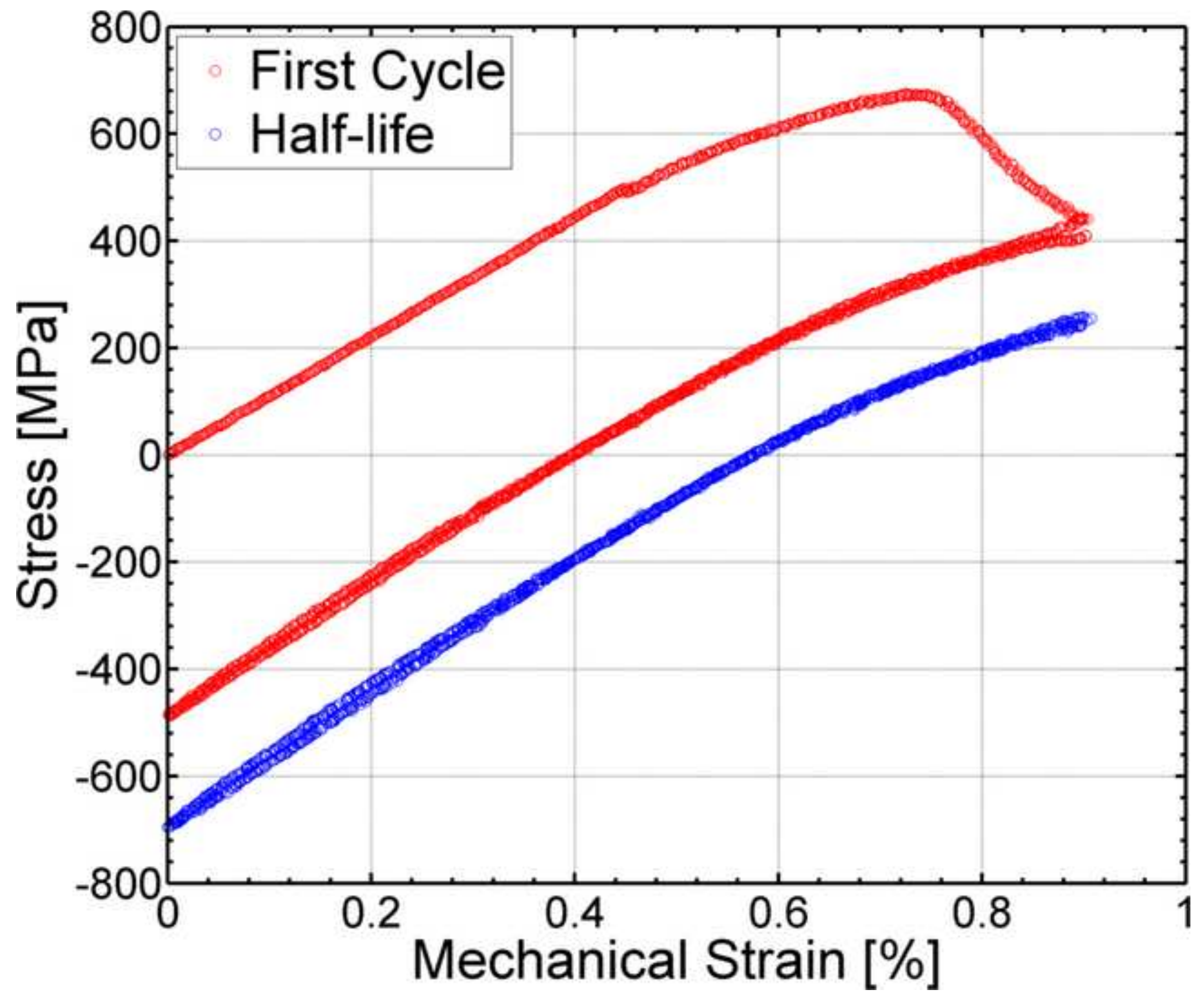




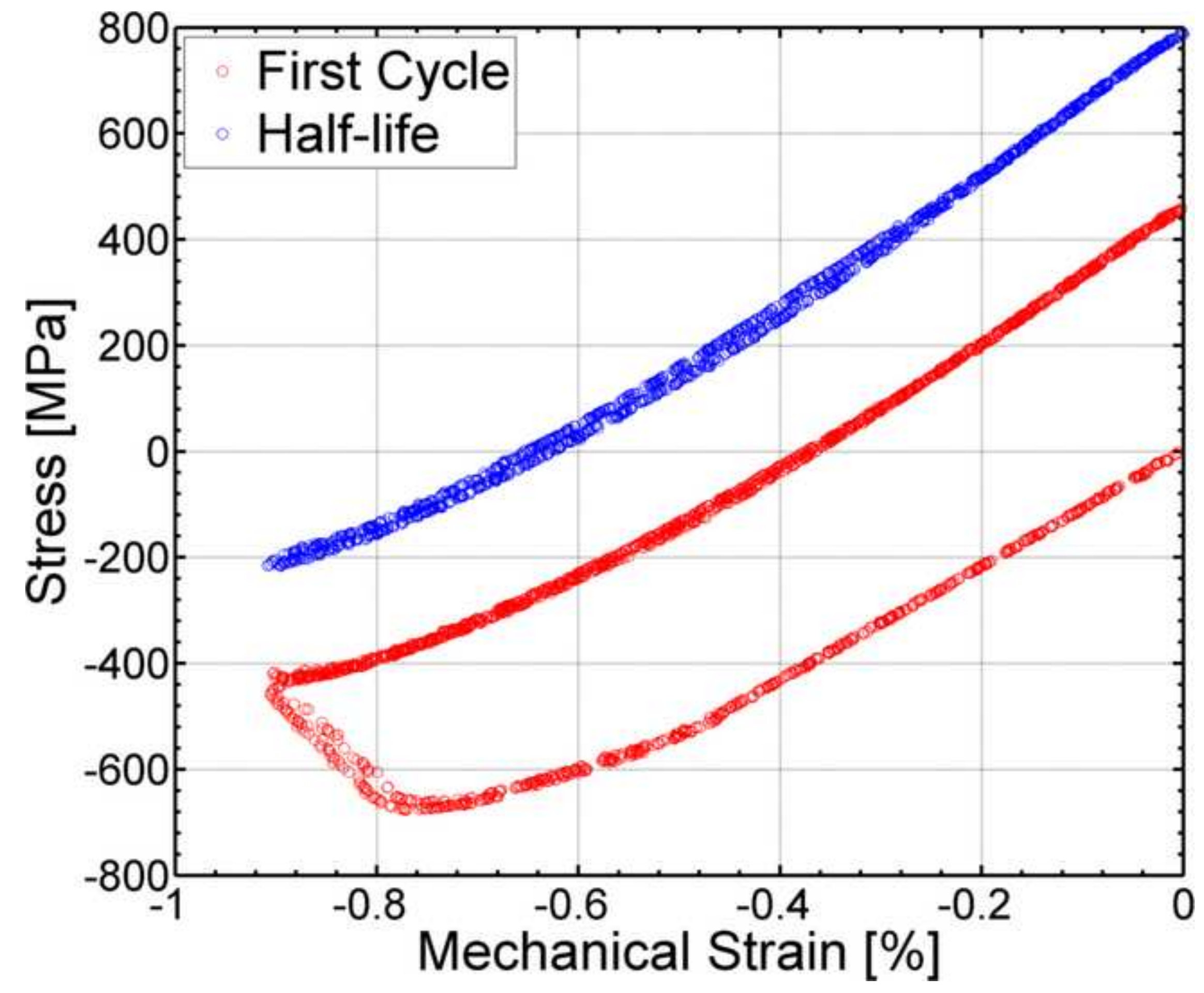




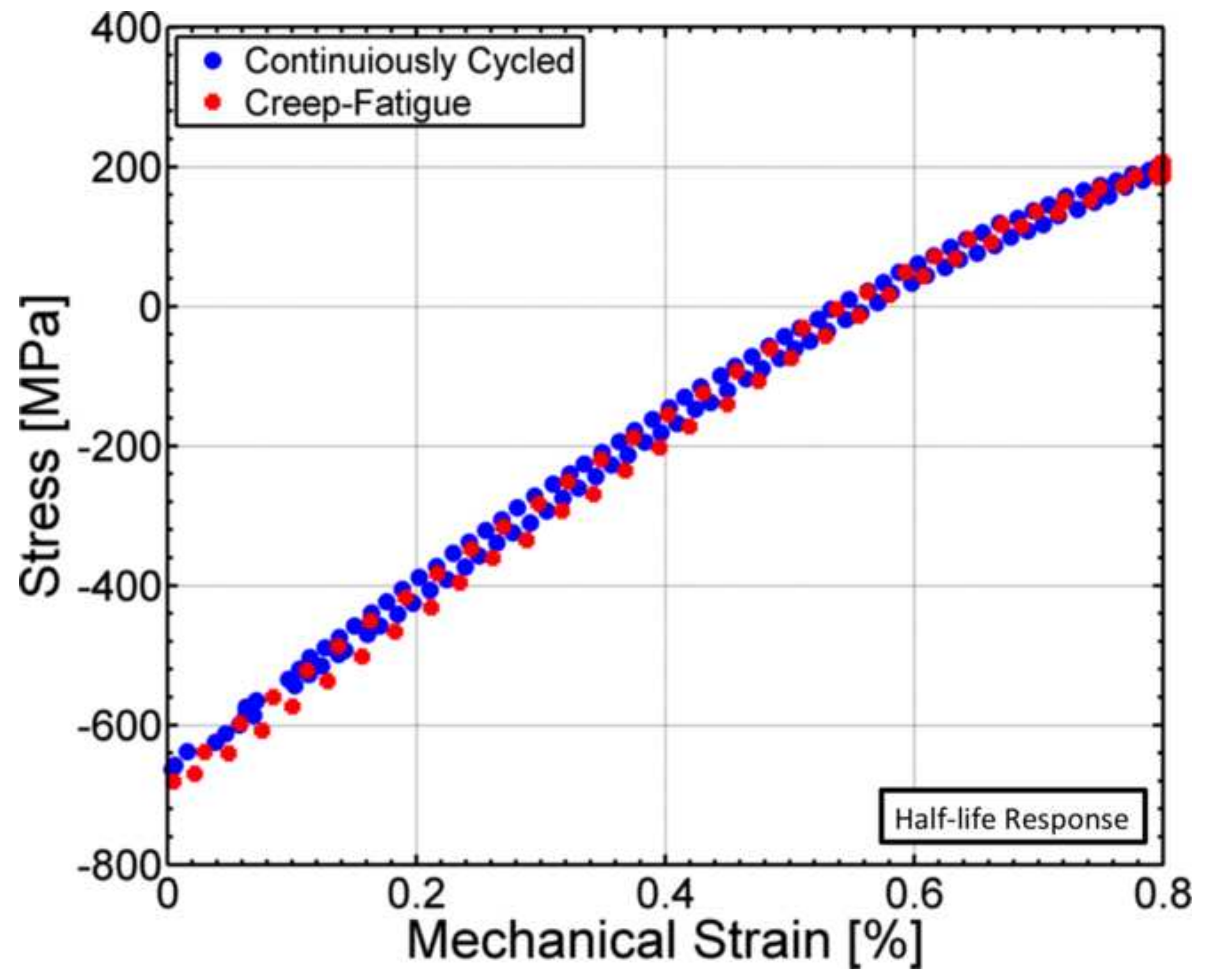




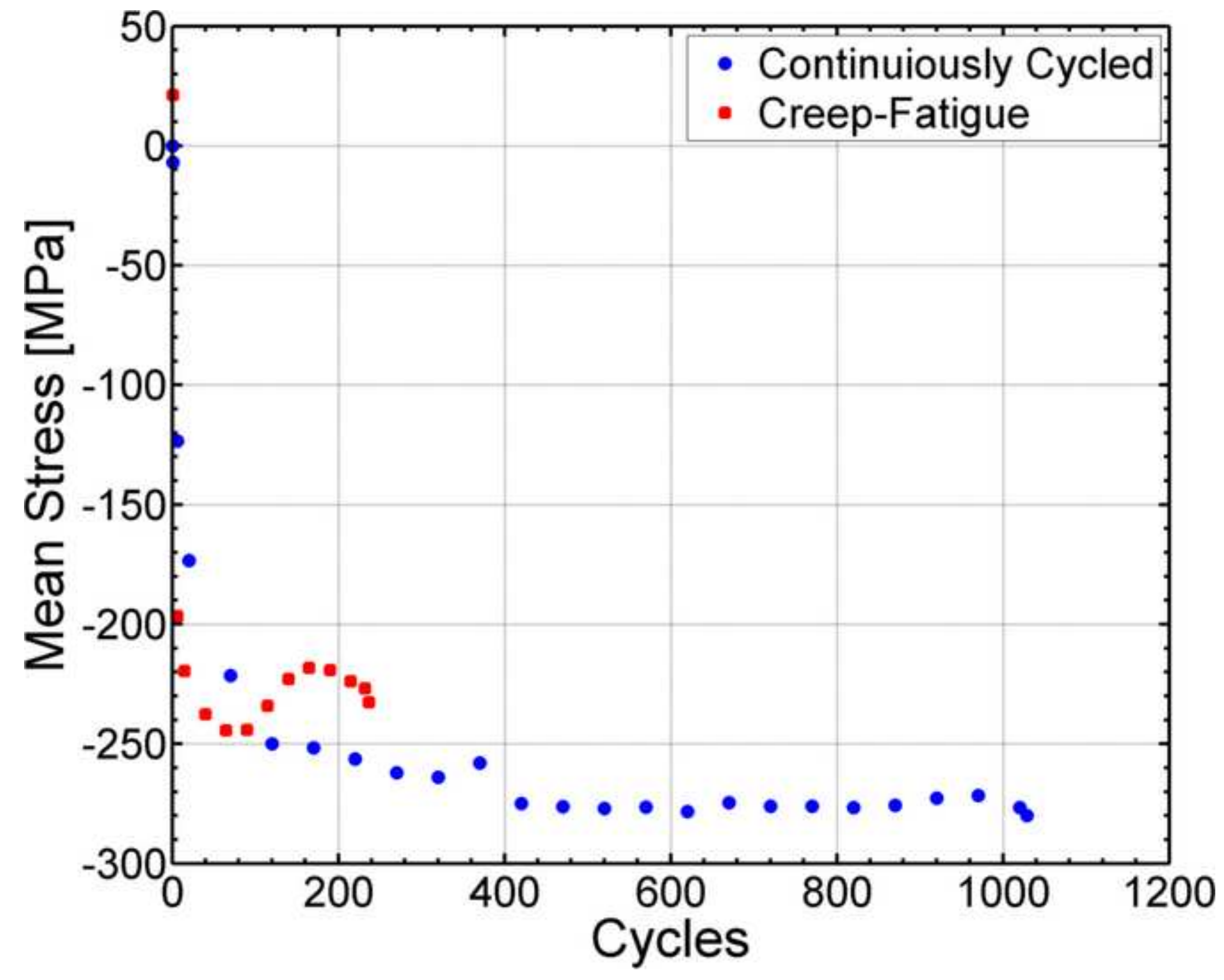




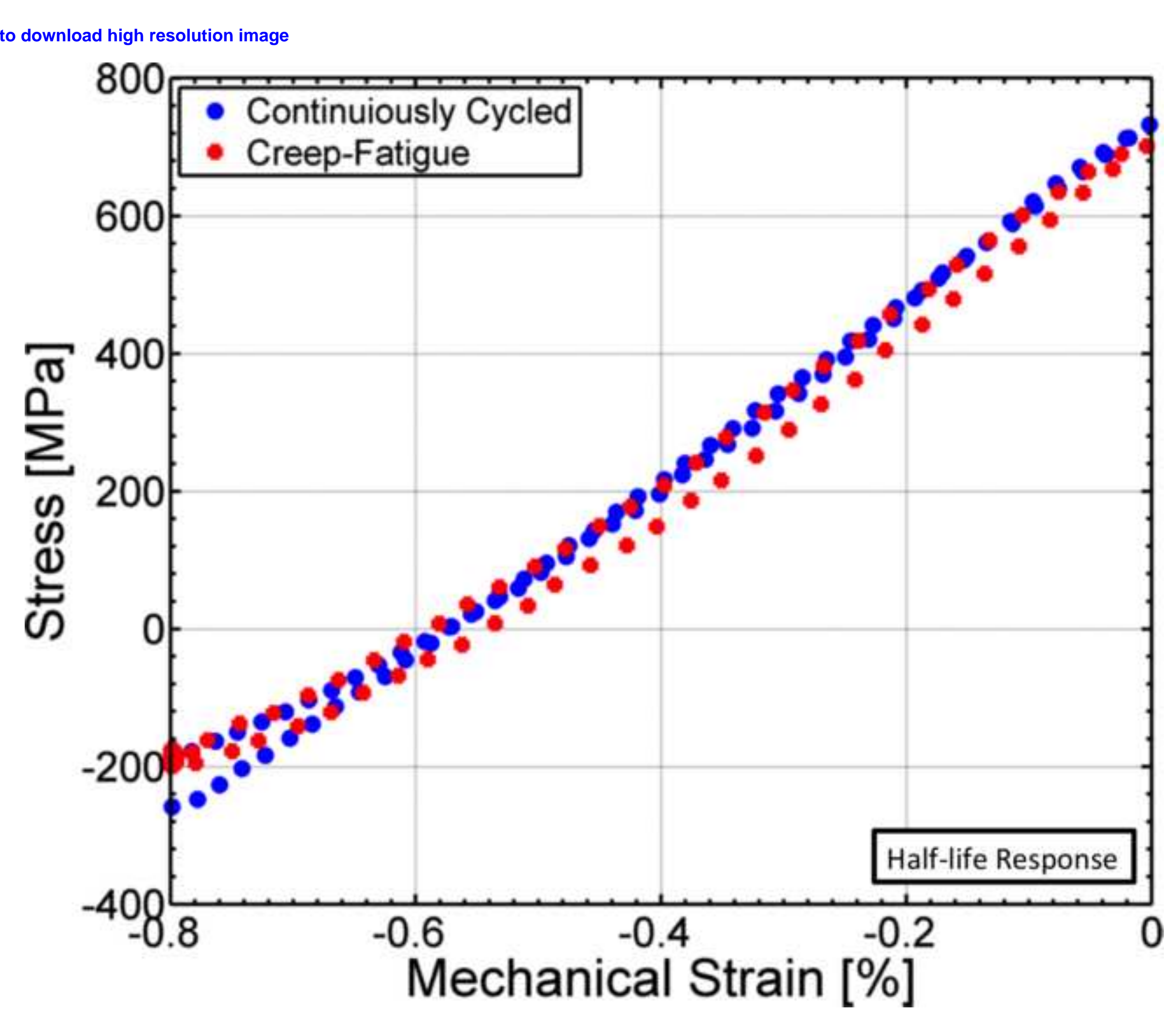




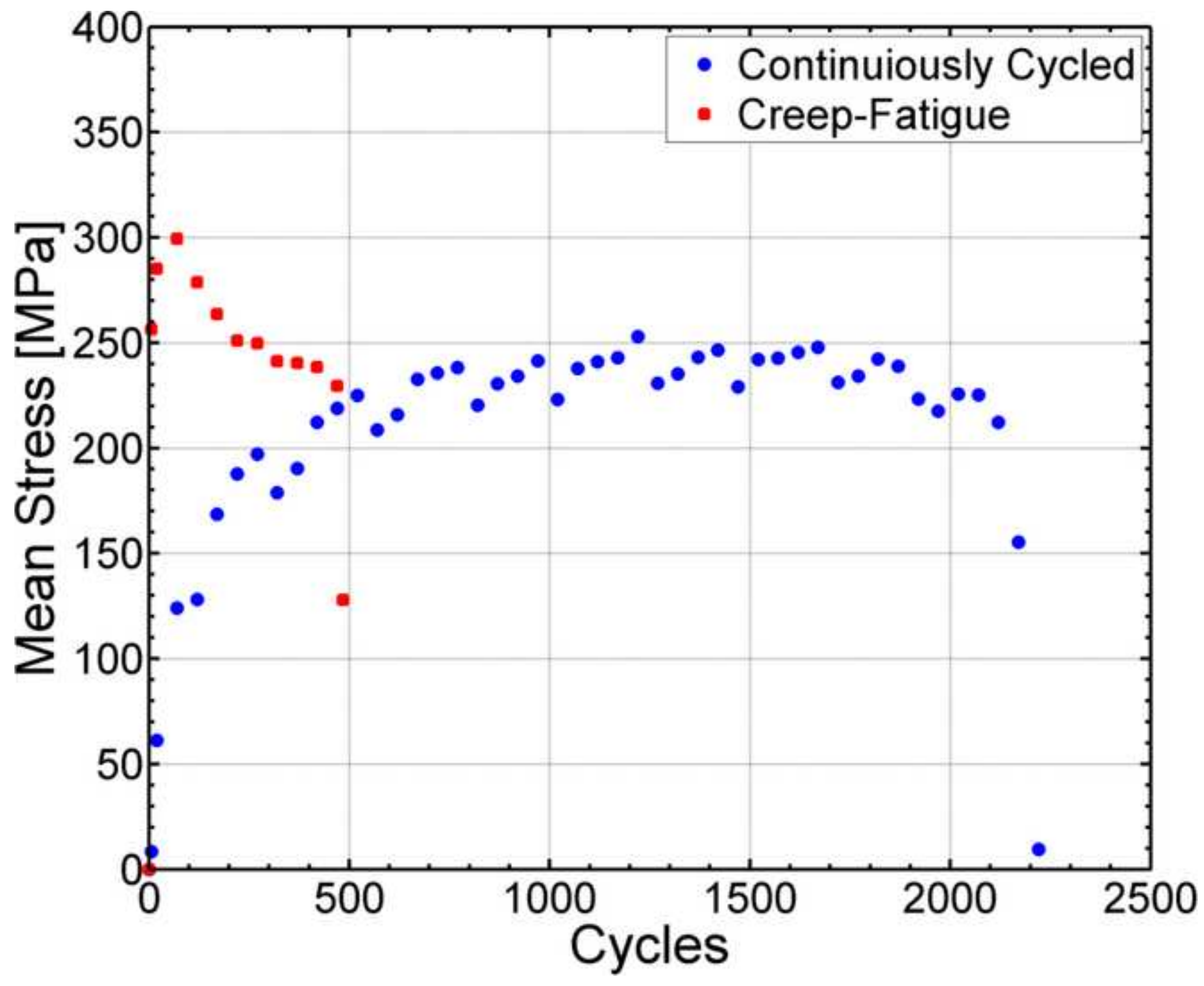


Click here to download high resolution image

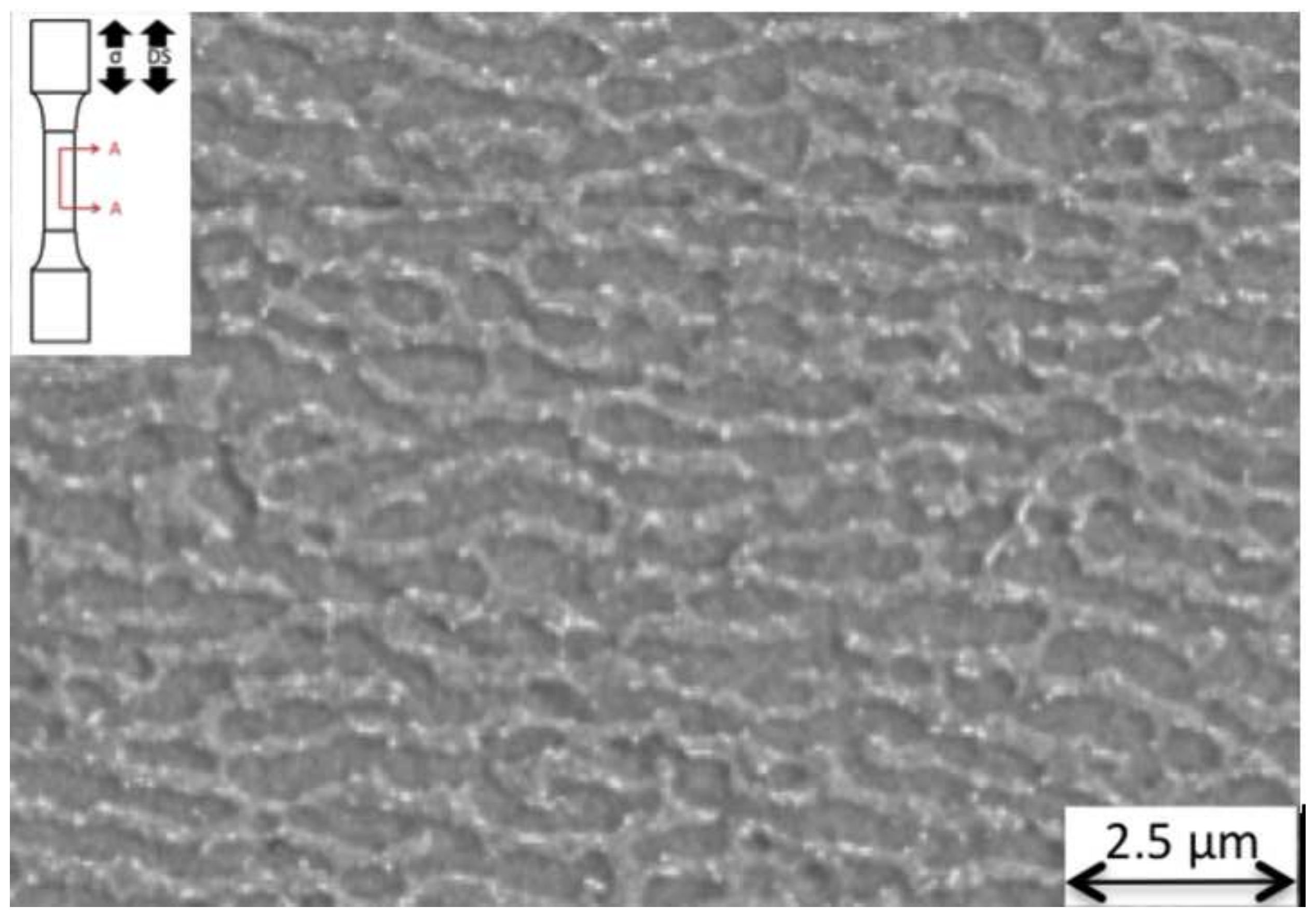


Click here to download high resolution image

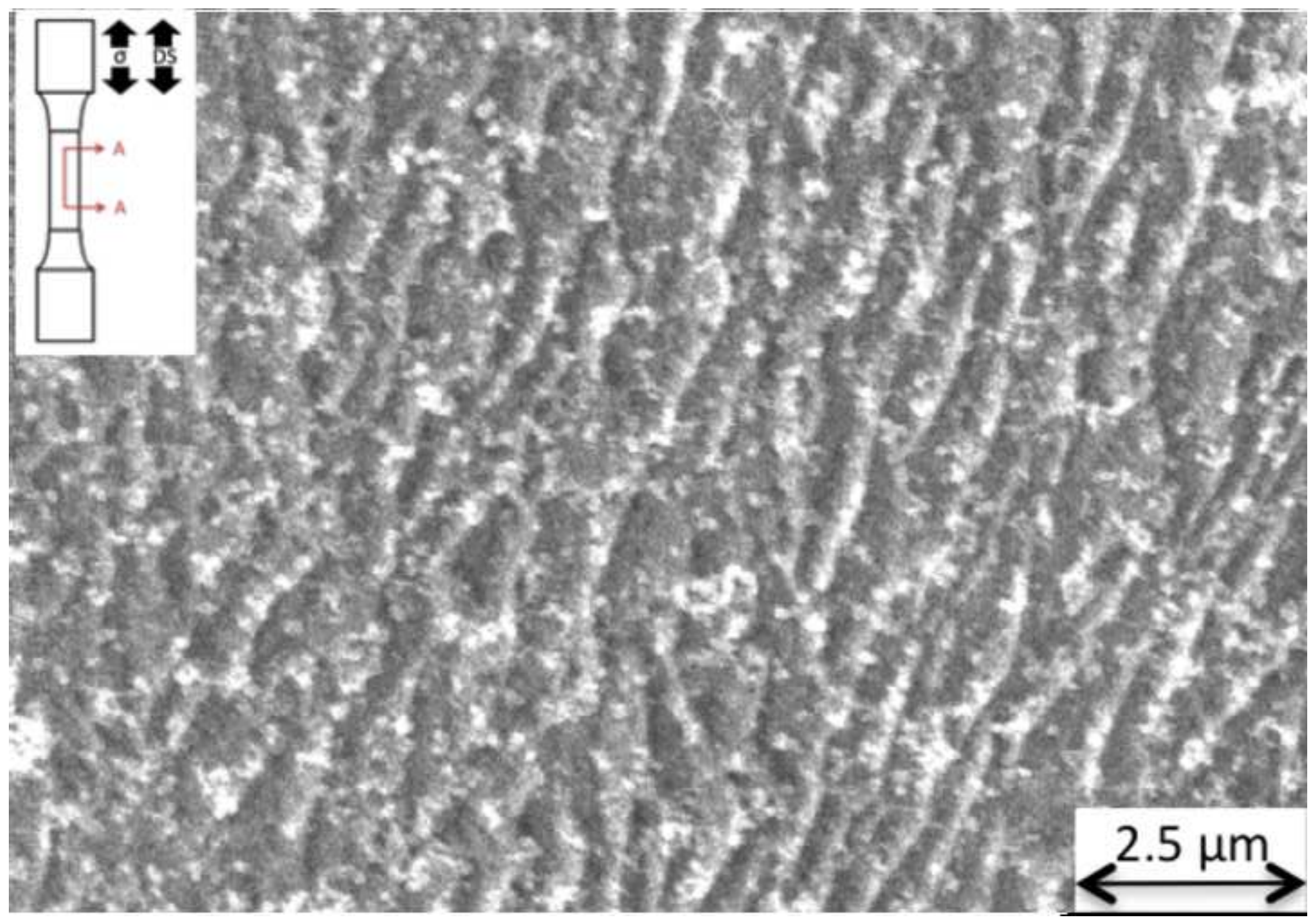




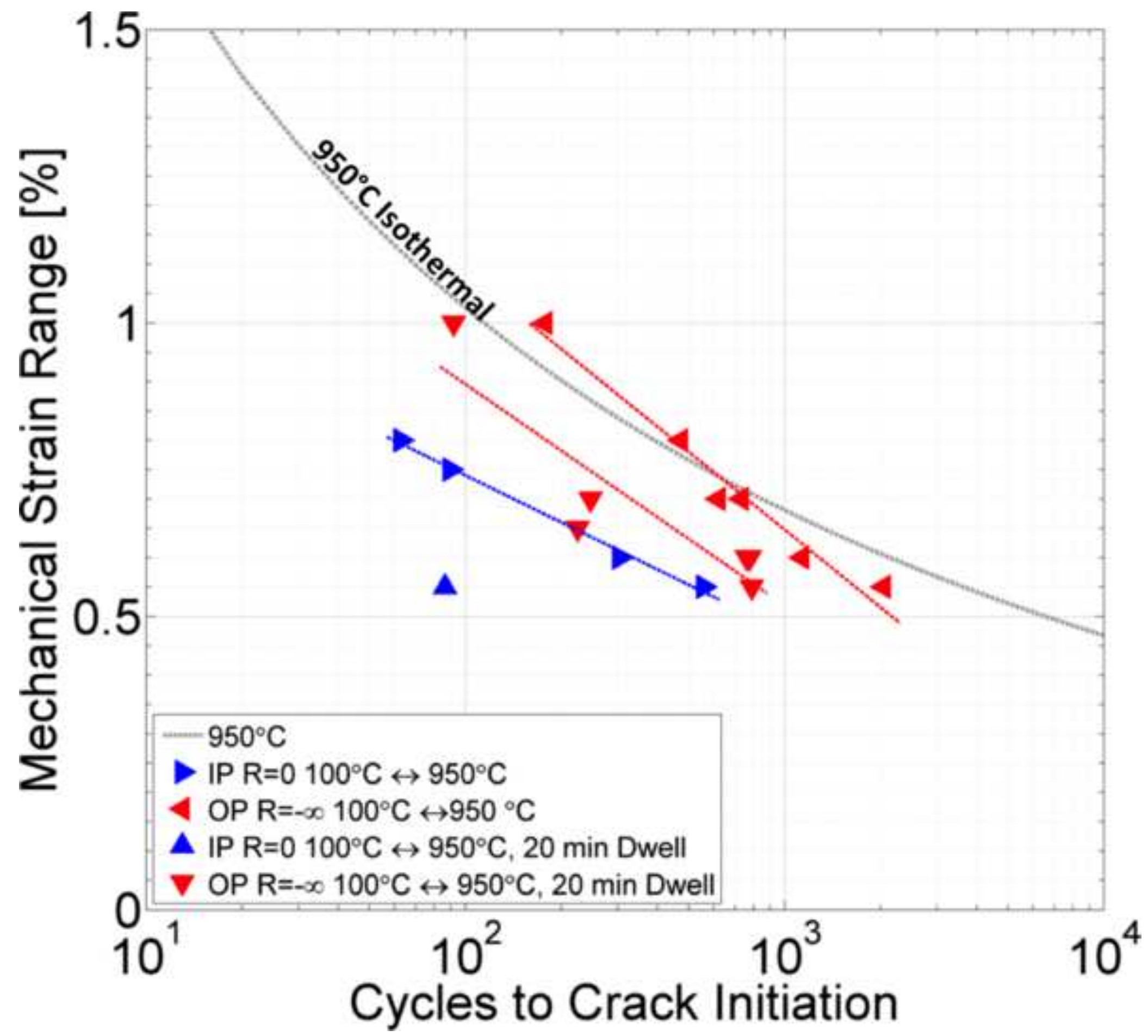




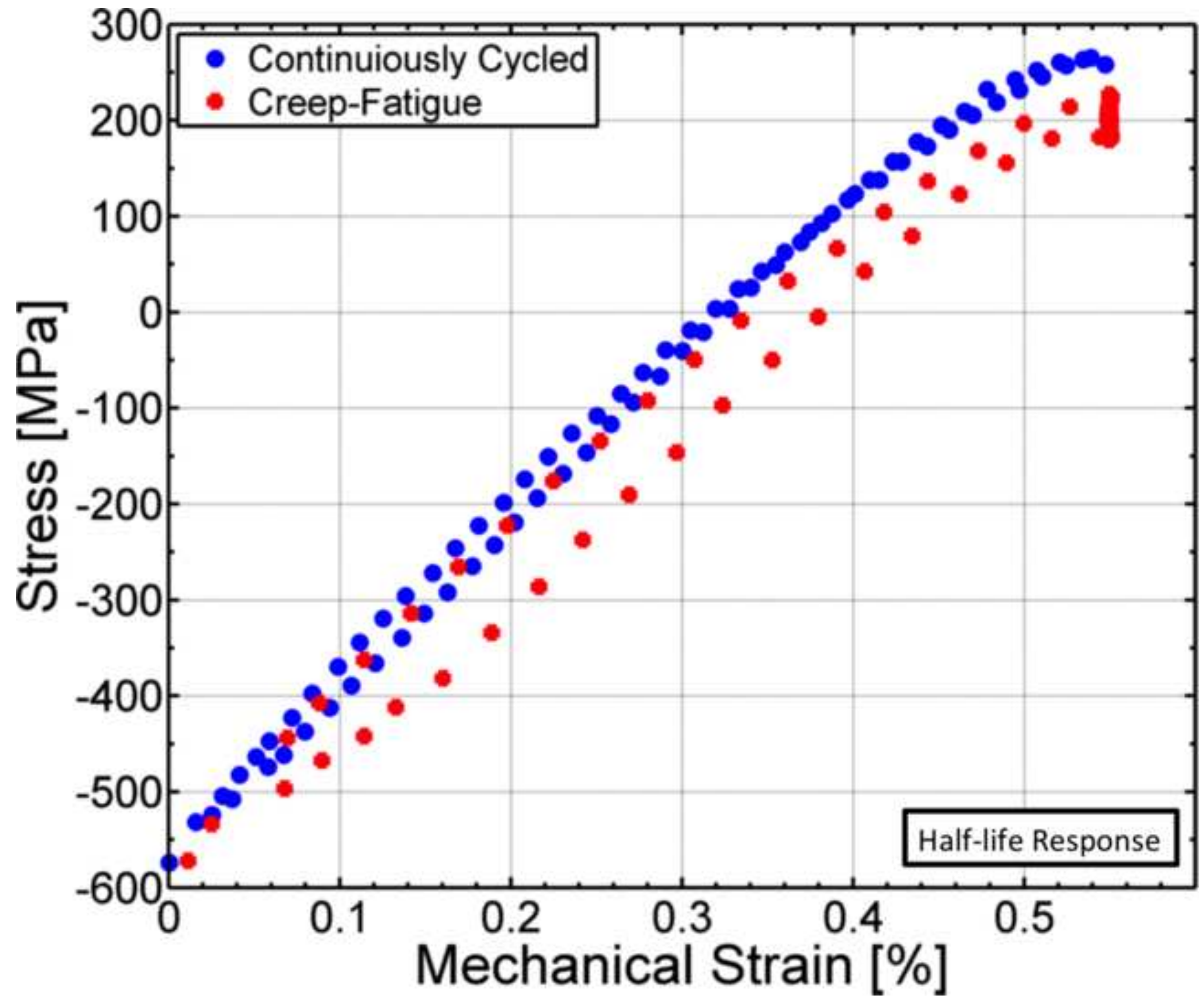




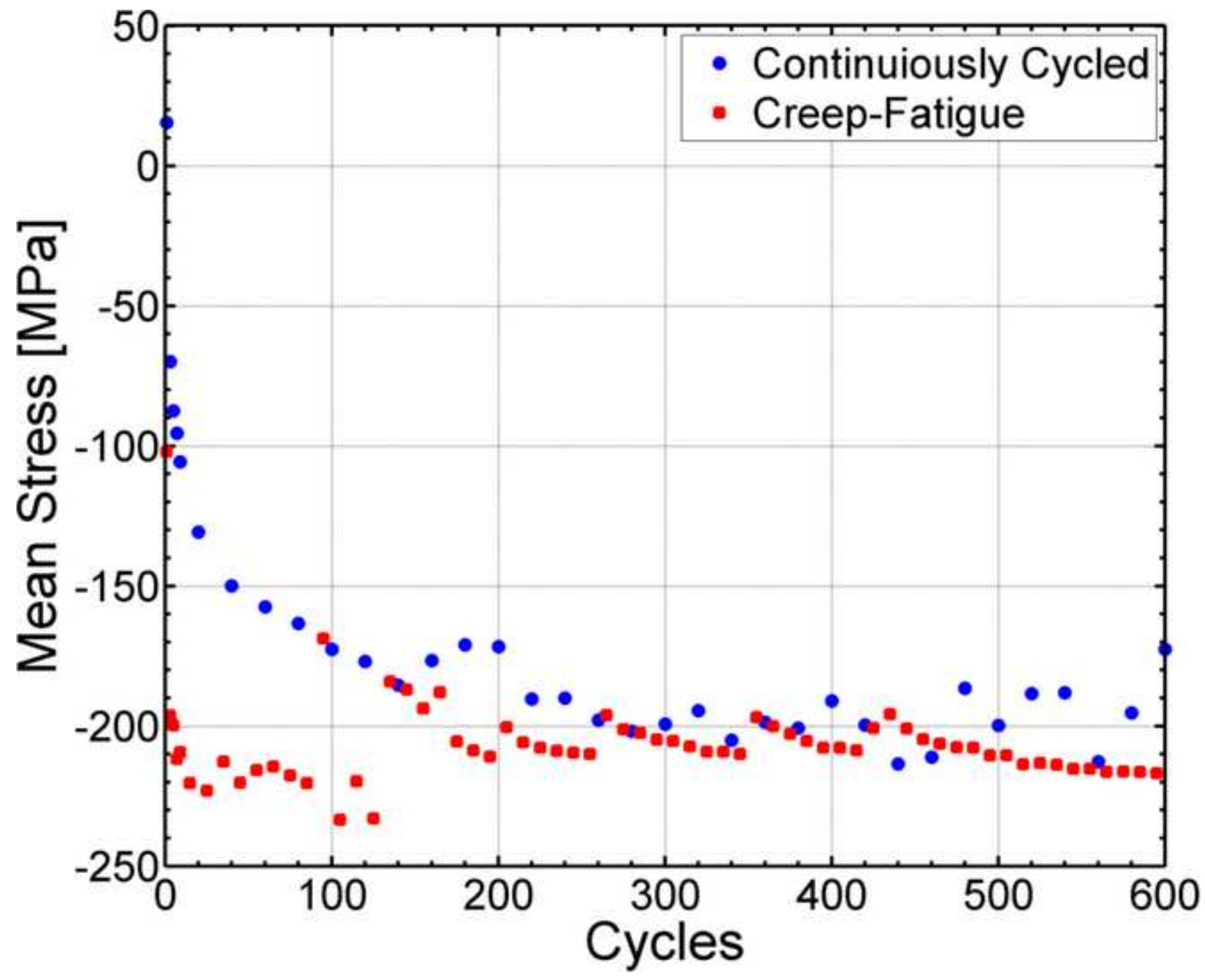


Figure 22a
Click here to download high resolution image

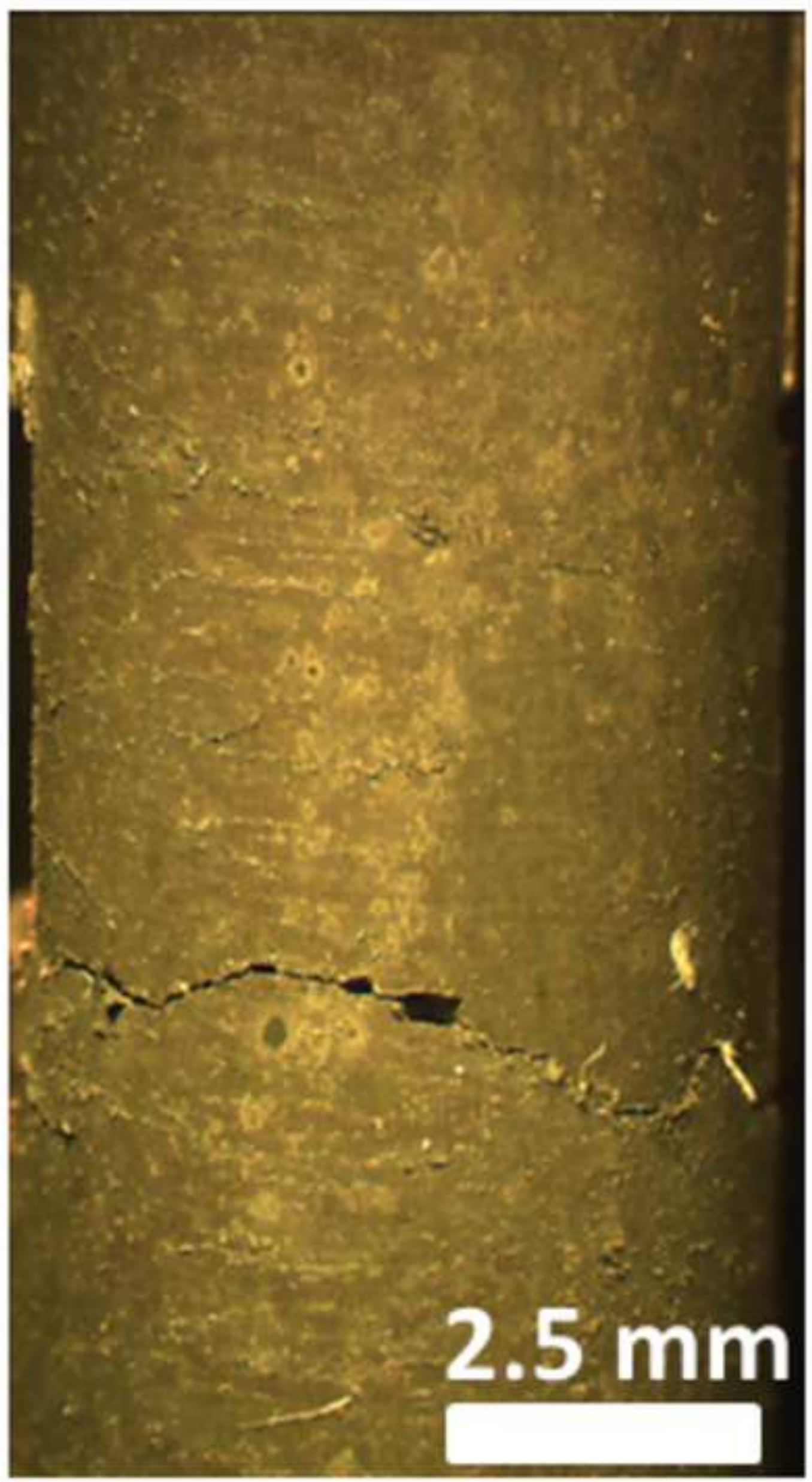




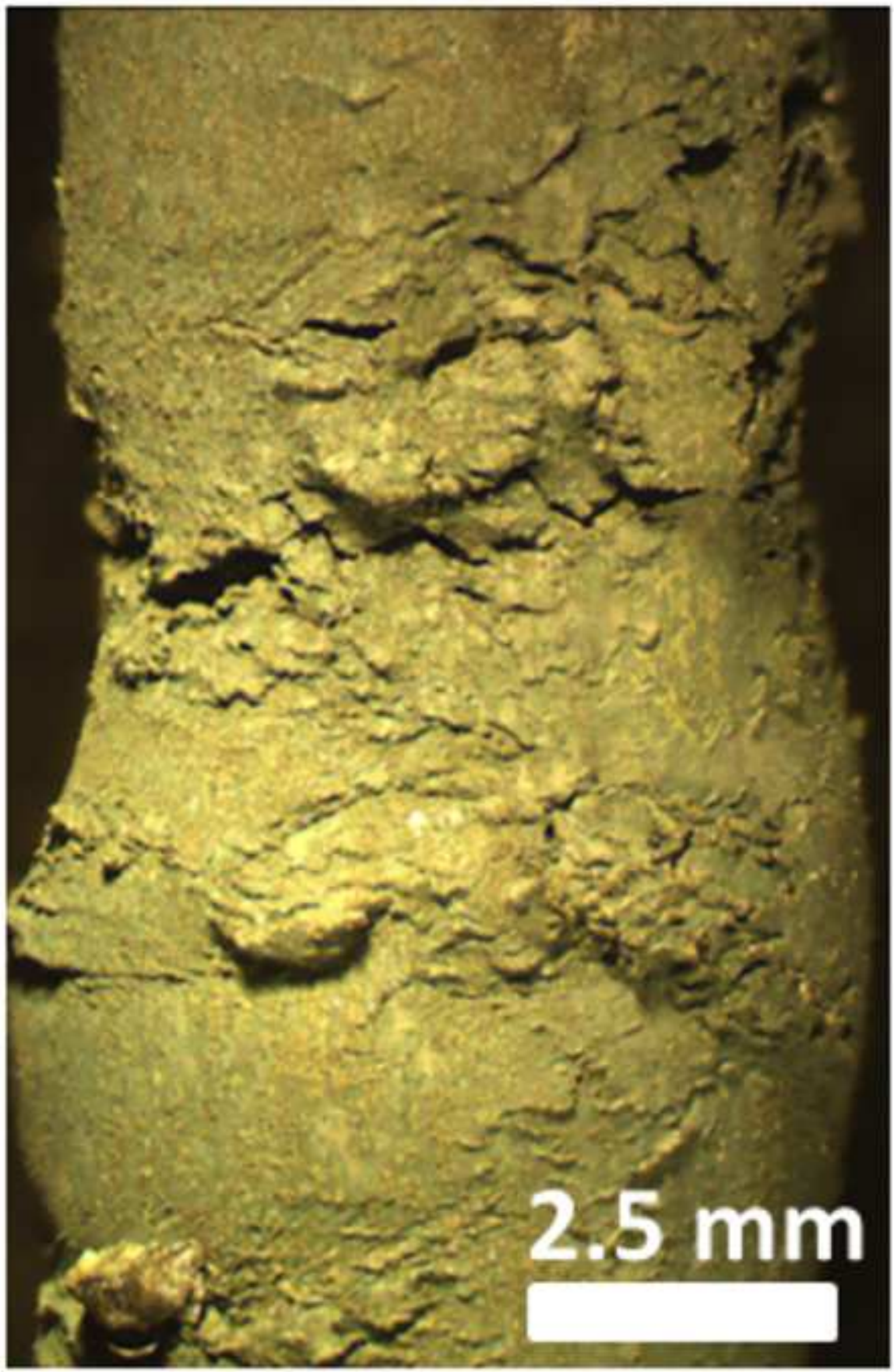


Click here to download high resolution image

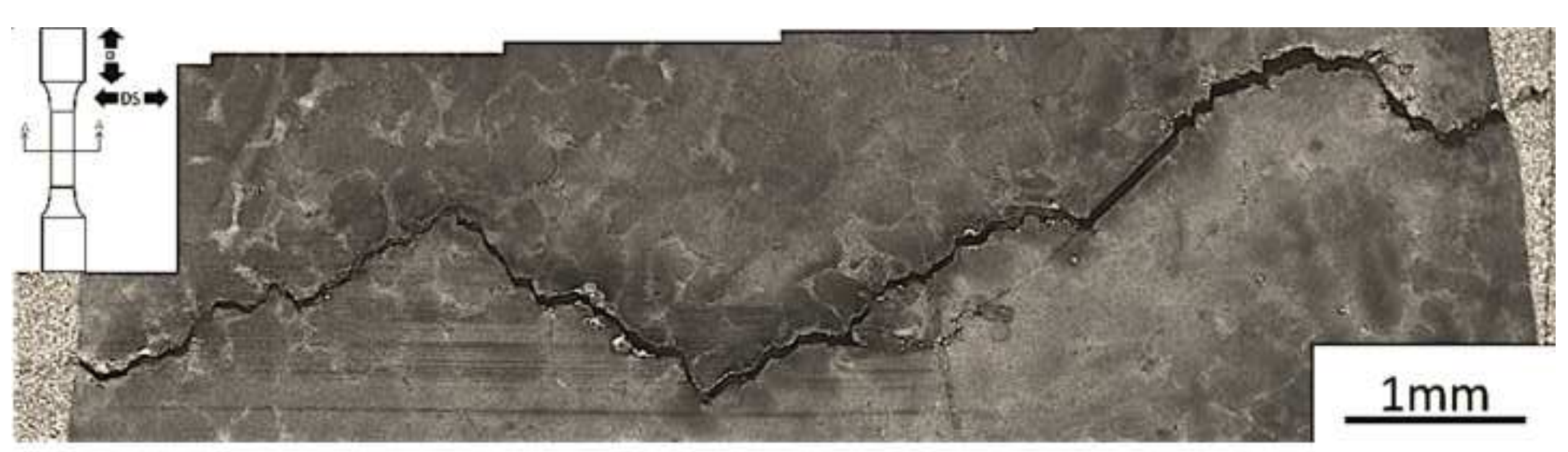

Click here to download high resolution image 
Figure 24

Click here to download high resolution image

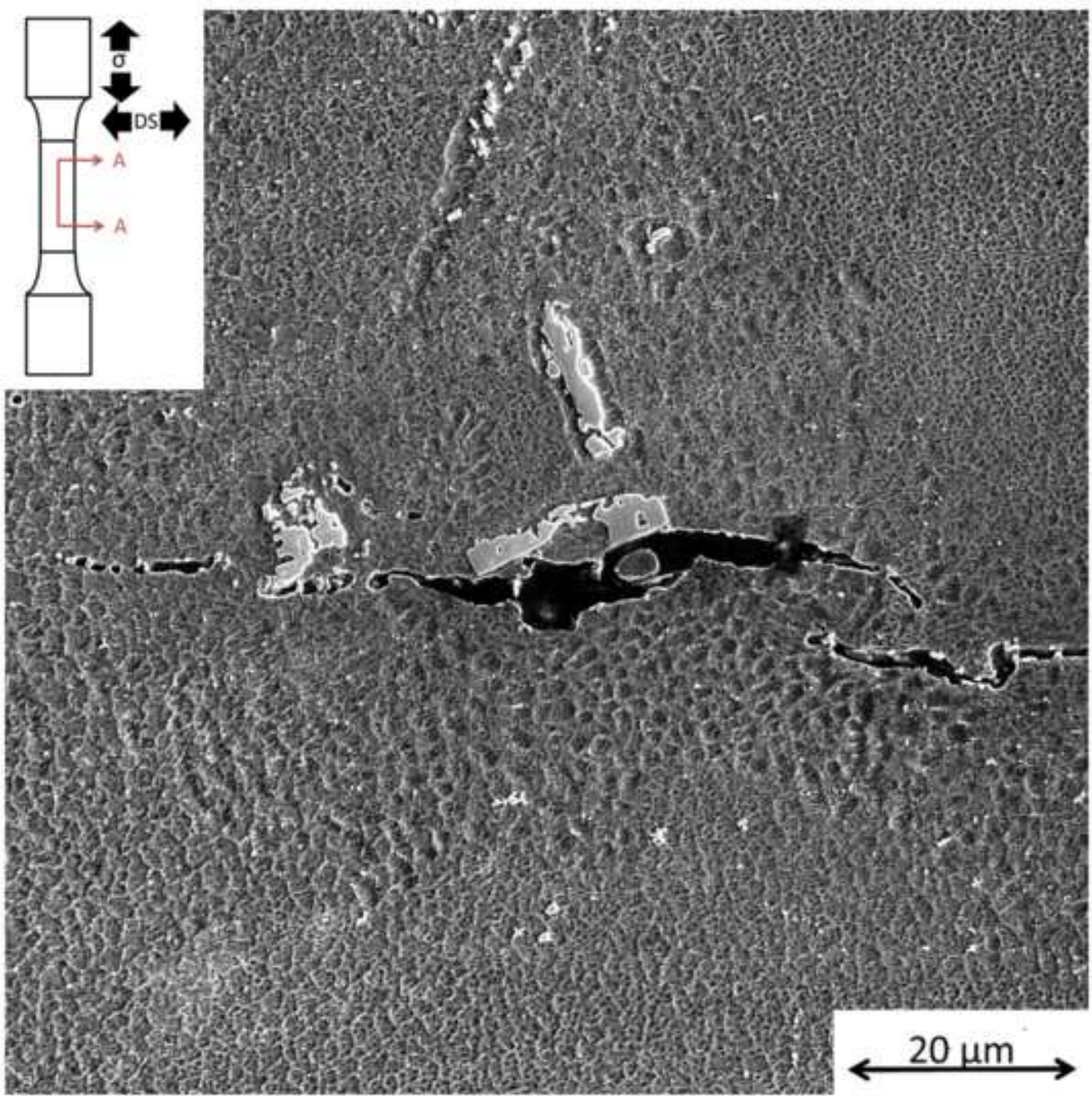

